University of Windsor

Scholarship at UWindsor

\title{
Identity and Emotional Competence as Mediators of the Relation between Childhood Psychological Maltreatment and Adult Love Relationships
}

\author{
Andrea R. Kapeleris \\ University of Windsor
}

Follow this and additional works at: https://scholar.uwindsor.ca/etd

\section{Recommended Citation}

Kapeleris, Andrea R., "Identity and Emotional Competence as Mediators of the Relation between Childhood Psychological Maltreatment and Adult Love Relationships" (2009). Electronic Theses and Dissertations. 35.

https://scholar.uwindsor.ca/etd/35

This online database contains the full-text of PhD dissertations and Masters' theses of University of Windsor students from 1954 forward. These documents are made available for personal study and research purposes only, in accordance with the Canadian Copyright Act and the Creative Commons license-CC BY-NC-ND (Attribution, Non-Commercial, No Derivative Works). Under this license, works must always be attributed to the copyright holder (original author), cannot be used for any commercial purposes, and may not be altered. Any other use would require the permission of the copyright holder. Students may inquire about withdrawing their dissertation and/or thesis from this database. For additional inquiries, please contact the repository administrator via email (scholarship@uwindsor.ca) or by telephone at 519-253-3000ext. 3208. 
Identity and Emotional Competence as Mediators of the Relation between Childhood Psychological Maltreatment and Adult Love Relationships

by

Andrea R. Kapeleris

\begin{abstract}
A Thesis
Submitted to the Faculty of Graduate Studies through the Department of Psychology in Partial Fulfillment of the Requirements for the Degree of Master of Arts at the University of Windsor
\end{abstract}

Windsor, Ontario, Canada 2009 (C) 2009 Andrea R. Kapeleris 
Identity and Emotional Competence as Mediators of the Relation between Childhood Psychological Maltreatment and Adult Love Relationships

by

Andrea Kapeleris

APPROVED BY:

S. McMahon
Faculty of Nursing

R. Menna

Department of Psychology

S. Paivio, Advisor

Department of Psychology

A. Pascual-Leone, Chair of Defense

Department of Psychology

September 30, 2009 


\section{Author's Declaration of Originality}

I hereby certify that I am the sole author of this thesis and that no part of this thesis has been published or submitted for publication.

I certify that, to the best of my knowledge, my thesis does not infringe upon anyone's copyright nor violate any proprietary rights and that any ideas, techniques, quotations, or any other material from the work of other people included in my thesis, published or otherwise, are fully acknowledged in accordance with the standard referencing practices. Furthermore, to the extent that I have included copyrighted material that surpasses the bounds of fair dealing within the meaning of the Canada Copyright Act, I certify that I have obtained a written permission from the copyright owner(s) to include such material(s) in my thesis and have included copies of such copyright clearances to my appendix.

I declare that this is a true copy of my thesis, including any final revisions, as approved by my thesis committee and the Graduate Studies office, and that this thesis has not been submitted for a higher degree to any other University or Institution. 


\begin{abstract}
This study tested whether identity formation and emotional competence mediated the relationship between childhood maltreatment and adult love relationships, as well as explored the differential long-term effects of psychological abuse and neglect. The sample was comprised of 187 undergraduates. Measures were the Childhood Trauma Questionnaire (Bernstein \& Fink, 1998), the Family Expressiveness Questionnaire (Halberstadt, 1986), the Emotion Control Questionnaire-2 (Roger \& Najarian, 1989), the Toronto Alexithymia Scale (Bagby et al., 2007), the Rosenberg Self-Esteem Scale (Rosenberg, 1965), The Robson Self-Concept Questionnaire (Robson, 1989), the Relationship Scales Questionnaire (Griffin \& Bartholomew, 1994), and the Relationship Questionnaire (Bartholomew \& Horowitz, 1991). Path analysis was used to test the proposed mediational model. Emotional competence mediated the relationship between psychological maltreatment and adult attachment styles, while identity integration did not. Emotional abuse and neglect were both associated with a fearful adult attachment style and alexithymia in adulthood. Results support the importance of emotional competence.
\end{abstract}




\section{ACKNOWLEDGEMENTS}

I would first like to express my sincere gratitude to Dr. Sandra Paivio for affording me the creative independence to pursue this project, and for her support along the way. I also wish to thank Dr. Roseanne Menna and Dr. Sharon McMahon for their enthusiasm and invaluable input.

I would like to extend a special thank you to Jennifer Voth for her statistical assistance, consistent availability, and support throughout this process.

In addition, I would like to acknowledge the students who participated in this study. Thank you for your interest and candor, as without you this project would not be possible.

Finally, I would like to thank my family and friends, for supporting my ambitions, expressing curiosity in my work, and most of all, making me laugh uncontrollably. Your presence in my life provides me with inspiration and keeps me grounded through the most challenging times. 
TABLE OF CONTENTS

AUTHOR'S DECLARATION OF ORIGINALITY iii

ABSTRACT iv

ACKNOWLEDGEMENTS V v

LIST OF TABLES viii

LIST OF FIGURES $\quad$ ix

CHAPTER

I. INTRODUCTION

Objectives 1

Rationale for the Study 4

Attachment Theory 6

Family Expressiveness $\quad 8$

Childhood Psychological Maltreatment 11

Adult Attachment Relationships $\quad 17$

Emotional Competence 28

Alexithymia 31

Identity Integration 36

The Present Study $\quad 40$

Participants 41

CHAPTER II. METHOD 41

Measures $\quad 42$

Procedure $\quad 48$

Analysis Plan $\quad 48$

CHAPTER III. RESULTS 51

Examination of the data 51

Severity of abuse $\quad 55$

Correlations $\quad 58$

$\begin{array}{ll}\text { Covariates } & 61\end{array}$

$\begin{array}{ll}\text { Model Testing } & 61\end{array}$ 
Research Question $\quad 64$

$\begin{array}{ll}\text { Modifications } & 72\end{array}$

$\begin{array}{ll}\text { Additional Analyses } & 76\end{array}$

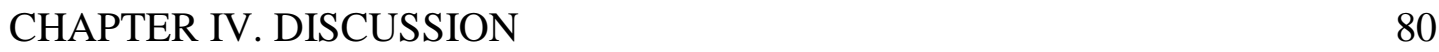

$\begin{array}{ll}\text { Summary of Findings } & 79\end{array}$

Long-term Effects of Maltreatment 83

Mediational Effects $\quad 86$

$\begin{array}{ll}\text { Specific Effects of Abuse and Neglect } & 91\end{array}$

$\begin{array}{ll}\text { Practical Implications } & 94\end{array}$

Conclusion and Directions for Future Research 96

$\begin{array}{lr}\text { REFERENCES } & 98\end{array}$

A: Family Expressiveness Questionnaire 116

$\begin{array}{ll}\text { B: Rosenberg Self-Esteem Scale } & 120\end{array}$

$\begin{array}{ll}\text { C: Relationship Questionnaire } & 121\end{array}$

$\begin{array}{ll}\text { D: Relationship Scales Questionnaire } & 124\end{array}$

$\begin{array}{ll}\text { VITA AUCTORIS } & 126\end{array}$ 


\section{LIST OF TABLES}

$\underline{\text { Table }}$

Page

1. Means, standard deviations, and ranges subscales

2. Characteristics of Sample

3. Adult attachment style categories

4. Correlation among model variables

5. Final fit indices for measurement and structural model

6. Standardized Regression Weights for the paths leading from

Psychological Neglect to individual measures

7. Standardized Regression Weights for the paths leading from Psychological Abuse to individual measures 


\section{LIST OF FIGURES}

Figure

Page

1. Path diagram of proposed model: Identity integration and emotional competence as mediators of the relation between childhood emotional abuse and neglect, and adult love relationships

2. Hypothesized measurement model representing the validity of the indicator variables in measuring the constructs of interest

3. Hypothesized structural model representing the direct relationship between psychological maltreatment and adult love attachment styles

4. Hypothesized structural model representing the indirect relationship between psychological maltreatment, identity integration and adult love attachment styles

5. Hypothesized structural model representing the indirect relationship between psychological maltreatment, emotional competence, and adult love attachment styles

6. Structural model representing the relationships between psychological maltreatment, identity integration, emotional competence, and adult love attachment style 


\section{Chapter I}

\section{INTRODUCTION}

\section{Objectives}

The present study will examine psychological maltreatment in childhood, particularly, emotional abuse and emotional neglect, as defined by the American Professional Society on the Abuse of Children (APSAC, 1995) which states: "Psychological maltreatment means a repeated pattern of caregiver behavior or extreme incident(s) that convey to children that they are worthless, flawed, unloved, unwanted, endangered, or of value only in meeting another's needs" (p.81). Child emotional abuse and neglect will be studied in terms of the differential long-term effects they may have on attachment in adult love relationships. The constructs of identity integration and emotional competence will be applied in search of possible fit as mediators in the pattern of psychological maltreatment based on earlier evidence demonstrated in previous studies by such theorists as Erickson, Egeland, and Pianta (1989), and Heifer and Kempe (1976). To date, it is known that individuals who experience psychological abuse and neglect during childhood have a limited capacity for self-regulation of affective states, and a sense of self dominated by shame, guilt, and self-blame (Webb, Heisler, Call, Chickering, \& Colburn, 2007; Reckling \& Buirski, 1996). These factors, in addition to the robustness of findings that support early insecure attachment styles, set the stage for a limited capacity to enjoy healthy adult romantic relationships (Treboux, Crowell, \& Waters, 2004). This contemporary study will examine the differential long-term effects of emotional abuse and emotional neglect. While many studies have examined the long-term effects of general child maltreatment (Smith, Ireland, Thornberry, \& Elwyn, 2008; 
McGee, Wolfe, \& Wilson, 1997; Herrenkohl, Herrenkohl, Egolf, \& Wu, 1991; Erickson, Egeland, \& Pianta, 1989), fewer have compared the separate effects of emotional abuse and emotional neglect on identity integration, emotional competence, and capacity for intimacy in adult love relationships (Allen, 2008). In sum, contemporary assumptions in attachment theory support the hypotheses that child maltreatment in general erodes the development of a positive sense of self and diminishes adaptive emotion regulation strategies, which in turn set the stage for dynamics of fear and avoidance in adult romantic relationships. This study tested the hypothetical model presented in Figure 1, with respect to psychological maltreatment. In addition, this study was designed to examine the differential effects of identity integration and emotional competence of individuals who were emotionally abused and emotionally neglected. 


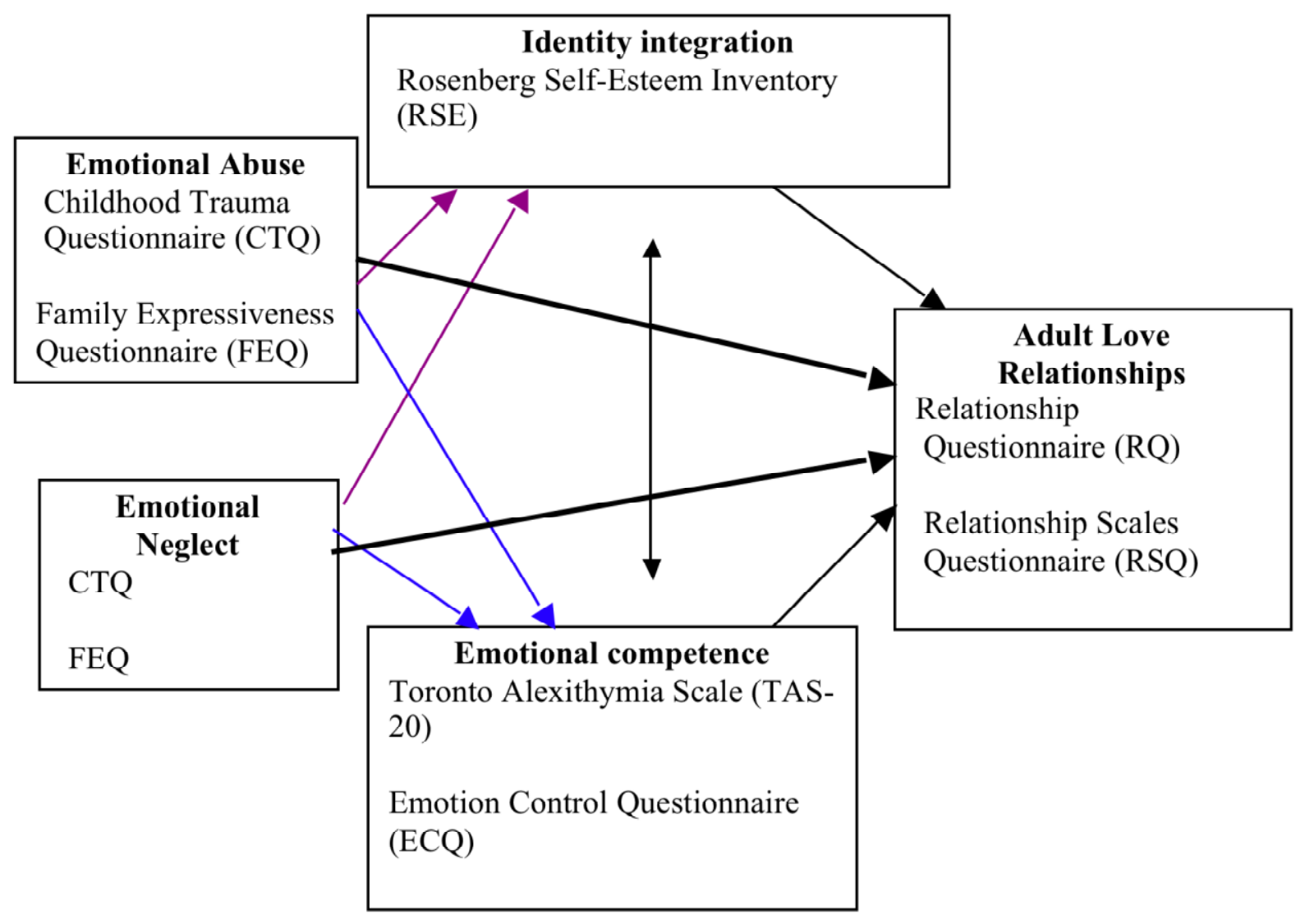

Figure 1. Path diagram of proposed model: Identity integration and emotional competence as mediators of the relation between childhood emotional abuse and neglect, and adult love relationships 


\section{Rationale for the Study}

Psychological abuse is prevalent in the general population and frequently among people with psychological problems. Psychological abuse is often highly correlated with other forms of abuse, especially physical abuse (Briere \& Runtz, 1990). However, research suggests that psychological abuse also occurs to a high degree in the absence of physical or sexual abuse as reported in a 2001 study by Paivio, in which $40 \%$ of college students reported having experienced chronic emotional abuse during childhood independent of any experiences with physical or sexual abuse. Similarly, in a 1998 study by Bifulco and colleagues, 33\% of a community sample in London, reportedly experienced significant parental antipathy (rejection and hostility) in the form of criticism, disapproval, verbal abuse, coldness, ignoring the child, favoritism, and even direct hatred from one parent, while 5\% reported experiencing it from both parents.

Emotional neglect is the subtlest form of maltreatment and often occurs in the context of physically met needs, yet its consequences are most severe (Allen, 2001). In a sample of 470 Canadian undergraduate students, $45.1 \%$ reported a history of emotional neglect (Paivio \& Cramer, 2004). One prospective longitudinal study on the effects of emotional neglect found that children who were emotionally neglected had insecure attachments, and showed difficulties such as excessive anger, non-compliance, negativism, anxiety, dependency, increased risk for depression, and a lower likelihood of being involved in a healthy romantic relationship (Erickson \& Egeland, 1999).

In their evidence-based guide for treating complex traumatic stress disorders, Courtois, Ford, Herman, and Van Der Kolk described that individuals who experience psychological abuse and neglect during childhood have been shown to have limited 
capacity for self-regulation of affective states, and a deficit in identifying, assessing, and managing the emotions of one's self and others (2009). Because they grew up in an environment that offered limited opportunities to learn about and express feelings, and had limited support for coping with painful emotional experiences, they tended to be less emotionally competent than individuals who had not experienced psychological maltreatment in childhood. Further research has recently reported that psychological child abuse and neglect is associated with intense negative affect and distress (Chernus, 2008; Ford, 2005).

In response to maltreatment, individuals often protect themselves by learning to avoid negative emotions. As a result, they tend to avoid introspective analysis of their affective experience, and discussion of their feelings, thus becoming alexithymic (Joukamaa et al., 2008; Paivio \& McCulloch, 2004). Alexithymia is considered an emotion regulation deficit (Taylor \& Bagby, 2004). It involves difficulties identifying feelings and distinguishing them from the bodily sensations of emotional arousal, difficulty describing feelings to other people, constricted imaginal capacities, externally oriented cognitive style, and deficits in regulating emotions (Spitzer, Siebel-Jurges, Barnow, Grabe \& Freyberger, 2005). Individuals who are unable to engage in introspection do not have the opportunity to develop an integrated identity or a positive sense of self. They often experience a sense of guilt, shame, and self-blame and a fragmented identity which is rooted in a sense of 'self-badness' (Feiring, 2005; Paivio \& Pascual-Leone, 2009).

The fracturing effect of childhood psychological maltreatment and abusive relationships has been proven to have a detrimental impact on emotions, and exacerbates 
the uncertainty and fear of both rejection and intimacy inherent in the attachment relationship to the primary caregiver. This loss of love and trust has been shown to have a greater detrimental and longer lasting impact on the individual's psyche than physical or sexual abuse in isolation (Boden, Fergusson, \& Horwood, 2008). It is the disruption to the sense of safety, security, loyalty, and trust that is most traumatic and extends to other relationships later in life. Limited capacities for understanding emotions and maintaining a positive sense of self leads to a limited capacity for healthy adult romantic relationships which require emotional intimacy. As intra- and interpersonal realities enter a vicious cycle of angry criticism followed by distancing and defensiveness, safe emotional engagement becomes impossible (Johnson, 2000).

\section{Attachment Theory}

The foundation for this study on psychological childhood maltreatment and its impact in adulthood will rest on the assumptions of attachment theory (Bowlby 1969, 1988; Bowlby \& Ainsworth, 1991). Striving for attachment is a human and animal survival-focused capacity which evolved from the helplessness of the young and the need to be around a competent, mature protector who can provide nurturance and modeling (Courtois et al., 2009). Attachment to a primary caregiver is critical for the development of the young. Early relationships with caregivers perpetuate cognitive and emotional representations of self and others that operate automatically and unconsciously to monitor attachment-related experiences on an ongoing basis. This is what Bowlby (1969) calls the Internal Working Model of the self. It is a set of values, beliefs, and expectations that an infant develops through attachment experiences with caregivers, which give them 
information about their own self-worth, the availability and trustworthiness of significant others, and attachment relationships in general (Ainsworth \& Bowlby, 1991; Bowlby, 1988; Main, 2000).

Attachment security is defined as the degree to which one experiences others as responsive to their needs for comfort and support, leading to trust when these needs are safely and regularly fulfilled (Bowlby, 1988). Attachment trauma is a relational trauma that occurs in relationships with primary caregivers (Courtois et al., 2009). Instances of attachment trauma include an insecurity of response and unavailability by the caregiver, mis-attunement and nonresponse constituting neglect, a lack of caring and reflection of self-worth, and a style of caregiving that is both the source of fear and comfort (Courtois et al., 2009). Above all, attachment trauma constitutes a failure of protection which places the child in danger; a situation where the child requires protection from the attachment figure (Allen, 2001). Thus, this type of attachment relationship is an example of a caregiving style that constitutes emotional abuse and neglect.

Substantial continuity of attachment from infancy to adolescence (e.g. Hamilton, 2000) and early adulthood (e.g. Waters, Merrick, Treboux, Crowell, \& Albersheim, 2000) has been found. The attachment relationship persists over time and forms individual differences in thoughts, feelings, and behavior in childhood, adolescence, and eventually is observed in intimate interpersonal functioning in adulthood (Jellis, 2001). In a 30-year study of approximately 180 high-risk families that investigated the continuity of early attachment styles into adulthood, Sroufe and colleagues (2005) reported that avoidant attachment predicted more behavior problems in children, such as hostility, isolation, and lack of compliance at age four (Sroufe et al., 1985) and continued to predict behavior 
problems, such as aggression especially in boys, into elementary school (Sroufe et al., 1989). Lewis, Feiring, and Rosenthal (2000) measured individuals' recollections of childhood at age 13 through the use of narratives, and found that those who had mainly negative recollections were insecurely attached to their parents at age 18 and also showed signs of maladjustment on parent, teacher, and self-report measures of social and emotional well-being. Adults with insecure attachment histories tended to score lower on measures of social competence (direct observation, peer sociometrics, teacher/councelor ratings, interviews with the young people) than those with secure attachment histories (Lewis et al., 2000). They tended to have more negative experiences in relationships, less emotional engagement with others, less skill in interactions, and lower levels of popularity (Lewis et al., 2000; Sroufe, 2005). By observing dyadic interactions between couples, Sroufe (2005) also found that adults with avoidant histories tended to have an emotional tone in their romantic relationships that was more instructive, controlling, and hostile.

\section{Family Expressiveness}

Family expressiveness is an index of the attachment relational context and is an example of how the quality of attachment in the family environment is manifested. Childhood emotional abuse and neglect are often embedded in a larger pattern of family dysfunction and environmental chaos that impedes child development (Myers et al., 2002). The family environment is an active social system where children first learn about emotional expressivity, emotion regulation, and appropriate social and affective behaviors. The pervasive quality of verbal and nonverbal communication in the family is 
an important determinant of socio-emotional functioning in adulthood (Bell, 1998; Burrowes \& Halberstadt, 1987). Emotional expression in the family involves recognizing subtle social cues and discovering a range of complex emotional expressions. Predictable and regulated emotional expressiveness is correlated with childrens' social competence, empathic skill, ratings of popularity and peer status, and prosocial behaviors (Jones, Abbey, \& Cumberland, 1998). Positive parental affect in general is correlated with childrens' greater knowledge about emotions, greater positive affect, and prosocial behavior with siblings (Jones et al., 1998).

Negative family expressiveness is associated with experiences of emotional abuse and neglect. High levels of negative emotions in the family overwhelm the child with distress and illustrate highly destructive and damaging ways to respond to and express emotion (Morris, Silk, Steinberg, Myers \& Robinson, 2007). This type of family environment is associated with children's inability to regulate negative emotions, the tendency to respond negatively towards distressed or angry others, and general low selfesteem. It is an environment that is associated with less control over feeling angry in college students, and increased rates of loneliness in college males (Burrowes \& Halberstadt, 1987; Carson \& Parke, 1996; Denham \& Grout, 1992). This argument does not propose that a lack of negative emotionality is beneficial or even desirable to a child's developing sense of self and emotional awareness. In actuality, mild to moderate levels of negative emotional expression help teach children about emotion regulation by exposing them to a range of emotions (Burrowes \& Halberstadt, 1987; McCullough, Bono, \& Root, 2007). 
Negative family expressiveness can further be subdivided into negative dominant expressiveness and negative submissive expressiveness. Negative dominant expressiveness is an environment infused with harsh, noninstructive negative affect such as anger and disgust. Expressing anger at someone else's carelessness, showing contempt for another's actions, criticizing, and blaming are the norm (Bell, 1998). This is the type of environment in which emotional abuse may take place. Negative dominant expressiveness has been found to be associated with children's use of self-protective display rules (defensive nonverbal behaviors that are used to protect the self in hostile environments) (Jones et al., 1998). It has also been found to be associated with greater preoccupation with attachment issues in college students (Bell, 1998).

Negative-submissive expressiveness is an environment where negative affect is predominant but more subtle, such as constantly sulking over unfair treatment by a family member, a high degree of crying and sadness within the family, and chronic expressions of sorrow and embarrassment (Bell, 1998). This submissive style of negative affect is the type of environment in which emotional neglect may take place. Although it is not overtly hostile, it fails to nurture the emotional needs of the child. Negative submissive expressiveness has been found to be associated with greater difficulty identifying one's own emotions, and less self-soothing behaviors in the college population (Berenbaum \& James, 1994). These different types of expressiveness potentially have distinct outcomes in adulthood, leading to an inability to adaptively integrate competing aspects of identity and a deficit in understanding emotions and how they can be used and modulated constructively. Together, these effects become particularly apparent in adult interpersonal relationships, where negative attachment relationships from childhood are perpetuated 
and carried out in adult romantic relationships (Johnson \& Greenman, 2006; Morris et al., 2007; Sroufe, 2005).

\section{Childhood Psychological Maltreatment}

Childhood psychological maltreatment is a type of trauma. Because trauma can be defined as any time a child, "experiences an intense event that threatens or causes harm to his or her emotional or physical well-being" (National Child Traumatic Stress Network [NCTSN], 2003) the term indicates both threat and consequence. Further specified, traumatic child abuse is, “...the unique individual experience, associated with an event or enduring conditions, in which the individual's ability to integrate affective experience is overwhelmed or the individual experiences a threat to life or bodily integrity..." (Pearlman \& Saakvitne, 1995). Trauma has historically been described in the literature as, "an experience of unbearable affect" (Krystal, 1978), and, "the sudden uncontrollable loss of affiliative bonds" (Lindemann, 1944). However, the core feature is the repetitive and sustained nature of the maladaptive interactions (Stolorow, 2007). An incident occurring in isolation does not constitute abuse, but a parent who consistently demonstrates an emotionally inappropriate response to a child's expression of emotion and its accompanying expressive behavior, will constitute emotional abuse (O'Hagan, 1995; Stolorow, 2007). It cannot be overemphasized that injurious childhood experiences in and of themselves need not be traumatic or pathogenic, as long as they are responded to appropriately. It is not the pain that creates the pathology, but rather it is the absence of adequate attunement and responsiveness to the child's painful emotional reaction that 
renders them unbearable and unendurable and thus a source of traumatic states and psychopathology (Stolorow, 2007).

Psychological abuse includes both emotional abuse and emotional neglect. Emotional abuse constitutes acts of commission, such as a mental attitude of hostility expressed behaviorally (Briere, 2002). While emotional neglect constitutes acts of omission constituted by a mental attitude of ignorance and indifference manifested in caregiver denial and unresponsiveness to the child's emotional needs and nurturing, particularly associated with pleas for physical, emotional, and relational warmth and comfort (Briere, 2002).

Childhood Emotional Abuse. Childhood emotional abuse has been described as, "[a] shatter[ing] of absolutisms, a catastrophic loss of innocence that permanently alters one's sense of being in the world" (Stolorow, 2007, p. 467). Emotional child abuse shatters one's sense of security and being safe in the world, creating a sense of "never [being] the same" (Courtois et al., 2009). Specifically, it involves caretaker acts of behavioral hostility such as criticism, humiliation, verbal assaults, and threats towards the child. It may involve rejection, isolating, terrorizing, ignoring, and corrupting. Parental responses convey the message that the child is worthless, flawed, unloved, endangered, or only valuable in meeting someone else's needs (Courtois et al., 2009; Stolorow, 2007). Emotional pain is repeatedly inflicted on the child through humiliation (public shaming), extreme rejection (such as telling the child of a wish for him or her to die), playing with the child's fears through cruel threats of abandonment and terrorizing, threats to harm others if the child does not comply (emotional blackmail), and witnessing family violence (Courtois et al., 2009; Stolorow, 2007). 
Parental denial of reality is also a form of emotional child abuse (LesnikOberstein, 1983). In this circumstance the child's sense of reality is impaired by invalidating his or her perceptions and memories. The resulting doubts about their truth may result in a feeling of 'being crazy' or not trusting one's self. Bernstein and Fink (1998) in the Childhood Trauma Questionnaire (CTQ) describe emotional abuse as verbal assaults on a child's sense of worth or well-being, or any humiliating, demeaning, or threatening behavior directed toward a child by an older person.

Childhood Emotional Neglect. Emotional neglect as a form of abuse has been relatively neglected in past literature. It is the most subtle form of maltreatment and often occurs in the context of physically met needs, yet its consequences are most severe (Allen, 2001). Emotional neglect is the failure of caretakers to provide basic psychological and emotional needs, such as love, encouragement, belonging and support; it leads to a sense of 'wanting to be touched' (Courtois et al., 2009). Emotional neglect can be seen as the central feature of all maltreatment. Newberger (1973) stated, "the essential element in child abuse is not the intention to destroy a child but rather the inability of a parent to nurture his or her offspring" (p.15). The parent or caregiver's failure to support the psychosocial development of the child is exemplified through a complete lack of responsiveness to the child's emotional states (Allen, 2001; Briere, 2002; Egeland \& Erickson, 1999).

Egeland and Erickson (1999) found that psychologically unavailable mothers were detached and unresponsive, often taking little pleasure in the relationship with the child, and interacting mechanically with no joy or satisfaction in the relationship. This type of interaction slowly and persistently, "eats away at children's spirits until they have 
little will to connect with others or explore the world" (Myers, 2006, p.92). Citing the American Humane Association, Brassard and colleagues (1987) describe emotional neglect as, "passive or passive-aggressive inattention to the child's emotional needs, nurturing, or emotional well-being" (p.267). Emotional availability, on the other hand, is a relational, multidimensional construct that involves parental sensitivity, child responsiveness, parental nonintrusiveness, and child involvement of the parent (Biringen \& Robinson, 1991). If emotional availability is seen as a continuous construct, emotional neglect would be at the extreme end of the continuum. Since neglect is often chronic rather than episodic, children may grow up thinking this is the normal way to treat and be treated by others, not realizing that it constitutes maltreatment (Wolfe, 1999).

Long-term Effects of Psychological Maltreatment. Emotional abuse and emotional neglect have overlapping and distinct outcomes. Differences in the developmental consequences of abuse and neglect validate the importance of studying them separately (Myers, 2002); but one must also keep in mind that multiple types of maltreatment usually occur together (Landy \& Menna, 2006).

In this study, psychological maltreatment will be discussed in terms of the shortand long-term impacts of emotional abuse and emotional neglect. The short-term effects of both abuse and neglect in childhood are more well-known than the long-term effects. However, long-term effects are clinically and empirically supported to some extent as noted in the work of Allen (2008), Bartholomew and Horowitz (1991), and Sroufe (2005). Again, the purpose of this study is to clarify these long-term effects, specifically in terms of the effects of relational trauma on adult romantic relationships. 
The effects of emotional abuse in the short-term are that it distorts a child's ability to learn about emotions, spontaneously express emotions, and regulate affect. It also negatively affects cognitive capacities such as intelligence, perception, attention, and memory (Simpson, 1990). In the long-term, maternal emotional abuse has been uniquely associated with interpersonal conflicts, abandonment concerns, identity impairment, and capacity for intimacy in adult love relationships (Briere \& Rickards, 2007).

It has been found that subtle forms of neglect have serious short and long-term consequences for child victims. In a longitudinal study of maltreated children called, the Minnesota Parent-Child project, two-year old children who were emotionally but not physically neglected displayed anger, noncompliance, lack of persistence, little positive affect, behavior problems, anxiety, negativistic attitudes, impulse control problems, were highly dependent on teachers, and exhibited self-abusive behavior (Sroufe, Egeland, Carlson, \& Collins 2005). Later in elementary school, these children were found to experience low peer acceptance and overall poor emotional health. They were more socially withdrawn, unpopular, had a higher rate of internalizing problems, were more aggressive, and less attentive (Sroufe et al., 2005). Among the neglected children, nearly all had insecure attachments to their caregivers and tended to avoid engagement with peers and adults (Sroufe et al., 2005). Other studies have found that emotionally neglected children tended to show notable attention-seeking behavior and superficial displays of affection (Egeland \& Erickson, 1999). As they grew older they began to be described as spiteful and selfish, and reportedly engaged in stealing in preadolescence (Egeland \& Erickson, 1999). In young adolescence, defiant, hostile behavior, and varied academic and behavior problems in the early elementary grades was apparent 
(MacCarthy, 1979 in Myers, 2006). Overall, emotionally neglected children tend to anticipate rejection and expect they will not get what they need from others, so they do not elicit support in intimate relationships (Erickson \& Egeland, 1999). Some may call this a learned helplessness or hopelessness response (Gibb, 2002). They tend to be unmotivated in tasks because they either don't expect to succeed, or they are too overwhelmed with their own unmet needs (Erickson \& Egeland, 1999; Gibb, 2002).

When abused and neglected children were compared to each other, it was found that abused children exhibited more aggression than neglected children, while both groups exhibited more aggression than nonmaltreated children (Egeland \& Erickson, 1999; Sneddon, 2003). Neglected children interacted less with peers, were more passive, tended towards helplessness under stress, and showed significant developmental delays in language comprehension and the termination of early self-soothing techniques such as thumb sucking and rocking, compared to either abused or nonmaltreated children (Crittenden \& Ainsworth, 1989; Glaser, 2002; Sneddon, 2003).

Overall, neglected children lacked the opportunity to form expectancies about caregiver's behavior, as there was often no behavior to expect (Gibb, 2002; Egeland \& Erickson, 1999). This affects the long-term ability to form adaptive expectations of self and others. Emotionally neglected children give up expecting to get what they need from others, and so they shrink away and give up trying to solicit care and warmth (Gibb, 2002; Glaser, 2002). They expect not to be successful in tasks, so they don't try to succeed (Egeland \& Erickson, 1999). Dependency needs may be so overwhelming that they are barely able to concern themselves with being motivated and task oriented. This 
causes lasting damage to a child's sense of self, and significant impairment in social, emotional, and cognitive functioning (Egeland \& Erickson, 1999).

\section{Adult Attachment Relationships}

Interpersonal trauma impacts the victims' capacity to develop and maintain relationships (Pearlman \& Courtois, 2005). Hazan and Shaver $(1987,1994)$ extended the original attachment theory founded by Bowlby (1969) and Ainsworth (1989) to romantic relationships (Bartholomew, 1990) and maintain that children generally replace parental attachment figures with peers, and especially with romantic partners.

In the short term, children who experience psychological abuse develop negative attachment relationships and maladaptive internal working models of how they view themselves and others. In the long term, these early experiences create a distortion of the normal give-and-take usually found in relationships, especially intimate relationships in adulthood (Pearlman \& Courtois, 2005). Traumatized individuals develop maladaptive expectations of others, which not only affects how they relate to others but also the ability of others to connect with them in ways that foster security and stability. As a result, many of these individuals become involved in unstable and chaotic relationships with partners who themselves have unresolved relational trauma and complementary deficits and needs (Pearlman \& Courtois, 2005). In this way, maladaptive relationships with early attachment figures are reenacted (Pearlman \& Courtois, 2005). These maladaptive relationships may include additional abuse, victimization, loss, abandonment, and mistrust, thus reinforcing negative views of others, further frustrating unmet needs for support, caring, and love, and reinforcing feelings of low self-worth in relationships 
(Johnson \& Best, 2003; Pearlman \& Courtois, 2005). Overall, beliefs about others and the self are reinforced by adult relationships that reenact traumatic ones from the past (Pearlman \& Courtois, 2005). Research has supported a negative learned pattern of relationships and a view that some adults maltreated as children may find comfort in the pain of current romantic relationships (Colman \& Widom, 2004). A prospective study by Colman and Widom (2004) followed substantiated cases of child abuse and neglect and their matched controls from 1967 to 1971 into adulthood and administered 2-hour inperson interviews. They found that abused and neglected females in particular were more likely than the control group to have negative perceptions of current romantic partners and be sexually unfaithful. In addition, both males and females who experienced maltreatment in childhood had higher rates of cohabitation, 'walking out', and divorce outcomes than controls, supporting the view that individuals 'seek what they know'. To summarize, experiencing maltreatment as a child sets the stage for a reenactment of maladaptive relationship dynamics in adulthood (Colman \& Widom, 2004).

The three behavioral systems that compose adult romantic love relationships are attachment, caregiving, and sex (Bowlby, 1969/1982; Impett, Gordon, \& Strachman, 2008; Shaver, Hazan, \& Bradshaw, 1988). Research suggests that insecure attachment effects each of these systems as early models of relationships with caregivers are reenacted to some extent in adulthood (Fraley \& Shaver, 2000) such that preexisting attachment styles are confirmed or modified by present relationships; an attempt to answer the question: "Can I count on this person to be there for me when I need them?" (Johnson, 2000). It has also been suggested that different attachment styles result from different attachment experiences (Fraley \& Shaver, 2000). In a psychologically abusive 
environment, children are more likely to develop a fearful attachment style in which they view themselves as unworthy and others as dangerous. In a psychologically neglectful environment, children are more likely to develop an avoidant attachment style in which they believe their needs will not be met by others and thus do not engage in relationships (Fraley \& Shaver, 2000). Examples concerning love relationships will be discussed in the following section.

Attachment styles have been associated with adjustment in relationships (Simpson, 1990), different responses to conflict (Simpson, Rholes, \& Philips, 1996) and seeking and giving support (Simpson, Rholes, \& Nelligan, 1992). It has been shown that attachment style is related to levels of satisfaction, commitment, levels of self-disclosure, emotional support, and love and trust in adult relationships (Mikulincer \& Nachshon, 1991). In addition, different attachment styles result in different attachment experiences (Mikulincer \& Nachshon, 1991). Experiencing childhood trauma causes significant alterations in relations with others, including an inability to trust, risk of revicitimization, and risk of victimizing others. Bartholomew and Horowitz's (1991) categorization of adult attachment styles describe how individuals falling into each category differ in their relations to others and with themselves; this has implications for expressed needs and behavior in intimate relationships.

Research shows that about $49 \%$ of adults have a secure attachment style, $12 \%$ a preoccupied style, $21 \%$ a fearful style, and $18 \%$ a dismissing style (Bartholomew \& Horowitz, 1991). Adults with a secure attachment style correspond to securely attached infants in the Hazan and Shaver (1987) model. As adults, this group can relate well, are coherent and straightforward, and have access to a range of emotions (Courtois et al., 
2009). They trust others and turn to them for support, viewing them as both caring and available. They also have a positive view of themselves as worthy of love and attention, and tend to be comfortable with both intimacy and autonomy (Courtois et al., 2009).

Preoccupied adults correspond to the anxious-ambivalent category in Hazan and Shaver's (1987) model. This category results from a history of inconsistent caregiving (Hazan \& Shaver, 1994). These individuals may be described as 'Velcro' personalities (Courtois et al., 2009) because they are super-attached, often worried and anxious about their attachment status, desire to be special, may feel entitled and be demanding, exhibit rage at times, and constantly track the behavior and motivation of others (Courtois et al., 2009). They tend to have a view of themselves as unlovable, have low self-esteem, and depend on other's acceptance to determine their own worth. They are drawn to others but experience them as generally unpredictable and difficult to understand, and experience distress when intimacy is not achieved. They lack the confidence that others will be responsive when needed, so are preoccupied with keeping others close and display an excessive need for intimacy and reassurance (Courtois et al., 2009). They may achieve intimacy and self-worth at the expense of autonomy (Allen, 2001). Preoccupied adults maintain an excessive involvement in early adverse relationships, tend to experience a high degree of anxiety, and are often highly emotional, angry, fearful, and overwhelmed by traumatic events (Allen, 2001).

Preoccupied adults often exhibit a high level of affect-based behavior, but do not have the cognitive capacity to organize and modulate their affect (Pearlman \& Courtois, 2005). They experience strong emotions such as anxiety, dependence, anger, and jealousy, and often oscillate between idealizing and depreciating others (Pearlman \& 
Courtois, 2005). Their sense of self is generally not well-developed and they have the tendency to engage in risk-taking or addictive behaviors to modulate affect (Pearlman \& Courtois, 2005). Due to their lack of interpersonal security, they may cling to unhealthy relationships in an effort to avoid being alone (Pearlman \& Courtois, 2005).

Fearful adults are similar to Hazan and Shaver's (1987) avoidant category, which results from a history of consistent unresponsiveness by caregivers. Fearful adults view others as inconsistent, unpredictable, and paradoxical; a source of both comfort and fear (Pearlman \& Courtois, 2005). They tend to have highly dysregulated emotions and exhibit features of alexithymia, such as the inability to name feelings or understand them; affect is generally intolerable. They exhibit a contradictory interaction style of both approaching and avoiding others. They may be dissociative, chronically hopeless, and appear more overtly distressed, depressed, and disorganized (Bartholomew \& Horowitz, 1991).

Fearfully attached adults generally have a negative view of themselves and others. They view themselves as unlovable, and others as rejecting, uncaring, and distant. They desire close relationships, but distrust others and fear rejection; thus, they actively avoid intimacy to protect against anticipated rejection. They tend to exhibit major problems with affect regulation and interpersonal avoidance (Bartholomew \& Horowitz, 1991).

Dismissing adults are similar to Main's (1985) detached group. They generally appear self-sufficient, self-reliant, and 'super normal'; they may apologize for having needs, and tend to avoid memories, feelings, and longings (Courtois et al., 2009). These individuals generally have a positive view of themselves and a negative view of others. Although they are uncomfortable with intimacy and view close relationships as 
dangerous, they deal with this anxiety by holding the belief that relationships are generally unimportant. They deny dependency, give the appearance of a lack of distress and invulnerability, and exhibit a defensive display of superiority (Hazan \& Shaver, 1994; Rothbard \& Shaver, 1994). They attain independence and feelings of self-worth at the expense of intimacy and may overvalue nonsocial activities, and place their selfworth solely in achievement-related activities. They have learned the ability to deny and minimize their feelings, and may be dismissing and condescending in relationships towards others (Pearlman \& Courtois, 2005).

Avoidant and ambivalent insecure attachment styles are related to relationship difficulties (McCarthy \& Taylor, 1999). Partners with an ambivalent style are vigilant to loss and threat, aggressively demand reassurance, tend to become overwhelmed by negative affect, particularly reactive anger, and lose sight of the impact of their responses on their partner (Johnson, 2000). Partners with an avoidant style have little or no reason to hope for security and responsiveness and tend to deny their need for attachment and focus on activities and tasks; they tend to detach and become unresponsive when they or their partners experience vulnerability (Johnson, 2000).

Research has found that individuals who experienced child abuse and neglect were six times more likely to be experiencing difficulties in adult love relationships (McCarthy \& Taylor, 1999). A study by McCarthy and Taylor (1999) involved 40 women from inner city London who experienced poor parenting in childhood. The women were interviewed about their experiences as children and were also given several self-reports that measured beliefs about the self and others (e.g. Adult Attachment Questionnaire, Rosenberg Self-Esteem Inventory, Relationship Attribution Measure). 
Results showed that it was an avoidant/ambivalent attachment style, rather than selfesteem or relationship attributions, that mediated the relationship between child abuse and adult romantic relationships (McCarthy \& Taylor, 1999). Thus, this study highlights the importance of the relational trauma for child abuse survivors; an insecure attachment style is often maintained and perpetuated in adult relationships, making it substantially more difficult for trauma survivors to trust others. Trauma survivors tend to either avoid intimacy altogether, leading to alienation and isolation, or engage others for support and protection with intensity, but then just as intensely, become afraid of dependence and withdraw (Johnson \& Keeler, 1998).

Adult Care-giving and Sexuality. Sexuality in romantic relationships refers to how people experience the erotic and express themselves as sexual beings (Rathus, Nevid, \& Fichner-Rathus, 2007). Adult romantic relationships are reciprocal relationships in which each partner gives and receives care physically, emotionally, and sexually. In intimate adult relationships, partners both seek care from (attachment) and provide protection or comfort to (care-giving) one another (Berman \& Sperling, 1994).

Sexual attraction, curiosity, and lust in the initial attachment serve the function of maintaining the relationship long enough for an emotional attachment to develop. Sexual feelings and behaviors have been found to link directly to attachment history, and are based on ideas about the views of others and how the relationship should be managed. Overall, individuals with a secure attachment style partake in a wide range of sexual activities usually in the context of a long-term relationship (Hazan, Zeifman \& Middleton, 1994). Those with an avoidant attachment style tend to engage in sexual behavior characterized by emotional detachment and promiscuity. They are more likely 
to fantasize about sex with someone other than their partner, engage in relatively brief sexual encounters and affairs, are more accepting of casual sex, "one night stands", and extra-relationship sex, and get less enjoyment out of physical contact (Feeney \& Noller, 1990; Hazan \& Shaver, 1987; Hazan \& Shaver, 1994). Individuals with an anxiousambivalent attachment may attempt to satisfy unmet needs for security and love through sexual activity. They may experience intense sexual passion and have jealousy in regard to their partners, become clingy and overly dependent, engage in higher rates of exhibitionism, voyeurism, domination-bondage, and obtain more enjoyment out of holding and caressing rather than the genital aspects of sex (Feeney \& Noller, 1990; Hazan, Zeifman \& Middleton, 1994).

Adult Love Relationships. The link between attachment styles and love styles described by Lee $(1973,1988)$ and Sternberg (1986) was first investigated by Levy and Davis (1988). As they preceded to integrate these theories of love, Levy and Davis (1988) tested the correlation between Lee's six love styles: a) passionate love (Eros), b) gameplaying love (Ludas), c) brotherly love (Storge), d) practical love (Pragma), e) possessive love (Mania), and f) altruistic love (Agape), and Hazan \& Shaver's (1987) measure of attachment style in dating couples. They found that secure attachment was positively related to Eros (passionate love) and Agape (selfless love), and negatively to Ludas (game-playing love). Avoidant attachment was related positively to Ludas and negatively to Eros; and anxious-ambivalent attachment was positively related to Mania (possessive love). Levy and Davis (1988) also tested the relationship between Sternberg's threecomponent model of love (1986) and attachment style in adulthood and found that all three components (intimacy, passion, and commitment) were positively related to secure 
attachment and negatively related to avoidant and anxious-ambivalent attachments. In other words, i) secure individuals are self-confident in love, not neurotic or intimacyavoiding; ii) avoidant participants lacked self-confidence and avoided intimacy; and iii) ambivalent participants lacked self-confidence but had a desperate and impulsive approach to love (Levy \& Davis, 1988). Both studies suggest that a secure attachment style is predictive of positive relationship dynamics and adaptive approaches to relational conflict, while avoidant and anxious-ambivalent styles are predictive of negative relationship characteristics such as emotional coldness or possessiveness (Levy \& Davis, 1988).

More recently, the theory of love relationships stipulated by Johnson $(2003 ; 2006)$ postulates that intra- and interpersonal realities of those who were abused or neglected as children sometimes re-emerge to create an adult relationship dynamic of angry criticism leading to distancing and defensiveness. This type of chronic interaction makes safe emotional engagement impossible and deteriorates the relationship (Johnson \& Greenman, 2006). The fear and helplessness experienced by one or both partners may trigger separation distress, namely the perceived loss of connection with a valued and irreplaceable other (Johnson \& Best, 2003). The intensity of this fear leads to psychological pursuing behavior in which one partner engages in a critical and contemptuous pursuit in an effort to hold on to the other or threaten against abandonment. However, this only creates a reciprocal behavior of distancing or 'stonewalling' in the other partner. This in turn causes a more intense pursuit and angry protest at the loss of connection which may manifest itself behaviorally as clinging and seeking. In the 
absence of any response from the other, despair and depression sink in, and detachment is the end result (Johnson \& Best, 2003).

Johnson and Greenman (2006) have developed an emotion focused therapy for couples (EFT) that expands emotional responses and cycles of interaction in order to help couples who may have histories of maladaptive attachment styles and need to learn better ways of showing love to their partner. Depending on attachment style, Johnson and Greenman (2006) explain that two strategies may take place when there is no response from one partner, they are: hyperactivated attachment and hypoactivated attachment. A partner with an anxious-preoccupied attachment style responds with a hyperactivated attachment strategy. They become highly anxious, clingy, and elicit responsiveness through critical remarks. They may be reciting an internal statement, such as: "Come here; I need you - but you are dangerous - go away" (Johnson \& Greenman, 2006, p. 599). The partner cannot respond consistently and the other typically responds by avoiding.

Partners with an avoidant attachment style often engage in a hypoactivated attachment strategy (Johnson \& Greenman, 2006). They avoid emotions through distraction or immersion in tasks, and deny attachment needs. Often their withdrawal occurs at the moment of their partner's greatest vulnerability (Johnson \& Greenman, 2006). Partners who are distressed often rely on coercive tactics as a strategy of defending against loss and the anxiety of abandonment and rejection, however, the vicious cycle is perpetuated when the more one partner pushes for a response, the more the other feels threatened and withdraws further. This cycle feeds both partners' insecurity and negative emotional states. 
Partner-seeking. Attachment style not only affects an individuals' typical responses and behavior in a relationship, it also predicts whether an individual is more likely to be in a romantic relationship or not. In a study by Tidwell, Reis, and Shaver (1996) a contemporaneous diary procedure was used to measure how attachment style is manifested in natural social activity. Seventy-one undergraduate students at the state university of New York, at Buffalo were previously assessed in their undergraduate classes using Hazan and Shaver's (1987) measure of adult attachment, and the investigators included an equal number of participants from each attachment style in the study (the proportions of males and females were also comparable). The participants were then sorted into two groups: those with a romantic partner and those without one. Results showed that the majority of securely attached (68.3\%) and ambivalently attached (69\%) individuals were more likely to be in a romantic relationship than avoidant individuals $(44.4 \%)$. In addition, the investigators wanted to measure whether attachment-related behaviors only applied to interactions with romantic partners, or whether they could be generalized to other relationships as well (friends and others/acquaintances). Four categories of dyadic interactions were compared: oppositesex romantic partner, opposite-sex other, same-sex best friend, and same-sex other. Results showed that in the absence of a romantic relationship, securely and ambivalently attached individuals relied on other members of the opposite-sex to meet their intimacy needs, whereas avoidantly attached people without romantic partners did not experience much intimacy in their socializing (Tidwell, Reis, \& Shaver, 1996). A major limitation of this study was that same-sex romantic partners were not considered. 
Overall, insecurely attached individuals seek out a partner to solve their own problems and illicit support, however their constant doubts and negative expectations about the relationship make it unlikely that any of their needs will be met (Johnson \& Best, 2003). For ambivalent adults, relationship 'ruts' may occur wherein a high sense of anxiety and a sense of intrusiveness and uncertainty prevail. This may result from a fear of abandonment and narcissistic intrusion by the other (Johnson \& Best, 2003). Those who are ambivalently attached tend to experience intense turmoil in their intimate relationships and may be more likely to reenact traumatic relationship patterns (Johnson \& Best, 2003). Avoidant adults, on the other hand, may experience a 'depressed' relationship with a chronic sense of emptiness and unarticulated dissatisfaction (Johnson \& Greenman, 2006). The avoidant partner may fear rejection and has adapted to this state of emotional deadness demonstrated by such behaviors as emotional and physical withdrawal, stonewalling, and a lack of positive expressiveness and spontaneity (Johnson \& Greenman, 2006). In the following section, mediating and causal variables that help explain the connection between early attachment experiences of abuse and neglect, and adult love relationships will be discussed.

\section{Emotional Competence}

The development of emotion regulatory capacities can be traced back to childhood relationships with caregivers (Gross, 2007). Adult emotion-expressive behavior alters children's behavioral development, through nonverbal guidance, 'emotion talk', and investment in ego control (Block, 1971; Dunn \& Brown, 1991; Hooven, Gottman, \& Katz, 1995). These emotion regulatory processes interact with childrens' 
temperamental factors such as, thresholds for negative or positive affect, and selfsoothing capacities, to create the internalization of emotion regulation (Davidson, 1992; Kopp, 1982). Research has shown that children who have been maltreated are significantly different from nonmaltreated children in their emotional reactions, for example, they have a significantly faster reaction time in labeling fearful emotional facial expressions when compared to nonmaltreated children (Masten et al., 2007). This may suggest that growing up in an abusive environment causes a child to become hypervigilant for danger and develop a negative attribution bias (Masten et al., 2007). In addition, research suggests that maltreated children are less skilled in emotion-situation pairings (Perlman, Kallish, \& Pollack, 2008). For example, one study presented maltreated and nonmaltreated school-age children with emotional situations that varied in outcome and common elicitors of negative and positive events (Perlman et al., 2008). They were then asked to rate whether a situation was likely to cause such an outcome. Results showed that while nonmaltreated children were able to distinguish between common elicitors of negative and positive events, while maltreated children interpreted positive, negative and equivocal events as being equally likely to cause sadness or anger. This suggests that growing up in an abusive environment where emotions are often unpredictable and extreme causes an atypical understanding of emotion consequences, which will inevitably effect later social interactions (Perlman et al., 2008.).

Emotions are fundamentally adaptive. They facilitate decision making, provide information about the environment and social functioning, inform us about the behavioral intentions of others, and give us cues as to whether something is good or bad (Gross, 2007). Emotion regulation can be defined as, "the processes by which individuals 
influence which emotions they have, when to express them, and how they experience and express these emotions" (Gross, 1998). In this sense, emotions can be viewed as response tendencies that can be modulated (Gross, 1998; Gross, 2007; MacLean, 1990). Emotional intelligence is a related construct, and can be defined as, "the verbal and nonverbal appraisal and expression of emotion, the regulation of emotion in the self and others, and the utilization of emotional context in problem solving" (Mayer \& Salovey, 1993; Depape, Hakim-Larson, Voelker, Page \& Jackson, 2006).

Emotion regulation requires a type of self-regulation which may be conscious or unconscious. The prefrontal region of the brain has been found to be associated with emotion change processes, specifically affect regulation and impulse control. Abuse in childhood is associated with changes to the neuroanatomical and psychological aspects of affect development (Taylor \& Bagby, 2004). An overwhelming amount of stress hormones particularly glucocorticoids, epinephrine, and norepinephrine impact the developing brain (Lupien, McEwen, Gunnar, \& Heim, 2009). These reduce blood flow, increase cell inflammation and reduce axon-dendrite connection in selected emotionfocused centers of the brain (Lupien et al., 2009). Maltreated children were found to have smaller cerebral and prefrontal cortex volumes than nonmaltreated children, and also show underdevelopment of the middle portion of the corpus callosum (DeBellis et al., 2002; Taylor \& Bagby, 2004;). These centers orchestrate the planning of complex cognitive behaviors, impulse control, and the transfer of information from one hemisphere to another (Lupien et al., 2009; Taylor \& Bagby, 2004). Also, the orbitofrontal cortex is associated with emotional awareness and emotion regulation; its 
morphological development is influenced by the quality of the emotional interactions between infants and their caregivers (Taylor \& Bagby, 2004).

Emotional responses are very important in interpersonal situations. They can give rise to attentional and cognitive changes, leading to changes in behavior, such as, approaching or avoiding certain people, places, or objects in order to regulate emotions (Schneider-Rosen \& Cicchetti, 1991). Emotion regulatory goals are often contextspecific, such as attempting to match the emotional state of an interaction partner (Aber \& Cicchetti, 1984). Research has found that poor emotion regulation along with high levels of negative emotion, predicts less social competence and decreased peer acceptance and liking (Shields, Ryan, \& Cicchetti, 2001). Seventy-six maltreated children aged 8-12 years were compared to 45 controls on the basis of parent representations (using narratives), emotional competence (Q-sort ratings completed by camp councelors), and peer preference (peer nominations) (Shields et al., 2001). The participants were from Mt. Hope Family Center for inner-city children, a summer camp in New York City. Results showed that individuals who experienced child maltreatment were more likely to have negative or incoherent representations of caregivers, which was associated with emotional liability, negativity, and situationally inappropriate affective expression. This emotional dysregulation appeared to act as a mediator in the relationship between maltreatment and peer rejection.

\section{Alexithymia}

Alexithymia can be described as an abnormal affective state arising from a deficit in symbolization (Lane, Ahern, Schwartz, \& Kaszniak, 1997). This deficit in 
symbolization leads to the tendency to focus on the somatic sensations that accompany emotional arousal, and to misinterpret these as signs of illness (Taylor \& Bagby, 2004). Although there is a deficit in the subjective experience of emotion, research shows that the physiological activation of emotional arousal still occurs (Lane et al., 1997).

The resulting effects of alexithymia are deficits in both verbal and nonverbal communication (Spitzer et al., 2005). The most prominent deficit in alexithymia is a difficulty in describing feelings. Alexithymic individuals have an inability to effectively use nonverbal communication skills such as facial expressions and body language to communicate emotion. This lack of verbal and nonverbal communication skills may explain why alexithymics have particularly dysfunctional interpersonal relationships (Spitzer et al., 2005).

It has been argued that alexithymia is related to attachment style (Montebarocci, Codispoti, Baldaro, \& Rossi, 2004). Affect modulation and the ability to regulate inner states are skills learned through the context of positive early attachment experiences (Pearlman \& Courtois, 2005). When individuals are unable to regulate intense emotions such as, rage, fear, or shame, a feeling of desperation may result leading to coping strategies such as dissociation or other psychological defense mechanisms (Pearlman \& Courtois, 2005). In a study by Montebarocci and colleagues (2004), 301 undergraduate students at the University of Bologna were given the Italian versions of the Attachment Style Questionnaire (ASQ: Feeney, Noller, \& Hanrahan, 1994) and the Toronto Alexithymia Scale (TAS-20: Bagby, Taylor, Quilty, \& Parker, 2007). Results revealed that several subscales of the ASQ, specifically, Discomfort with Closeness, Relationships as Secondary, and Preoccupation with Relationships were positively correlated with the 
Difficulty Identifying and Communicating Feelings subscale of the TAS-20. This study supports the claim that individuals high in alexithymia have an insecure attachment style (most commonly anxious-avoidant), which becomes behaviorally manifested in interpersonal relationships through cold and socially avoidant behavior. They may approach others in an unempathic, cold, or detached way, avoid close relationships, and relate to others in a manner that is either dependent or impersonal so that the relationship remains superficial (Montebarocci et al., 2004). Thus, this study presents support for the association between the cognitive and affect-regulation deficits of alexithymia, and attachment styles (Montebarocci et al., 2004). It also supports the use of the attachment theory perspective in investigating the interaction between adult attachment behavior, relationship quality, and alexithymic characteristics (Montebarocci et al., 2004).

Alexithymia in adulthood has been associated with a childhood history of parental dysfunction in emotional or cognitive domains, particularly poor parental bonding (Fukunishi, Sei, Morita, \& Rahe, 1999). One study assessed 201 college students living in Tokyo on the relation between maternal attachment in childhood and the development of alexithymic characteristics (Fukunishi et al., 1999). Participants were given the Japanese version of two self-report measures: The TAS-20 and the Parental Bonding Inventory (PBI: Parker, Tuplong, \& Brown, 1979) and correlations between the two were measured. Results showed that participants' score on the Difficulty Identifying and Communicating Feelings subscale of the TAS and the TAS-total score, was significantly and negatively correlated with the Mother Care factor on the PBI (e.g. "My mother did not help me as much as I needed") but was not significantly correlated with the Mother Overprotection factor (e.g. "My mother did not want me to grow up") or the Father Care and 
Overprotection factors (Fukunishi et al., 1999). The most important finding of this study is that it lends support to the theory that poor parental bonding, specifically maternal bonding, is related to perceived difficulty in articulating feelings (Fukunishi et al., 1999).

A history of child maltreatment and dysfunctional family environment is associated with problems in the recognition and expression of emotion (Montebarocci et al., 2004). In childhood environments that are physically and emotionally unsafe and where the expression of emotion is discouraged, children do not learn successful coping strategies and may become uncomfortable expressing emotions. In addition, this type of environment lacks a positive role model for the nonthreatening display of emotion, leading to discomfort and ambivalence about emotional expression (Berenbaum \& James, 1994). In one experiment, 183 undergraduate students from the University of Illinois were assessed to investigate the relationship between childhood family environment and discomfort or ambivalence in the expression of emotion (Berenbaum \& James, 1994). Subjects were given self-report questionnaires including the TAS-20, Ambivalence Over Emotional Expressiveness Questionnaire (AEQ), Emotional Experience Discomfort Scale (EEDS), Positive and Negative Affect Schedule (PANAS), and the Childhood Experiences Questionnaire (CEQ). Results showed that alexithymia was significantly correlated with ambivalence concerning the expression of emotion, and with discomfort concerning negative emotional states. Higher levels of alexithymia were associated with retrospective reports of low family expressiveness and with feeling less emotionally safe during childhood (Berenbaum \& James, 1994). Thus, this study supports the view that ambivalence concerning the expression of emotion is associated with the degree of open family communication in childhood (Berenbaum \& James, 1994). Individuals learn from 
their families whether it is safe to communicate emotions openly, and this influences their relative difficulty or ease in communicating their emotions in adulthood (Berenbaum \& James, 1994).

A lack of knowledge and experience with adaptive emotional processes, leads to a deficit in empathy and the modulation of emotional states in others. This diminished capacity for perceiving and handling affective states is associated with a limited capacity for experiencing positive emotions such as joy, happiness, and love in interpersonal relationships, and less capacity for using social interaction for affect regulation (Spitzer, 2005; Vanheule et al., 2007). Difficulty communicating feelings is the most common alexithymia construct associated with child maltreatment (Montebarroci et al., 2004).

Alexithymia is related to a reduced capacity to use social interactions for affect regulation and the tendency to internalize distress, leading to maladaptive interpersonal relationships (Spitzer et al., 2005). In one study, a group of 49 inpatients in a group psychotherapy program completed the Toronto Alexithymia Scale (TAS-20) and the Inventory of Interpersonal Problems (IIP-C) (Spitzer et al., 2005). Results showed that high alexithymic patients had significantly more interpersonal problems than low alexithymic patients, especially in the area of hostility and social avoidance. In addition, the Difficulty Describing Feelings subscales of the TAS-20 had the highest correlations with interpersonal problems.

The interpersonal style associated with alexithymia is non-assertive, cold interpersonal functioning (dull, devoid of a feeling of resonance between the participants), lower capacity to see things from the point of view of others, lower empathic concern and a stronger tendency to react to others' negative experiences with 
distress, and interpersonal indifference (little is expected from others and there is no urge to fulfill their expectations) (Vanheule, Vandenbergen, Desmet, Rosseel, \& Insleghers, 2007). Researchers investigated relationship themes (Core Conflictual Relationship Theme Interview; CCRT) and alexithymia (TAS-20) in a sample of 30 chronically fatigued primary care patients (Vanheule et al., 2007a). Results showed that the more alexithymic someone is, the less likely they are to want to be helped by others and the less likely it is that they will interact with others in order to feel good about themselves (Vanheule et al., 2007a). There is a rejection of the idea that interpersonal relationships are helpful and can enhance one's well-being (Vanheule et al., 2007a).

Research has shown that the tendency to deny affective states and refrain from symbolizing affect is linked to distance-taking behavior and low degrees of affection for others. At the same time, it manifests itself in a kind of interpersonal passivity and little concern for manifesting one's own desires and needs to others (Vanheule, Desmet, Meganck, \& Bogaerts, 2007). In terms of social supports, alexithymic individuals are more likely to be unmarried and to have low levels of social contacts and acquaintances (Kauhanen, Kaplan, Julkunen, Wilson, and Salonen, 1993). The alexithymic's inability to be aware of their own emotions makes it very difficult to establish intimate relationships with romantic partners where self-disclosure and emotional trust are necessary ingredients (Kauhanen et al., 1993).

\section{Identity Integration}

The inability to know oneself emotionally is encompassed by a general deficiency in identity integration. An individual's sense of identity is impacted by psychological 
child abuse and neglect, creating changes in one's sense of self, self-awareness, and alterations in personal meaning (Pearlman \& Courtois, 2005). In adulthood, these difficulties are carried through to impact interpersonal relationships and romantic love relationships (Pearlman \& Courtois, 2005). While emotional abuse is generally associated with the development of a negative sense of self and identity, emotional neglect is associated with identity confusion; a sense of not being able to answer the question, 'Who am I?' (Colman \& Widom, 2004).

An integrated identity has been defined as the ability to identify one's own needs, maintain an internal reference point during times of stress, predict one's own behavior and reactions to external events, and access a positive sense of self by being one's own 'best friend' (Briere \& Scott, 2006). Problems with identity integration stem from early insecure attachment relationships with caregivers. Humiliation and shaming by caregivers creates a powerful source of self-blame, guilt, and erosion of self-esteem at a crucial developmental stage, which results in unintegrated and underdeveloped capacities to feel, think, and relate to others in adaptive ways (Paivio \& Pascual-Leone, 2009).

Positive self-esteem and self-worth have been defined as a global evaluation of the self as good, capable, and moral (Allen, 2001). The development of this positive sense of self depends on a 'good-enough' environment that is both stable and empathic, and gives the child the opportunity to idealize important others and have needs met (McCann \& Pearlman, 1990). Interpersonal trauma, and psychological abuse in particular, may uniquely contribute to low self-worth and low self-esteem (Briere \& Runtz, 1990; Howes, Hamilton, \& Phillipsen, 1998). Negative self-worth can seriously impede or derail a person's life course, including the ability to relate to others in ways 
that are healthy. Specific types of low self-esteem experienced by abuse survivors include severe self-criticism, guilt, and perceived undeservingness (Briere \& Runtz, 1990). Low self-esteem has been associated with low quality of friendships and marital relationships due to lack of self-disclosure, and this predicted relationship breakup over a period of several years (Boden, Fergusson, \& Horwood, 2008).

Psychological child abuse causes alterations in self-perception leading to feelings of guilt, responsibility, shame, ineffectiveness, and feeling that one is permanently damaged, unlikely to be understood by others, and unimportant (minimization of one's own experiences) (Courtois, Ford, Herman, \& Van Der Kolk, 2009). Alterations in systems of meaning may lead to despair and hopelessness; an existential feeling that the self is 'cursed' (Courtois et al., 2009). Experiencing psychological abuse as a child involves direct humiliation, berating, rejection, shaming, and withdrawal by parental figures, with overt messages of blame and criticism being chronically communicated (Courtois et al., 2009). As a result of this, the child does not develop self-soothing capacities, and gentle reassurance is often frightening or uncomfortable for them (Gilbert \& Procter, 2006). Overt messages from caregivers become internalized over time and erode self-esteem; individuals develop a sense of themselves as fundamentally flawed despite rational beliefs to the contrary (e.g. feeling 'stupid' even though one holds a business degree) (Paivio \& Pascual-Leone, 2009). Emotional neglect involves a lack of engagement and mirroring from a caregiver, resulting in a fundamental sense of identity confusion in adulthood (Paivio \& Pascual-Leone, 2009). This lack of response to the child's needs from caregivers becomes internalized over time and leads to the unwillingness to elicit care and warmth from others in adulthood (Erickson \& Egeland, 
1999); a sense of not being able to identify one's emotions and needs, and furthermore, not recognizing that they deserve to be fulfilled.

Self-blame is a major theme in the identity of an individual who has been psychologically abused in childhood. During childhood, self-blame may provide a tool of perceived control for victims of abuse as it is less threatening for the child to blame himself than to admit that their attachment figure, whom they are entirely dependent on, is the source of danger and pain (Paivio \& Pascual-Leone, 2009). The child is faced with a dilemma in which they either recognize that their parents are incapable of love and will not provide protection, or they believe that their parents are good people who are only reacting appropriately to a bad child (Herman, 1992). The second choice leads to an internalized sense of 'badness' that maintains the attachment relationship (Herman, 1992). The developing self becomes overwhelmed with feelings of inadequacy, low selfefficacy, shame, guilt, hopelessness, rejection, isolation, and alienation from self and others (Allen, 2001). The fundamental assumptions of viewing the world as benevolent, meaningful, and the self as worthy, are shattered (Allen, 2001).

In adulthood, feelings of self-blame become manifested as feelings of inferiority and anxiety. This 'shame-anxiety' is based in a fear of exposure; a fear that defective aspects of the self will be exposed and negatively evaluated by others (Paivio \& PascualLeone, 2009). This fear leads to anxious over-control and self-monitoring, an inability to be spontaneous and genuine, difficulty asserting oneself for fear of rejection or disapproval, engaging in extensive efforts to please others, and submissive or selfblaming behaviors as a response to another's aggression or lack of care towards them (Paivio \& Pascual-Leone, 2009). In severe cases of a lack of identity integration, 
individuals may engage in dissociation to escape the pain of reality. The unacknowledged experiences of psychological child abuse cause a lack of coherence and a fragmentation of the self (Siegel, 1999).

\section{The Present Study}

The long-term effects of psychological maltreatment are prevalent in community and clinical populations, and can be observed independent of the effects of physical and sexual abuse (Allen, 2001; Bifulco et al., 1998; Paivio \& Bahr, 1998; Paivio \& Cramer, 2004). The present cross-sectional study used path analysis to examine the following research questions: 1) Does psychological maltreatment in childhood affect attachment style in romantic relationships in adulthood? 2) Does identity integration and emotional competence mediate the relationship between psychological child maltreatment and adult attachment style? 3) Is psychological abuse uniquely associated with a negative sense of self, while psychological neglect is uniquely associated with identity confusion? 4) Is psychological abuse uniquely associated with affect dysregulation, while psychological neglect is uniquely associated with alexithymia? 5) Is psychological abuse uniquely associated with a fearful adult attachment style, while psychological neglect is uniquely associated with a dismissing attachment style? 


\section{Chapter II}

\section{METHOD}

\section{Participants}

Forty-eight male and 139 female undergraduate students $(\mathrm{N}=187)$ in opposite-sex dating relationships of at least 3 months, were recruited through the psychology department participant pool at the University of Windsor and compensated through course credit. All participants provided written, informed consent before completing the preliminary demographic questionnaire, and then proceeded to complete the main questionnaires, which took approximately 25-35 minutes to complete and were administered randomly to control for order effects.

A post-hoc power analysis of the present study indicated that power for this study was 0.42 , with a critical $X^{2}$ of 77.93 and a noncentrality parameter $(\lambda)$ of $17.01(\mathrm{~N}=187$, $\mathrm{df}=59$, alpha $=.05$, effect size $=0.3$ ). Thus, the statistical power to detect a medium effect size in the present sample was in the medium range. According to Kline (2004), the sample size in the present study $(\mathrm{N}=187)$ is in the medium range for path analysis.

Participants ranged in age from 18 to 50 years old $(\mathrm{M}=22, \mathrm{SD}=5.5)$, and ethnicity was predominantly Caucasian (66.6\%), followed Afro-Caribbean (9\%), Asian (7.9\%), Other/Multi-ethnic (6.9\%), East Indian (6.3\%), Aboriginal (1.6\%), and Hispanic (0.5\%). Relationship length ranged from 3 to 144 months $(\mathrm{M}=24, \mathrm{SD}=22.4)$.

Inclusion and Exclusion criteria. Participants were screened initially through a phone interview to determine that they are currently involved in a dating relationship of at least three months duration and are not married, engaged to, or living with a romantic 
partner. They were to be in contact with their dating partner or have been in contact with them during the past 30 days, and be dating a person of the opposite sex (DiLillo, Lewis \& Di Loreto-Colgan, 2007; Okun, Huff, August \& Rook, 2007; Simon, Kobielski, \& Martin, 2008).

\section{Measures}

The Relationship Questionnaire (RQ: Bartholomew \& Horowitz, 1991) is a single item measure that consists of four short paragraphs describing theoretically ideal or prototypical adult attachment styles as they apply to close adult relationships. Respondents rate how well they resemble each of the four attachment patterns (Secure, Fearful, Preoccupied, and Dismissing) on a 7-point Likert scale ranging from "not at all like me" (1) to "very much like me" (7). In addition, participants also choose a single, best-fitting attachment style. Each of the four attachment patterns is conceptualized in terms of a person's self-model (worthiness and lovability) and a person's image of others (available and supportive, or rejecting and uncaring) and thereby measures their degree of anxiety and dependency, and their tendency to seek out or avoid closeness in relationships.

The Relationship Scales Questionnaire (RSQ: Griffin \& Bartholomew, 1994a, 1994b) is a 30-item inventory that measures attachment style, rated on a 5-point Likert scale based on the extent to which each statement best describes their characteristic style in close relationships. Of the 30 items, 17 correspond to Bartholomew and Horowitz's (1991) Secure, Fearful, Preoccupied, and Dismissing attachment styles which also correspond to Hazan and Shaver's (1987, 1990) Secure, Avoidant, and 
Anxious/Ambivalent styles. The remaining 13 items are taken from Collins and Read's (1990) Adult Attachment Scale. After consulting Kurdek (2002) the items were included as part of the continuous measure of Bartholomew and Horowitz's (1991) four attachment styles. Just as with the RQ, each participants self-model and other-model was calculated by subtracting the sum of their secure and preoccupied score from the sum of their fearful and dismissing score.

Both scales show moderate test-retest reliability over a 2-month period; stability was .71 for secure, .64 for fearful, .59 for preoccupied, .49 for dismissing (average stability coefficient was .61) and moderate convergent validity (.58 for the self-model dimension and .57 for the other model-dimension). Convergent validity is shown by significant correlations $(\mathrm{r}=.34)$ between the RQ measure and the two semi-structured interview measures, the Family Attachment Interview (Bartholomew \& Horowitz, 1991) and the Peer Attachment Interview (Bartholomew \& Horowitz, 1991). Discriminant validity is indicated by a small correlation $(\mathrm{r}=.03)$ between self-model and other-model dimensions measured by the RQ. Construct validity was demonstrated through SEM by comparing theoretical constructs from RQ to peer attachment interview ratings (Griffin \& Bartholomew, 1994b). The self-model of the RQ (sense of self-worth) highly predicted self-reports of self-concept (structural coefficient $=.64$ ), and the other-model of the RQ (desire for closeness) highly predicted self- and friend-reports of subjects' interpersonal orientation (structural coefficient $=.69$ ). RQ ratings for the self-model also significantly correlated with Rosenberg Self-Esteem Inventory (Rosenberg, 1965). In general, the two scales (RQ and RSQ) are quite similar (Jellis, 2001). As suggested by Bartholomew and Horowitz (1991), the present study did not use the RQ in statistical analyses, but 
administered the questionnaire as a counterbalance for any ordering effects that may occur as participants self-categorize their attachment orientation.

The Robson Self-Concept Questionnaire (RSCQ; Robson, 1989) is a 30-item inventory that assesses the attitudes and beliefs that people hold about themselves, rated on a 7-point Likert scale ranging from Completely Disagree to Completely Agree. Respondents answer questions based on how they typically feel most of the time. A single aggregated score is obtained, where low numbers indicate low levels of selfesteem.

Factor analysis suggested that the RSEQ has five factors: "attractiveness, approval by others", "contentment, worthiness, significance", "autonomous self regard", "competence, self efficacy", and "value of existence, and personal destiny." In the present study, the subscales "Contentment, worthiness, significance" and "Autonomous self-regard" which contain 15 items in total were used to assess identity confusion.

The five factors have high internal consistency (coefficient alpha $=0.8$ in normative sample), indicating the existence of a strong central theme (presumably "self esteem”). In a control sample $(\mathrm{n}=200)$, both global and factor scores were normally distributed. Correlations between the RSEQ and related constructs show moderate convergent validity ( $\mathrm{r}=.46$ with RQ) (Jellis, 2001). Correlations between the factors and the constructs provided moderate support for the independent validity of each of the dimensions.

The Rosenberg Self-Esteem Scale (SES; Rosenberg, 1965) is a 10-item inventory that assesses how the respondent feels about him or herself, rated on a 4-point Likert 
scale ranging from Strongly Agree to Strongly Disagree. Higher scores indicate lower levels of self-esteem. In the present study, this scale was used to assess self-deprecation.

The Toronto Alexithymia Scale (TAS-20; Bagby, Taylor, Quilty, \& Parker, 2007) is a 20 -item inventory that measures the severity of alexithymia, rated on a 5-point Likert scale ranging from Strongly Disagree (1) to Strongly Agree (5). Factor analysis has shown that TAS-20 has three factors associated with different facets of alexithymia: difficulty identifying feelings, difficulty describing feelings, and externally oriented thinking. Alexithymia as measured by the TAS has been shown to be associated with attachment style (ASQ), interpersonal style (IIP), and relationship satisfaction (Ciarrochi \& Robb, 2005). In the present study, Total Alexithymia score was used to measure the latent variable, alexithymia. Scores 51 and below indicating no alexithymia, scores between 52 and 60 indicating possible alexithymia, and scores of 61 or above indicate the presence of alexithymia.

There is evidence for the generalizability of the TAS-20 cross-culturally, as it has been shown to demonstrate reliability and factorial validity in various languages and cultures. Internal consistency in a sample of 965 undergraduate students was .81 , and test-retest reliability in a subsample of 72 students over a 3-week interval was .77 (Taylor \& Bagby, 2004).

The Emotion Control Questionnaire-2 (ECQ-2; Roger \& Najarian, 1989; Roger \& Masters, 1997) is a 56-item true-false inventory that measures the tendency to inhibit the expression of emotional responses. It consists of four factors of emotion control, with fourteen items in each factor. The four factors include: Rehearsal, Emotional Inhibition, Aggression Control, and Benign Control. The two scales that were selected for this study 
to assess emotional inhibition include the Rehearsal scale and the Emotional Inhibition scale. The Rehearsal scale measures the tendency to ruminate, it has been found to be positively associated with neuroticism. The Emotional Inhibition scale measures the overregulation of emotion, or the tendency to exhibit high levels of emotional control, it has been found to be negatively associated with sociability. Kuder-Richardson reliability coefficients for the four factors range from 0.77 to 0.86 and test-retest reliabilities range from 0.73 to 0.92 .

The Childhood Trauma Questionnaire - Short Form (CTQ-SF; Bernstein \& Fink, 1998; see Appendix) is a 28-item retrospective measure of the frequency and severity of emotional, physical, and sexual abuse, and emotional, and physical neglect. Participants are asked to rate statements about childhood experiences (before age 18) on five-point Likert-type scales ("never true" to "very often true"). Three validity items are also included to assess minimization and denial. The CTQ provides a measure of overall childhood maltreatment, as well as individual subscale scores of the various forms of abuse described above.

CTQ scores have predictive validity in nonclinical samples and have been found to predict alexithymia, interpersonal functioning, and self-injurious behavior in university students. The questionnaire is also more sensitive to less severe experiences of abuse and neglect, making it suitable for use with a nonclinical group. Berstein and Fink (1998) report acceptable reliability and validity with test-retest reliabilities ranging from .66 to .94 , and alpha reliabilities ranging from .70 to .93 (physical neglect subscale yielded the lowest reliability coefficients). The mean minimization/denial score was $.54(\mathrm{SD}=.81)$, which is within the acceptable range ( $<1$; Bernstein \& Fink, 1998). 
The Family Expressiveness Questionnaire (FEQ; Halberstadt, 1986) is a 40-item scale that measures an individual's history of family expression, rated on a 9-pt scale ranging from (1) 'not at all frequently in my family' to (9) 'very frequently in my family'. The FEQ yields an overall rating of family expressiveness, as well as four 10item subscales in which affect (positive/negative) is crossed with power (dominant/submissive). They include: Positive Dominant (PD), Positive Submissive (PS), Negative Dominant (ND), and Negative Submissive (NS). The scales relevant to this study measure the frequency of Negative-Dominant expressions and NegativeSubmissive expressions. Negative-Dominant expressions captures criticism, contempt, and anger (emotional abuse), and Negative-Submissive expressions captures sorrow, disappointment, and embarrassment (emotional neglect).

Test-retest reliability was very high; $r(30)=.91, .92, .89$, and .91 for PS, PD, NS, and ND quadrants respectively indicating a great deal of stability in individual reports of FE (Halberstadt, 1986). Internal consistency of the subscales is high; for PS $a=.88$; for PD a=.87; for NS $a=.75$; for ND $a=.88$ (Halberstadt, 1986). Good discriminant and convergent validity has been established. Family expressiveness correlated positively with self-expressiveness, $\mathrm{r}(67)=.35, p \leq .01$, and negatively with shyness, $\mathrm{r}(67)=-.49$, $p \leq .001$, for men, but little relation was exhibited with either self-expressiveness, $r(62)=$ .16 , or shyness, $r(62)=.00$, for women (Halberstadt, 1986).

In summary, the test bank included valid and reliable elements from the following questionnaires: 1) The Relationship Questionnaire, 2) The Relationship Scales Questionnaire, 3) The Robson Self-Concept Questionnaire, 4) The Rosenberg SelfEsteem Scale, 5) The Toronto Alexithymia Scale, 6) The Emotion Control Questionnaire- 
2, 7) The Childhood Trauma Questionnaire-Short Form, and 8) The Family Expressiveness Questionnaire. These were assembled into a combined instrument with consideration of question rotation to prevent response fatigue or bias.

\section{Procedure}

The Research Ethics Board of the University of Windsor approved this study as a student research submission. Participants enrolled in introductory psychology classes at the university signed up online to participate in a study on the relations among childhood experiences, aspects of self, and adult relationships, in exchange for a course bonus point. Participants were assessed in groups of 5-10 individuals and were informed in writing at the beginning of the session about their right to discontinue participation at any time. No student chose to discontinue. Each student then anonymously responded to the questionnaires, which were given in random order to control for order effects. Care was taken to provide counseling contact and links to the supervising faculty should participants feel upset or concerned about themselves after the questionnaire completion exercise. No participant followed up on this resource, supporting the belief by the authors that this was a low-risk study.

Analysis Plan

Path Analysis was used to test the initial model (see Figure 1) separately for emotional abuse and emotional neglect. The purpose of path analysis is to trace the implications of a set of causal assumptions that are imposed on a system of relationships determined through theory and literature (Stage, Carter, \& Nora, 2004). It allows for the 
simultaneous study of direct and indirect effects with multiple independent and dependent variables.

The Structural Equation Modelling Software, EQS, was used for this purpose, as it allows for examination of the parameters of the model. Regressions were conducted for each dependent variable to produce a correlation matrix, which was then compared to the observed correlation matrix. Each path was independently modified by removing nonsignificant paths and adding significant paths that had not been predicted. In the first set of analyses, a measurement model was assessed to determine if the hypothesized latent variables of psychological maltreatment, emotional competence, identity integration, and adult attachment style fit the data. A measurement model is similar to a confirmatory factor analysis in which the constructs are allowed to correlate freely (Anderson \& Gerbing, 1988). It assesses the validity of the indicators in measuring the construct of interest (latent variables). Assessment of the measurement model is essential, as a good fitting model provides the researcher with more confidence in evaluating the hypothesized structural model (Byrne, 2001).

In the exploratory portion of the study, the measures for each construct were divided into two separate analyses in order to directly compare the differential long-term trajectories of emotional abuse and emotional neglect. The measures used in the path analysis for emotional abuse were as follows: the predictor variable included a combination of the Emotional Abuse subscale of the CTQ (Bernstein \& Fink, 1998) and the Negative Dominant Expressive subscale of the FEQ (Halberstadt, 1986). The identity construct was measured using the Rosenberg Self-Esteem Scale (Rosenberg, 1965). The emotional competence construct was measured using the Emotional Inhibition and 
Emotional Rehearsal subscale of the Emotion-Control Questionnaire (Roger \& Najarian, 1989). The adult attachment style was measured using the Fearful attachment scale on the Relationship Scales Questionnaire (Griffin \& Bartholomew, 1994).

The measures used in the path analysis for emotional neglect were as follows: the predictor variable included the Emotional Neglect subscale of the CTQ. Negative Submissive Expressiveness was found to be a poor predictor of unique variance in the model in a prior analysis, and thus was not included in the predictor variable. The identity construct was measured using the Contentment, Worthiness, Significance, and Autonomous Self-Regard subscales of the Robson Self-Concept Questionnaire (Robson, 1989). The emotional competence construct was measured using the total score on the Toronto Alexithymia Scale (Bagby et al., 2007). Finally, adult attachment style for emotional neglect was measured using the Dismissing attachment scale on the Relationship Scales Questionnaire.

Goodness-of-fit indices were assessed in order to evaluate the extent to which the model accurately reflected the data. The chi-squared value to degrees of freedom ratio, comparative fit index (CFI), Tucker-Lewis index (TLI), incremental fit index (IFI), and root-mean square error of approximation (RMSEA) were used to evaluate the models (Hu \& Bentler, 1998). Good fit is indicated if the ratio of chi-squared to degrees of freedom does not exceed 3.0 (Cole, 1987), CFI is larger than .95, TLI and IFI are larger than .90, and RMSEA is below .06. 


\section{Chapter III}

\section{RESULTS}

Path analysis was used to examine how psychological child maltreatment related to identity integration, emotional competence, and romantic attachment in adulthood. A general theoretical model was tested: Psychological child maltreatment is related to attachment style in adult love relationships, and identity integration and emotional competence mediate this relationship. All analyses were conducted in AMOS 7 using maximum likelihood parameter estimation.

\section{Examination of the data}

Cronbach's alpha coefficients were computed to assess the reliability of measures and subscales. The mean, standard deviation, Cronbach's alpha, and range for each measure used in the present study are available in Table 1. The coefficients presented in Table 1 range from .61 to .90 . Researchers in the social sciences have indicated that, generally, a reliability coefficient over .70 is acceptable (Garson, 2009; Byrne, 2001). The subscales which indicated a less than adequate level of inter-item reliability include Autonomous Self-Regard (.61), Dismissing attachment style (.63), and Secure attachment style (.67). Since Cronbach's alpha increases as the number of items in the scale increases, the reason for the low item-item reliability for the Autonomous Self-Regard subscale could be the fact that there are only 5 items in the scale. For the three subscales that presented less than adequate reliability levels, the inter-item correlations were analyzed in an effort to identify problematic items that may be lowering the reliability of that particular scale. Items with low item-total correlations (<.3) indicate that the item has 
a low correlation with the overall scale (Garson, 2009). However, although several items had correlations below .3, no items were removed from the subscales because of the assumption that scales with a greater number of items are more reliable (Garson, 2009). All subscales were included in analysis as those below the .70 cut-off were still in a satisfactory range (Byrne, 2001; Garson, 2009), however, this may be a limitation of the study. 
Table 1.

Means, standard deviations, and range of subscales

\begin{tabular}{|c|c|c|c|c|}
\hline Subscale & $\mathrm{M}$ & SD & $\begin{array}{r}\text { Cronbach's } \\
\text { Alpha } \\
\end{array}$ & $\begin{array}{l}\text { Range } \\
(\mathrm{x}-\mathrm{y})\end{array}$ \\
\hline \multicolumn{5}{|l|}{ Childhood Trauma Questionnaire } \\
\hline Emotional Abuse & 8.32 & 4.23 & .86 & $5-24$ \\
\hline Emotional Neglect & 8.55 & 4.24 & .90 & $5-24$ \\
\hline \multicolumn{5}{|l|}{ Family Expressiveness Questionnaire } \\
\hline Negative Dominant Expressiveness & 48.30 & 14.25 & .86 & $17-87$ \\
\hline Negative Submissive Expressiveness & 52.58 & 12.32 & .71 & $14-86$ \\
\hline \multicolumn{5}{|l|}{ Robson Self-Concept Questionnaire } \\
\hline Contentment, Worthiness, Significance & 4.62 & 0.89 & .76 & $1-7$ \\
\hline Autonomous Self-Regard & 4.63 & 0.95 & .61 & $2-7$ \\
\hline Rosenberg Self-Esteem Scale & 18.03 & 4.75 & .87 & $10-32$ \\
\hline Toronto Alexithymia Scale & 43.66 & 12.01 & .86 & $23-79$ \\
\hline \multicolumn{5}{|l|}{ Emotion Control Questionnaire } \\
\hline Emotional Rehearsal & 21.94 & 3.17 & .77 & $15-28$ \\
\hline Emotional Inhibition & 22.94 & 3.03 & .77 & $14-28$ \\
\hline \multicolumn{5}{|l|}{ Relationship Styles Questionnaire } \\
\hline Secure Attachment & 22.98 & 4.53 & .67 & $13-33$ \\
\hline Fearful Attachment & 18.56 & 6.08 & .77 & $7-35$ \\
\hline Preoccupied Attachment & 25.47 & 6.56 & .86 & $12-45$ \\
\hline Dismissing Attachment & 20.15 & 3.61 & .63 & $9-28$ \\
\hline
\end{tabular}

Note: For all variables, interval level data was used and relationships among the variables were linear. 
Visual inspection of the variables revealed no significant univariate outliers. Mahalanobis Distance was examined to assess normality and possible multivariate outliers in the data. The Mahalanobis Distance identifies any case for which the observed scores differ markedly from the centroid scores for all cases and should be deleted as outliers (Byrne, 2001). In the present study, two cases had the largest d-values and also had small $\mathrm{p}$-values in the second column $(\mathrm{p} \leq .001)$, thus they were deleted from further analyses (Byrne, 2001; Arbuckle, 1997). This brought the total sample size to 187 participants.

In addition, all variables in the study were visually inspected and statistically assessed for skewness and kurtosis. Emotional abuse and emotional neglect were both positively skewed $\left(\mathrm{P}_{\text {Emotional abuse }}=1.65 ; \mathrm{P}_{\text {Emotional neglect }}=1.41\right)$. For this reason, $\log$ transformations were conducted for these two variables and used in all subsequent analyses.

Prior to conducting a path analysis, all variables were examined for missing data. There were 27 cases with missing data. Most missing cases were found on the Alexithymia scale (52\%) and were related to a formatting error. However, since this was deemed to be a small amount of missing data, these cases were deleted from the data set instead of being imputed (El-Masri \& Fox-Wasylyshyn, 2005). Some researchers favor deletion (El-Masri \& Fox-Wasylyshyn, 2005; Kline, 2004) because it allows for all analyses to be conducted on the same number of cases reducing ambiguity and fostering standardization. Deletion is an appropriate technique if the proportion of missing data does not exceed 20\% (El-Masri \& Fox-Wasylyshyn, 2005). Therefore, the final sample size on which all analyses were performed was 187 . A post-hoc power analysis of the 
present study indicated that power for this study was 0.42 , with a critical $X^{2}$ of 77.93 and a noncentrality parameter $(\lambda)$ of $17.01(\mathrm{~N}=187, \mathrm{df}=59$, alpha $=.05$, effect size $=0.3)$. Thus, the statistical power to detect a medium effect size in the present sample was in the medium range. According to Kline (2004), the sample size in the present study $(\mathrm{N}=187)$ is in the medium range for path analysis.

\section{Severity of abuse}

Severity rates for the different types of abuse were calculated separately for males and females. Participants were categorized as having experienced abuse or neglect based on the cut-offs for "low" severity on the CTQ short-form subscales recommended by Bernstein and Fink (1998). The means, standard deviations, and prevalence rates for males and females are available in Table 2. Means and cut-scores are close in value because, as expected, the various types of abuse are positively skewed, with most of these nonreferred participants scoring in the low range. In the present sample, $34.5 \%$ of women experienced emotional abuse and $26.6 \%$ experienced emotional neglect in childhood. In males, $29.2 \%$ experienced emotional abuse and $35.4 \%$ experienced emotional neglect in childhood. Females reported a greater extent of emotional abuse compared to males, while males reported a greater extent of emotional neglect. 
Table 2.

Characteristics of the Sample

\begin{tabular}{llll}
\hline Criteria & $\mathrm{M}(\mathrm{SD})$ & $\mathrm{N}(\%)$ & Percent above C \\
\hline Age & $22(5.5)$ & & \\
Relationship length (months) & $24(22.4)$ & & \\
Family income (\$) & $97973.4(105.9)$ & & \\
& & & \\
Males & & $48(25.4)$ & 29.2 \\
Emotional abuse & $7.4(2.9)$ & & 29.2 \\
Physical abuse & $7.0(2.6)$ & & 16.7 \\
Sexual abuse & $5.5(1.6)$ & & 35.4 \\
Emotional neglect & $8.4(3.2)$ & $139(73.5)$ & 22.9 \\
Physical neglect & $6.2(1.9)$ & & 35.4 \\
Females & & & 23.0 \\
Emotional abuse & $8.7(4.6)$ & & 20.9 \\
Physical abuse & $6.8(3.2)$ & & 15.1 \\
Sexual abuse & $6.7(4.4)$ & & \\
Emotional neglect & $8.6(4.6)$ & & \\
Physical neglect & $5.9(1.8)$ & $126(66.6)$ & \\
& & $17(9.0)$ & \\
Ethnicity & & $15(7.9)$ & \\
Caucasian & & $13(6.9)$ & \\
Afro-Carribbean & & $12(6.3)$ & \\
Asian & & & \\
Other/Multi-ethnic & & & \\
East Indian & & & \\
Aboriginal & & & \\
Hispanic & & & \\
\hline
\end{tabular}

Note: Percent above $\mathrm{C}=$ cut-scores on the Childhood Trauma Questionnaire (Bernstein and Fink, 1998): Emotional abuse, $\mathrm{C}=8$; Physical abuse, $\mathrm{C}=7$; Sexual abuse, $\mathrm{C}=5$; Physical neglect, $\mathrm{C}=7$ ) 
The percentage of participants that fell into each category of adult attachment style is shown in Table 3. The percentage of participants in each category was calculated and compared to the frequencies reported by Bartholomew and Horowitz (1991). Previous research has reported that about $49 \%$ of adults have a secure attachment style, $12 \%$ a preoccupied style, $21 \%$ a fearful style, and $18 \%$ a dismissing style (Bartholomew \& Horowitz, 1991). The present study showed similar results for each category.

Table 3.

Adult attachment style categories

\begin{tabular}{lll}
\hline Attachment Style & N & Percentage \\
\hline Secure & 82 & 43.9 \\
Preoccupied & 21 & 11.2 \\
Fearful & 46 & 24.6 \\
Dismissing & 33 & 17.6 \\
Unknown & 5 & 2.7 \\
\hline
\end{tabular}




\section{Correlations}

Pearson correlations among the variables in the model are presented in Table 4. As expected, psychological maltreatment, identity integration, emotional competence, and attachment in adult love relationships are all significantly correlated, with the exception of negative submissiveness and emotional inhibition. All of the correlations were in the expected direction in that more severe emotional abuse and emotional neglect in childhood were associated with lower levels of identity integration, lower levels of emotional competence, and a higher likelihood of insecure attachment style in adulthood. These significant correlations suggest that the relationships between these variables warrant investigation using path models. 
Table 4.

\section{Correlation among model variables}

\begin{tabular}{|c|c|c|c|c|c|c|c|c|c|c|c|c|c|c|c|c|c|}
\hline & EA & EN & PA & PN & SA & ND & NS & $\mathrm{C}$ & A & SE & $\mathrm{AL}$ & IN & $\mathrm{RH}$ & $\mathrm{SC}$ & $\mathrm{PO}$ & $\mathrm{FF}$ & $\mathrm{DM}$ \\
\hline EA & -- & $.76^{* *}$ & $.51^{* *}$ & $.59 * *$ & $.29 * *$ & $.61^{* *}$ & $.18 * *$ & $-.27 * *$ & $-.23 * *$ & $.25^{* *}$ & $.37 * *$ & $-.20 *$ & $-.22 *$ & $-.34 * *$ & $.24 * *$ & $.45^{* *}$ & $.38 * *$ \\
\hline & & -- & $.45^{* *}$ & $.59 * *$ & $.24 * *$ & $.51 * *$ & .08 & $-.29 *$ & $-.27 * *$ & $.27 * *$ & $.35^{* *}$ & $-.22 * *$ & $-.23 * *$ & $-.34 * *$ & $.24 * *$ & $.40 * *$ & $.35 * *$ \\
\hline EN & & & -- & $.38 * *$ & $.25^{* *}$ & $.41 * *$ & .11 & $-.17 *$ & -.10 & $.16^{*}$ & $.33 * *$ & $-.17 *$ & $-.14 *$ & $-.20 * *$ & .12 & $.34 * *$ & $.34 * *$ \\
\hline PA & & & & -- & $.18 * *$ & $.32 * *$ & .11 & $-.21 * *$ & $-.16^{*}$ & $.18^{* *}$ & $.34 * *$ & $-.14 *$ & $-.16^{*}$ & $-.25 * *$ & $.14 *$ & $.31 * *$ & $.34 * *$ \\
\hline PN & & & & & -- & .11 & .02 & -.09 & -.03 & -.05 & $.24 * *$ & .00 & .01 & $-.14 *$ & .12 & $.22 * *$ & .12 \\
\hline SA & & & & & & -- & $.44 * *$ & $-.29 * *$ & $-.26^{* *}$ & $.30^{* *}$ & $.28 * *$ & -.10 & $-.34 * *$ & $-.33 * *$ & $.25 * *$ & $.39 * *$ & $.36 * *$ \\
\hline ND & & & & & & & -- & $-.21 * *$ & -.10 & $.17^{*}$ & .13 & .11 & $-.26^{* *}$ & $-.14 *$ & $.30 * *$ & .13 & $.18^{* *}$ \\
\hline NS & & & & & & & & -- & $.69 * *$ & $-.78 * *$ & $-.62 * *$ & $.25 * *$ & $.54 * *$ & $.56^{* *}$ & $-.42 * *$ & $-.42 *$ & $-.35^{* *}$ \\
\hline $\mathrm{C}$ & & & & & & & & & -- & $-.72 * *$ & $-.48 * *$ & $.25^{* *}$ & $.38 * *$ & $.44 * *$ & $-.34 * *$ & $-.26 * *$ & $-.19 * *$ \\
\hline A & & & & & & & & & & -- & $.52 *$ & $-.27 * *$ & $-.53 * *$ & $-.55 * *$ & $.40 * *$ & $.39 * *$ & $.30 * *$ \\
\hline SE & & & & & & & & & & & -- & $-.42 * *$ & $-.36 * *$ & $-.53 * *$ & $.33 * *$ & $.56^{* *}$ & $.40 * *$ \\
\hline IN & & & & & & & & & & & & -- & .05 & $.42 * *$ & -.03 & $-.50 * *$ & $-.31 * *$ \\
\hline $\mathrm{RH}$ & & & & & & & & & & & & & -- & $.48 * *$ & $-.38 * *$ & $-.40 * *$ & $-.35 * *$ \\
\hline $\mathrm{SC}$ & & & & & & & & & & & & & & -- & $-.34 * *$ & $-.68 * *$ & $-.58 * *$ \\
\hline $\mathrm{PO}$ & & & & & & & & & & & & & & & -- & $.31^{* *}$ & \\
\hline FF & & & & & & & & & & & & & & & & -- & $\begin{array}{l}.66^{* *} \\
--\end{array}$ \\
\hline
\end{tabular}


As shown in Table 4, negative submissive family expressiveness (NS) had generally low correlations with the majority of variables in the model with correlations ranging from .02 to .44 . It is notable that the highest correlation coefficient was between negative submissive and negative dominant family expressiveness, indicating that this subscale had a substantial amount of overlap and was a less than adequate measure of predicting unique variance in the other variables of the model. This variable was investigated further to determine if it should be included in the model.

Emotional inhibition was not associated with negative dominant (ND) or negative submissive family expressiveness (NS), and also was not correlated with emotional rehearsal, or preoccupied attachment style in adulthood. Emotional abuse and emotional neglect were positively correlated. Emotional abuse was also positively correlated with negative dominant expressiveness. However, emotional neglect was not associated with negative submissive expressiveness as predicted, but instead was positively correlated with negative dominant expressiveness.

A second set of correlational analyses was conducted to determine whether forms of abuse other than emotional abuse and emotional neglect were related to the variables in the model. The correlations in Table 4 show that all types of child maltreatment were significantly related to one another. The other forms of abuse not pertaining to this study were not investigated further, however, it was noted that the present model could be generalized to include the long-term effects of physical abuse and physical neglect, but not sexual abuse. 


\section{Covariates}

T-tests indicated that males and females did not differ significantly on any of the model variables (i.e. psychological maltreatment, identity integration, emotional competence, and attachment in adult love relationships). A one-way analysis of variance was conducted for ethnicity, relationship length (months), and age. Results showed that family income yielded no significant differences on model variables between participants. In general, relationship length and age also showed no significant differences. In terms of ethnicity, the only significant correlation was Caucasian ethnicity with secure attachment, however, ethnicity was not entered as a variable in the model since secure attachment was not one of the variables of interest for the present study.

\section{Model Testing}

Measurement model. In the first set of analyses, a measurement model was assessed using Goodness-of-fit indices to determine if the hypothesized latent variables of psychological maltreatment, emotional competence, identity integration, and adult attachment style fit the data (Figure 2). The chi-squared value to degrees of freedom ratio, comparative fit index (CFI), Tucker-Lewis index (TLI), incremental fit index (IFI), and root-mean square error of approximation (RMSEA) were used to evaluate the models (Hu \& Bentler, 1998). Good fit is indicated if the ratio of chi-squared to degrees of freedom does not exceed 3.0 (Cole, 1987), CFI is larger than .95, TLI and IFI are larger than .90, and RMSEA is below .06. 


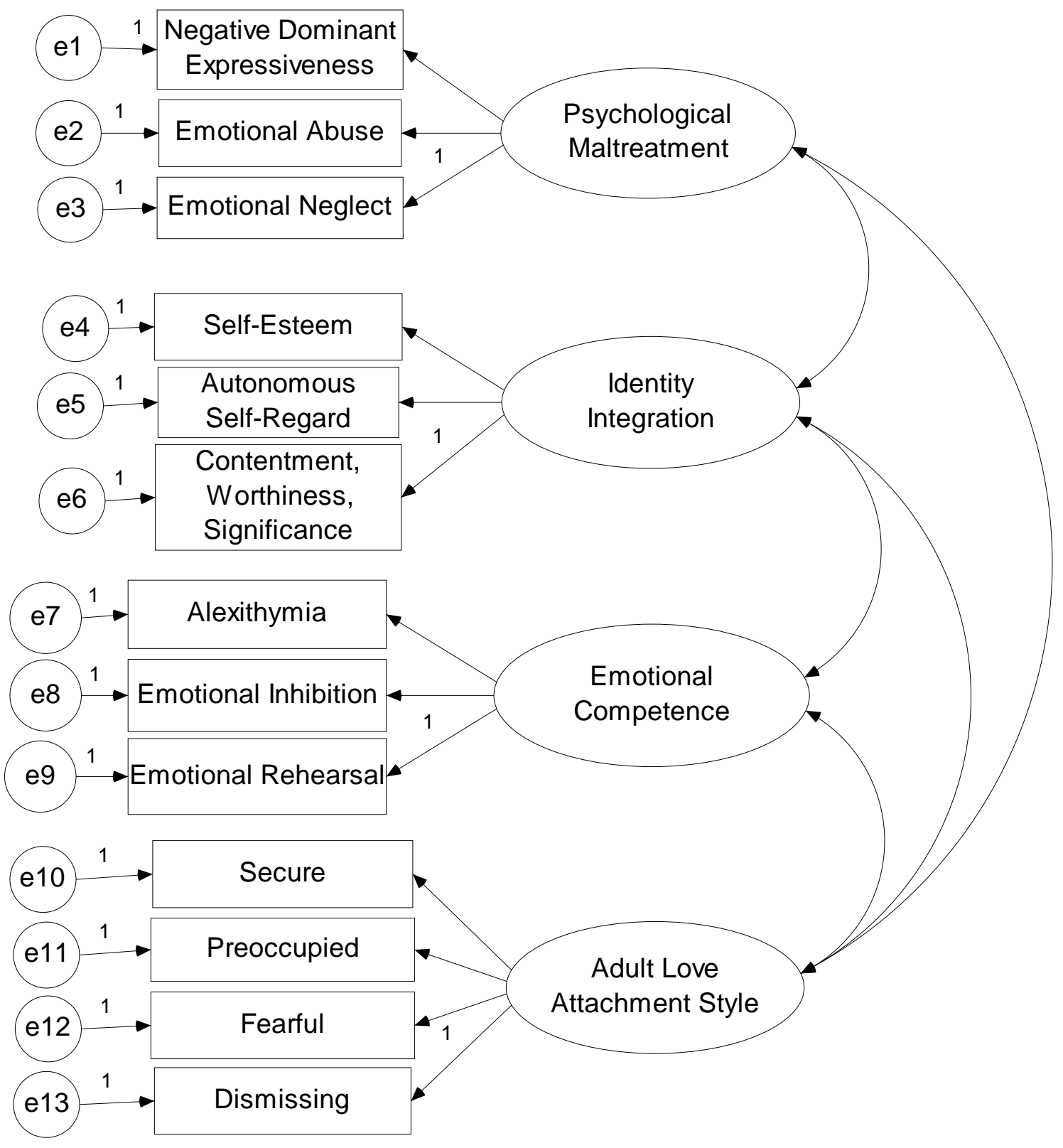

Figure 2. Hypothesized measurement model representing the validity of the indicator variables in measuring the constructs of interest.

Note. e=error terms; 'rectangular boxes'=indicator variables; 'ovals'=constructs of interest 
Initially, the measurement model demonstrated a poor fit to the data. The modification indices showed that negative submissive family expressiveness was highly intercorrelated with negative dominant family expressiveness and preoccupied adult attachment style. This suggested multicolliniarity and problematic cross-loadings, such that negative submissive family expressiveness did not demonstrate enough unique variance to be included as a separate measure in the model.

Modification indices were analyzed in order to assess in detail why negative submissiveness was so problematic for this model. In path analysis, modification indices for estimated regression weights are associated with a decrease in chi-square if the path between the two variables is eliminated (Byrne, 2001). One common rule of thumb is to eliminate the parameter with the largest modification index, then observe the effect as measured by the chi-square fit index (Byrne, 2001). However, the elimination of a parameter must always make substantive as well as statistical sense. In the present case, the largest modification index is 27.37 for the path from negative submissiveness to negative dominance, followed by a modification index of 10.83 for the path from negative submissiveness to preoccupied attachment style. This suggests that there were unanalyzed associations between negative submissiveness, negative dominance, and preoccupied attachment. This indicates that removing negative submissiveness would decrease the chi-squared statistic significantly. The smaller the chi-square statistic, the more accurately the hypothesized model fits the data. In addition, the squared multiple correlation $\left(\mathrm{R}^{2}\right)$ for negative submissiveness was very low $\left(\mathrm{r}^{2}=.09\right)$ indicating that the proportion of variability in a data set that is accounted for by negative submissiveness is not statistically relevant. 
This finding also makes sense theoretically because negative submissive family expressiveness appears to be a milder form of negative dominant family expressiveness (e.g. passive-aggressiveness). In a post-analysis of the questions that made up these two scales it was noted that the questions describe different degrees of a negative family environment and thus are not that differentiated. For example, an item that made up the negative dominant scale was: "Expressing dissatisfaction with someone else's behavior" and an item that made up the negative submissive scale was: "Expressing disappointment over something that didn't work out." Thus, an individual who endorses the negative dominant items would be very likely to also endorse the negative submissive items.

All of the above factors strongly suggested that negative submissiveness should be dropped from further analyses. Indeed, after negative submissiveness was removed from the model, the model showed a good fit to the data $\left(\mathrm{X}^{2}(59, \mathrm{~N}=187)=133.48, p<.05\right.$; CFI=.94, TLI=.92, IFI=.94, RMSEA=.08(90\%CI:.06-.10).

\section{Research Question}

It was hypothesized that identity integration and emotional competence would mediate the relationship between childhood psychological maltreatment and adult attachment style in love relationships. Maximum likelihood estimation was used to test these meditational relationships among the latent variables. In order to test this meditational model, several steps indicated by Holmbeck (1997) were tested.

The first step was to test the direct relationship between psychological maltreatment and adult attachment style (Figure 3). This model had a very good fit to the data, $\mathrm{X}^{2}(13, \mathrm{~N}=187)=15.37, p=.35 ; \mathrm{CFI}=1.0, \mathrm{TLI}=1.0, \mathrm{IFI}=1.0, \mathrm{RMSEA}=.02$ 
(90\%CI:.00-.08) indicating that psychological maltreatment directly predicts attachment style in adulthood. In addition, standardized regression weights indicate that, as predicted, higher levels of psychological maltreatment is positively associated with all insecure attachment styles (fearful attachment in particular) and negatively associated with secure attachment. 


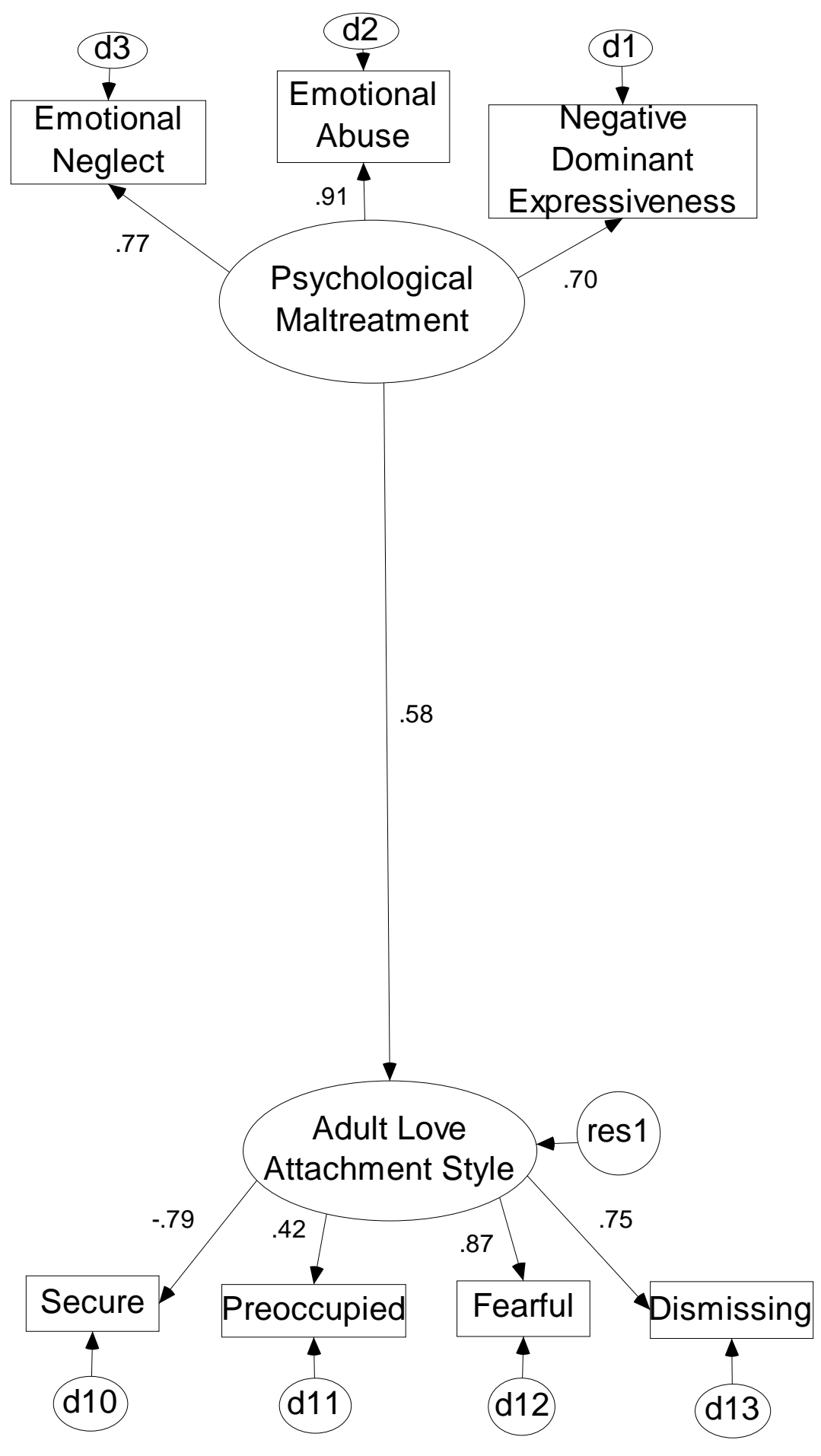

Figure 3. Hypothesized structural model representing the direct relationship between psychological maltreatment and adult love attachment styles. 
The second step according to Holmbeck (1997) is to test for mediation. Thus, the direct relationship between psychological maltreatment and identity integration, and identity integration and adult attachment style, was tested (Figure 4). This model showed good fit to the data, $\mathrm{X}^{2}(33, \mathrm{~N}=187)=89.87, p<.05 ; \mathrm{CFI}=.94, \mathrm{TLI}=.92$, IFI=.94, RMSEA $=.10$ (90\%CI:.07-.12). Direct paths between psychological maltreatment, identity integration, and adult attachment style were all significant and in the predicted directions. This indicates that the greater the severity of psychological maltreatment in childhood, the lower the levels of identity integration in adulthood. In addition, the greater the levels of identity integration, the greater the likelihood of having a secure attachment style in adulthood and the lower the likelihood of having an insecure attachment style. 


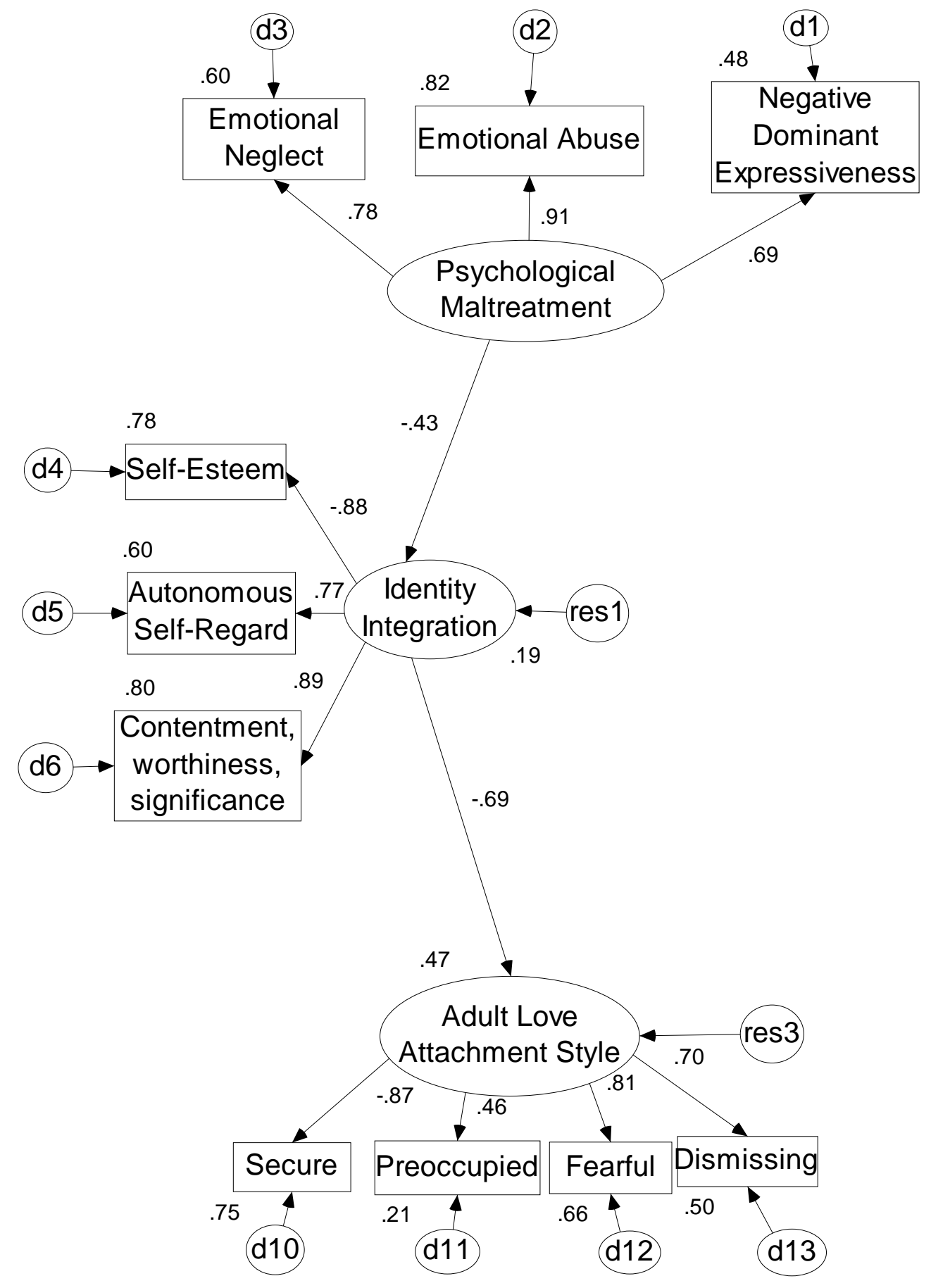

Figure 4. Hypothesized structural model representing the indirect relationship between psychological maltreatment, identity integration and adult love attachment styles.

Note. The negative correlation for self-esteem is due to the fact that higher scores are indicative of lower levels of self-esteem 
The next step, according to Holmbeck (1997) is to test the meditational effect of this mediator under two conditions: (1) When the direct path between psychological maltreatment and adult attachment styles is constrained to zero, and (2) when the direct path between psychological maltreatment and adult attachment styles is not constrained to zero. The improvement in overall fit of the model is measured based on the significance of the difference in the chi-square between the two models. If there is a meditational effect, the additional path between psychological maltreatment and adult attachment styles should not improve the fit.

For the first mediator, identity integration, when the direct path was constrained to zero, the data fit the model well, $\mathrm{X}^{2}(33, \mathrm{~N}=187)=86.1, p<.05 ; \mathrm{CFI}=.95$, TLI=.93, $\mathrm{IFI}=.95, \mathrm{RMSEA}=.09(90 \% \mathrm{CI}: .07-.12)$. When the direct path was not constrained to zero, chi-squared decreased significantly, $\mathrm{X}^{2}(32, \mathrm{~N}=187)=59.9, p<.05 ; \mathrm{CFI}=.97$, TLI=.96, IFI=.97, RMSEA=.07(90\%CI:.04-.10). Thus, in this case, the additional path did improve the model's overall fit to the data, $\mathrm{X}_{\mathrm{D}}^{2}(1, \mathrm{~N}=187)=26.2, \mathrm{p}=.000$, indicating that identity integration does not mediate the relationship between psychological maltreatment and adult attachment styles.

For the second mediator, emotional competence, the above steps were repeated. First, the direct relationship between psychological maltreatment and emotional competence, and emotional competence and adult attachment styles, was tested (Figure 5). This model showed excellent fit to the data $\left(\mathrm{X}^{2}(32, \mathrm{~N}=187)=56.36, p<.05 ; \mathrm{CFI}=.97\right.$, TLI=.96, IFI=.97, RMSEA=.06(90\%CI:.04-.09). Again, the direct paths between psychological maltreatment and emotional competence and emotional competence and adult attachment styles were all significant and in the predicted directions. This indicates 
that the greater the severity of psychological maltreatment in childhood, the lower the emotional competence in adulthood. Also, greater levels of emotional competence are predictive of higher levels of secure attachment and lower levels of insecure attachment styles in adulthood. 


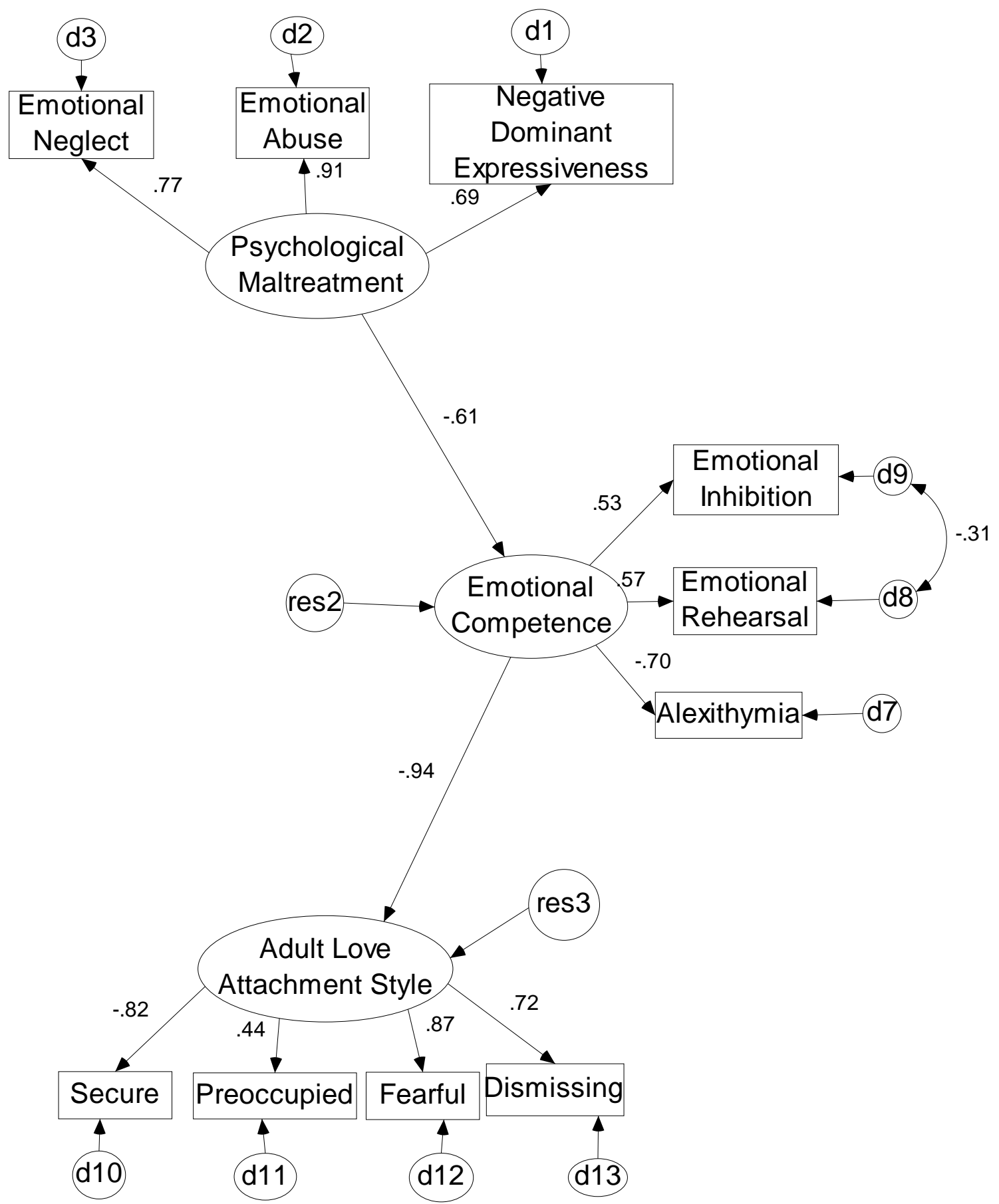

Figure 5. Hypothesized structural model representing the indirect relationship between psychological maltreatment, emotional competence, and adult love attachment styles. 
For the second mediator, emotional competence, when the direct path was constrained to zero, the model fit the data well, $\mathrm{X}^{2}(32, \mathrm{~N}=187)=56.4, p<.05 ; \mathrm{CFI}=.97$, TLI=.96, IFI=.97, RMSEA=.06 (90\%CI:.04-.09). When the direct path was not constrained to zero chi-squared did not decrease significantly and model fit to the data was nearly identical, $\mathrm{X}^{2}(31, \mathrm{~N}=187)=55.8, \quad p<.05 ; \quad \mathrm{CFI}=.97, \quad \mathrm{TLI}=.95, \quad \mathrm{IFI}=.97$, RMSEA=.07 (90\%CI:.04-.09). In this case the additional path did not improve the model's overall fit to the data, $\mathrm{X}_{\mathrm{D}}^{2}(1, \mathrm{~N}=187)=0.6, \mathrm{p}=3.8$, indicating that emotional competence fully mediates the relationship between psychological maltreatment and adult attachment styles. In sum, while identity integration does not mediate the relationship between psychological maltreatment and adult attachment styles, emotional competence does mediate it.

\section{Modifications}

Since it was determined that identity integration does not mediate the relationship between psychological maltreatment and adult attachment styles, modification indices were assessed in order to determine how exactly identity integration fits into the model, if at all.

The modification indices showed that there was a relation between identity integration and emotional competence that was not being accounted for. In path analysis, modification indices for estimated regression weights are associated with a decrease in chi-square if the path between the two variables is eliminated (Byrne, 2001). One common rule of thumb is to eliminate the parameter with the largest modification index, then observe the effect as measured by the chi-square fit index (Byrne, 2001). However, 
as noted earlier, the elimination of a parameter must always make substantive as well as statistical sense. In the present case, the largest modification index was 38.62 for the path from identity integration to emotional competence, followed by a modification index of 23.55 for the path from emotional competence to identity integration. In addition, the standardized regression weight for the direct path between identity integration and adult love relationships $(\beta=-.12)$ was much smaller than the standardized regression weight for the direct path between emotional competence and adult love relationships $(\beta=-.87)$. Thus, statistically it was warranted to include a direct path from identity integration to emotional competence in order to lower chi-squared and achieve a better fit of the model to the data. Theoretically, it is also a sound decision to add a direct path from identity integration to emotional competence, because research has shown that a more coherent sense of self predicts better capacity for emotional, behavioral, and cognitive self-control (Mikulincer \& Shaver, 2008; Pals, 2006). This additional path significantly improved the fit of the model to the data, $\mathrm{X}_{\mathrm{D}}^{2}(1, \mathrm{~N}=187)=86, \mathrm{p}<.05$, confirming that in the present sample a more coherent sense of identity predicts more emotional competence.

After the addition of this direct path, modification indices were reexamined and revealed a relatively high modification index value $(M I=11.17)$ for the link between the error terms of emotional inhibition and emotional rehearsal. This suggested that there was a relationship between emotional inhibition and emotional rehearsal that was not being accounted for, and perhaps that these two variables covary and occur together often. Error associated with observed variables represents nonrandom error, such that the error variance arises from some characteristic that is specific to the particular indicator variable, in this case, emotional competence. Thus, shared variance exists between the 
error terms associated with the observed variables, emotional inhibition and emotional rehearsal. Theoretically, it is also true that inhibition and rumination (rehearsal) occur together (Roger, De la Banda, Lee \& Olason, 2001). Thus, the error terms for these two variables were allowed to correlate and this improved model fit to the data substantially. The final model with the best fit to the data is presented in Figure 6, and fit indices for the measurement model and final structural model are presented in Table 5. This model showed a 'double mediation', in which early psychological maltreatment predicted identity integration during adulthood. Identity integration in turn predicted participants' emotional competence in adulthood, and emotional competence fully mediated the relationship between psychological maltreatment and adult attachment styles. 


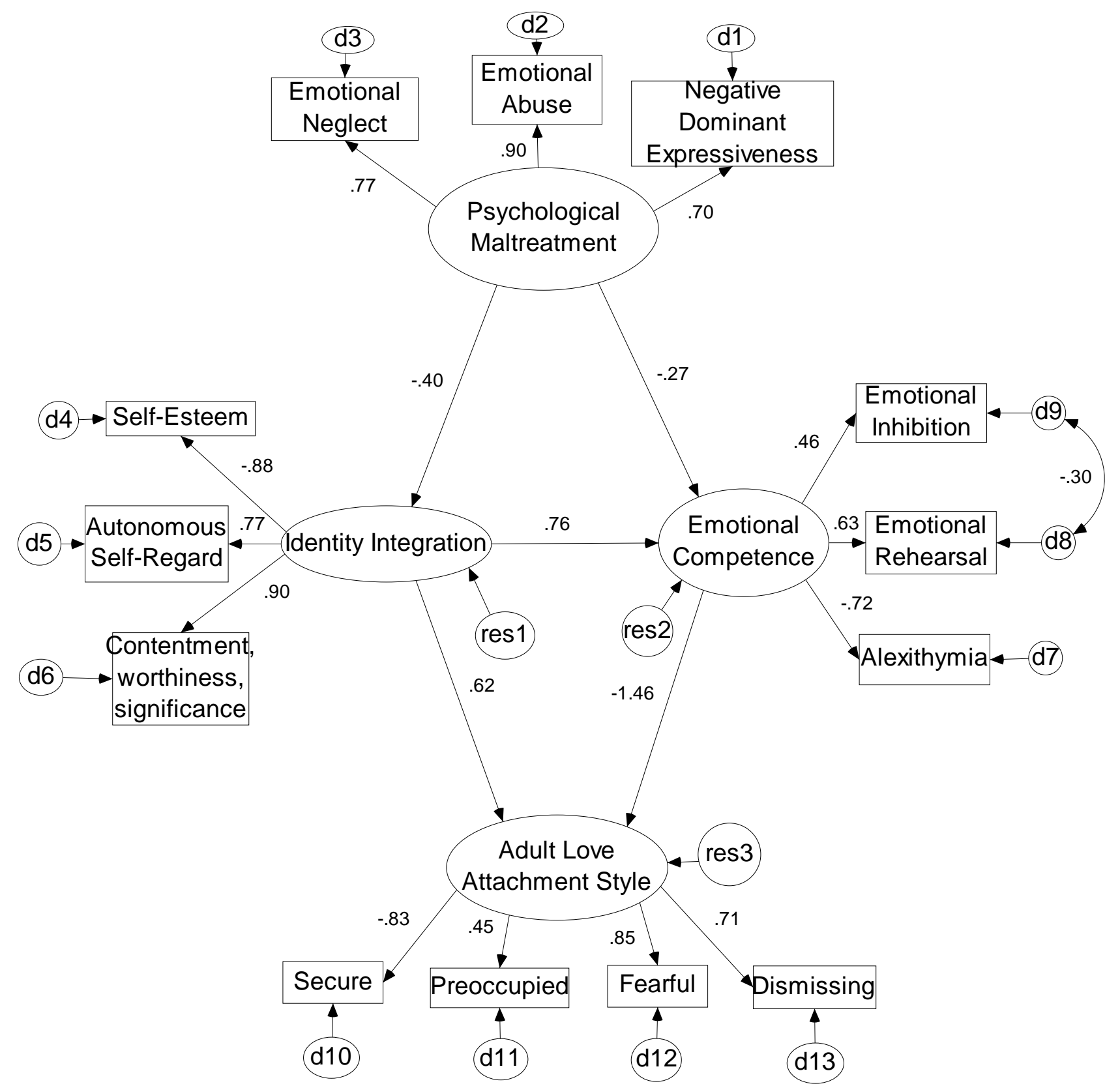

Figure 6. Structural model representing the relationships between psychological maltreatment, identity integration, emotional competence, and adult love attachment style. 
Table 5

Final fit indices for measurement and structural models

\begin{tabular}{llllllll} 
Model & $\mathrm{X}^{2}$ & $\mathrm{df}$ & $\mathrm{p}$ & $\mathrm{CFI}$ & $\mathrm{TLI}$ & $\mathrm{IFI}$ & $\begin{array}{l}\text { RMSEA } \\
(90 \% \mathrm{CI})\end{array}$ \\
\hline Measurement model & 133.48 & 59 & .000 & .94 & .92 & .94 & $\begin{array}{l}.08 \\
(.06-.10)\end{array}$ \\
Structural model & 121.79 & 59 & .000 & .95 & .94 & .95 & $\begin{array}{l}.08 \\
(.06-.09)\end{array}$ \\
\hline
\end{tabular}

Note . CFI = Comparative Fit index; TLI = Tucker Lewis index; IFI = Incremental Fit index; RMSEA = Root mean square error of approximation.

\section{Additional Analyses}

This section of the study was strictly exploratory. The research question was whether there were differences in the long-term trajectories for emotional abuse and emotional neglect. In terms of identity integration, it was expected that neglect would be associated with identity confusion, measured by a lack of autonomous self-regard (SCQ: Autonomy) and contentment (SCQ: Contentment), and abuse would be associated with a negative sense of self, measured by low self-esteem (RSE). In relation to emotional competence, it was expected that neglect would be associated with alexithymia (TAS-20), while abuse would be associated with problems in emotion regulation (ECQ: Rehearsal, ECQ: Inhibition). In terms of adult attachment, it was expected that neglect would be associated with a dismissing adult attachment style (RSQ: Dismissing), while abuse would be associated with a fearful adult attachment style (RSQ: Fearful).

In order to test these questions statistically, standardized regression weights were observed for each variable in the model when each predictor was constrained to zero. In 
the first analysis, all paths leading from Psychological Abuse to each observed variable were constrained to zero, and standardized path coefficients from Psychological Neglect to each observed variable were observed (Table 6). In the second set of analyses, all paths leading from Psychological Neglect to each observed variable were constrained to zero, and standardized path coefficients from Psychological Abuse to each observed variable were observed (Table 7). In path analysis, constraining a path to zero is akin to holding that variable constant and removing its effects (Byrne, 2001). Results in Tables 6 and 7 showed that rather than finding differential effects for psychological abuse and neglect, converging results were found. Abuse and neglect did not produce differential long-term trajectories but rather were both found to be most highly associated with a lack of contentment, alexithymia, and a fearful attachment style in adulthood.

Table 6.

Standardized Regression Weights for the paths leading from Psychological Neglect to individual measures

\begin{tabular}{ll}
\multicolumn{1}{c}{ Measures } & Estimate \\
\hline RSE & .293 \\
SCQ: Autonomy & -.286 \\
SCQ: Contentment & -.336 \\
& \\
TAS-20 & .371 \\
ECQ: Rehearsal & -.277 \\
ECQ: Inhibition & -.206 \\
& \\
RSQ: Secure & -.340 \\
RSQ: Preoccupied & .278 \\
RSQ: Fearful & .406 \\
RSQ: Dismissing & .339 \\
\hline
\end{tabular}

Note. RSE = Rosenberg Self-Esteem scale; SCQ = Self-Concept Questionnaire; TAS-20 $=$ Toronto Alexithymia Scale; ECQ = Emotion Control Questionnaire; RSQ: Relationship Scales Questionnaire 
Table 7.

Standardized Regression Weights for the paths leading from Psychological Abuse to individual measures

\begin{tabular}{ll}
\multicolumn{1}{c}{ Path to Psychological Abuse } & Estimate \\
\hline RSE & .314 \\
SCQ: Autonomy & -.291 \\
SCQ: Contentment & -.337 \\
& \\
TAS-20 & .359 \\
ECQ: Rehearsal & -.352 \\
ECQ: Inhibition & -.187 \\
& \\
RSQ: Secure & -.386 \\
RSQ: Preoccupied & .293 \\
RSQ: Fearful & .458 \\
RSQ: Dismissing & .393 \\
\hline
\end{tabular}

Note. RSE = Rosenberg Self-Esteem scale; SCQ = Self-Concept Questionnaire; TAS-20 $=$ Toronto Alexithymia Scale; ECQ = Emotion Control Questionnaire; RSQ: Relationship Scales Questionnaire 


\section{Summary of Findings}

Overall, results from the present study revealed a double mediation, specifically, early psychological maltreatment predicted identity integration during adulthood. Identity integration in turn predicted participants' emotional competence in adulthood, and emotional competence fully mediated the relationship between psychological maltreatment and adult attachment styles. Generally, people who were more severely psychologically maltreated during childhood tended to have more extreme insecure attachment styles characterized by a fear and lack of trust in others; difficulty expressing emotions and maladaptive emotional processing accounted for this association. In addition, results of this study showed that emotional abuse and emotional neglect did not produce differential long-term trajectories but rather were both found to be most highly associated with a lack of contentment, worthiness, and significance; as well as with alexithymia; and a fearful attachment style in adulthood. 


\section{Chapter IV}

\section{DISCUSSION}

The present study investigated the mechanisms through which childhood maltreatment has long-term negative effects on adult romantic relationships. The purpose of this study was two-fold. The first aim was to explore whether identity integration and emotional competence were mediators of the relationship between childhood psychological maltreatment and insecure attachment in adult romantic relationships. The second aim of this study was to explore whether there were differential long-term effects of emotional abuse and emotional neglect on identity integration, emotional competence, and the capacity for intimacy in adult love relationships (insecure attachment).

Findings of this study suggest that problems with relationships and intimacy experienced by young adults can be partly attributed to difficulties with emotional competence, that is, a tendency to inhibit the expression of emotion and to ruminate over emotional situations. Contrary to expectations, emotional competence was, in turn, a function of a positive sense of self and an integrated identity in adulthood. In contrast to hypotheses, identity integration did not mediate the relationship between psychological maltreatment and adult relationships. Moreover, contrary to expectations, emotional abuse and emotional neglect did not produce different long-term trajectories; rather, both were associated with a lack of contentment, worthiness, and significance; difficulties identifying feelings (alexithymia); and a fearful attachment style in adulthood. The following sections will discuss each of the major findings, beginning with characteristics of the sample.

The range of severity of abuse in the present sample of young adults is comparable 
to that found in community samples, thus providing evidence for the generalizability of the results of the present study. Similarly, prevalence rates for the different types of abuse in the present study parallel prevalence rates reported in previous studies using undergraduate and community samples (Bernstein \& Fink, 1998; Paivio \& Cramer, 2004; Scher, Stein, Asmundson, McCreary, Forde, 2001; Turner \& Paivio, 2002). As expected, emotional abuse and neglect were both positively skewed because, in this nonreferred sample, most participants scored low in terms of maltreatment severity. Results of the present study therefore cannot be generalized to clinical samples or to more severely maltreated individuals.

Another finding in the present study was that all types of child maltreatment were significantly related to one another, which is in line with literature stating that multiple forms of abuse often occur together (Dong, Anda, Felitti, Dube, Williamson, Thompson, Loo, \& Giles, 2004). This may help to explain the failure to find differential long term effects for different types of psychological maltreatment. In addition, all forms of childhood abuse, except sexual, were related to negative dominant family expressiveness. Physical abuse and neglect exhibited the same general pattern as emotional abuse and neglect with significant correlations in the same direction. Sexual abuse, on the other hand, was the only variable that was not significantly correlated with other variables in the model (negative dominant family expressiveness, contentment, autonomy, selfesteem, emotional control, or preoccupied and dismissing insecure attachment styles). One plausible explanation for this is that the most important long-term effects of sexual abuse experiences for this group were distinct from other types of abuse. This may be because of low severity of abuse (not chronic) or perpetrator identity (individuals outside 
the family) (Mullen, King, \& Tonge, 2000). The long-term consequences of child sexual abuse may have particular implications for body image and sexual dysfunction, including problems such as eating disorders or sexual identity issues (Mullen et al., 2000), rather than be more strongly associated with variables in the present sample. As well, less frequent or less severe experiences of sexual abuse and abuse not perpetrated by members of the family may have different long-term consequences than experiencing chronic forms of physical and emotional abuse by a primary caregiver (Mullen et al., 2000). However, the present study did not assess perpetrator identity or the number of times abuse occurred. Thus, the present model may apply to physical abuse and neglect but not to sexual abuse.

The present sample was not representative of diverse cultural groups and therefore is not generalizeable to other community samples. A higher-than-average proportion of Caucasians signed up as part of the study (66.6\%), followed Afro-Caribbean, Asian, and East Indian all had proportions around the 10\% range, with the smallest proportions being Aboriginal and Hispanic ethnicities $(\leq 1 \%)$. This may be due to a flaw with my demographic measure that presented European and Caucasian decent as mutually exclusive categories, which may have increased the proportion of individuals that endorsed these categories. In addition, results indicated that Caucasian ethnicity was significantly associated with secure attachment style in the model. This bias toward secure attachment did not affect results due to the fact that the present study was primarily concerned with insecure attachment styles. 


\section{Long-term Effects of Maltreatment}

Romantic Relationships. The finding that psychological maltreatment in childhood has long-term negative effects on adult relationships validated the hypotheses of this study based on attachment theory and research. The results of the present study indicate a link between childhood psychological abuse and a fearful and dismissing attachment style in romantic relationships. This finding is consistent with prior research in this area which showed that adults with a history of attachment trauma are likely to exhibit avoidance-based attachment styles in their current romantic relationships (Roisman et al., 2002, 2005; Sroufe et al., 2005). Both avoidance-based attachment styles (fearful and dismissing attachment) are associated with the avoidance of intimacy, as the fearful adult avoids intimacy to save themselves from rejection, and the dismissing adult avoids intimacy to avoid depending on others who will inevitably let them down.

The present study found that an assessment of childhood psychological maltreatment that combined the Childhood Trauma Questionnaire (CTQ), which directly assesses maltreatment experiences, with the Family Expressiveness Questionnaire (FEQ), which assesses family environment, provided information about the associations between early adverse childhood experiences and romantic adult attachment. The FEQ measures the frequency of positive dominant, positive submissive, negative dominant, and negative submissive expressions. The negative dominant and negative submissive subscales were of interest in the present study; the former captures criticism, contempt, and anger (akin to emotional abuse), and the latter captures sorrow, disappointment, and embarrassment (akin to emotional neglect) (Halberstadt, 1986). In general, individuals who experienced emotional abuse were more likely to grow up in an environment dominated by either 
anger, hostility, criticism, and threats, while those who experienced emotional neglect were more likely to grow up in an environment dominated by sadness, helplessness, and emotional withdrawal (Halberstadt, 1986). The culmination of these adverse childhood experiences was associated with insecure attachment to one's romantic partner.

In addition, results of the present study supported the postulated link between attachment trauma in childhood and avoidance-based attachment styles in adulthood. Adults who were neglected as children have the tendency to develop a dismissing attachment style because of their extreme self-reliance and lack of care from caregivers (Feeney, 2008). Thus, they tend to emphasize achievement and self-reliance in their adult lives, maintaining a sense of self-worth at the expense of intimacy (Feeney, 2008). Interpersonal problems associated with this attachment style involve excessive coldness (Bartholomew \& Horowitz, 1991; Feeney et al., 1994; Feeney, 2008). Young adults with this type of relational style who are in romantic relationships may tend to consistently put their own interests ahead of their partners and make relationship decisions that benefit themselves, without making an effort to meet their partner's needs. In other words, the relationship becomes 'one-sided' and 'self-focused' (Feeney, 2008). On the other hand, adults who were emotionally abused as children have the tendency to develop a fearful attachment style because of their extreme distrust stemming from a fear of rejection from their caregivers (Feeney, 2008). Thus, these individuals desire intimacy but distrust others, and avoid close involvements that may lead to rejection or loss (Feeney, 2008). Interpersonal problems associated with this attachment style involve social insecurity, need for approval, and lack of assertiveness (Bartholomew \& Horowitz, 1991; Feeney et al., 1994; Feeney, 2008). Young adults with this type of relational style may tend to 
appear 'clingy' in relationships and their lack of trust for their partner may appear in the form of jealousy or possessiveness. (Feeney, 2008).

Sense of self and emotional competence. Current research has questioned what exactly are the intermediate relationships and representations through which early attachment predicts later romantic relationships (Berlin, Cassidy, \& Appleyard, 2008). The present study has suggested an answer: emotional competence and identity integration in adulthood.

The present study supports recent research in that it shows that healthy adult relational functioning is a product of both early relationships and current emotional functioning and self-concept (Sroufe et al., 2005; Roisman et al., 2005). One of the most influential studies to assess the associations between early attachments and other relationships has been a prospective, longitudinal study called, the Minnesota ParentChild Project. This was a 30-year study of approximately 180 high-risk families that investigated the continuity of early attachment styles into adulthood (Sroufe et al., 2005; Roisman et al., 2005). The most important results of the Roisman (2002) study was that researchers found that having a secure attachment style in adulthood was predictive of functional relationship processes regardless of whether these individuals had been securely or insecurely attached to their mothers as infants. In one study, infant-mother attachment security predicted relationship security at age 20-21, even after observed relationship quality and duration were controlled (Sroufe et al., 2005). In another study by Roisman and colleagues (2002) using the same sample, participants with secure attachment classifications at age 19 showed significantly more positive relationship processes (e.g. support, autonomy promotion, shared affect, and secure-base provision) 
with their romantic partner at age 20-21 than individuals with insecure attachment classifications. This highlights the limits of early attachments, specifically insecure attachments, on later romantic relationships, and suggests that working models are malleable and based on both early experiences as well as current experiences in adulthood (Simpson et al., 2007). Although the present study was not longitudinal, it showed that current emotional-cognitive processes, such as emotional competence and identity integration, dictate attachment style in adulthood.

\section{Mediational Effects}

Emotional competence. Results of the present study supported the postulated meditational role of emotional competence in the association between childhood maltreatment and adult attachment styles. Emotional competence can be defined as, "the verbal and nonverbal appraisal and expression of emotion, the regulation of emotion in the self and others, and the utilization of emotional context in problem solving" (Depape et al., 2006; Mayer \& Salovey, 1993). Emotional inhibition, on the other hand, refers to 'bottling up' or inhibiting the expression of experienced emotion, while emotional rehearsal refers to the tendency to be preoccupied with emotional upset about past or future events (Roger et al., 2001). Thus, if someone is accustomed to hiding their feelings, they do not acknowledge strong emotions or go through the necessary emotional processes to resolve their emotional conflict, which could then lead to rumination or perseveration. Someone who habitually uses an emotional inhibition or rehearsal strategy would be considered to have a low level of emotional competence. In the present study, emotional inhibition and emotional rehearsal (rumination) were correlated so that 
modifications had to be made to the statistical model. These modifications significantly improved the fit of the model to the data. Research has found that, indeed, emotional inhibition and rumination (rehearsal) often co-occur together (Roger et al., 2001).

Low levels of emotional competence can be defined as the habitual use of emotional inhibition or rehearsal strategies. However, in addition to this, various studies have found a link between emotional competence and identity self-concept (Allen, 2001; Erickson \& Egeland, 1999; Gilbert \& Procter, 2006; Harroks \& Callahan, 2006; Pals, 2006) but the present study was unique in that it illuminated a possible directionality between identity and emotional competence. To my knowledge the link between emotional competence and identity integration has not been empirically tested in relation to the experience of adult survivors of child abuse. Although the present study used path analysis and thus could not prove causation, the results suggest that negative self-concept may be predictive of poor emotion management. For example, individuals with a negative self-concept may resort to defensive self-enhancement strategies that inflate positive selfviews and disregard any negative evaluations of themselves. This coping mechanism is used in order to protect a fragile ego that is the product of an environment in which the individual had to struggle to maintain a sense of self-worth and security (Arndt et al., 2002; Mikulincer \& Shaver, 2008; Schimel et al., 2001). This defensive strategy is not conducive to adaptively processing feelings about the self. Results of the present study support this view and suggest that low self-worth can negatively influence emotional competence.

In addition to the above meditational effect, the results of the present study show that emotional competence is directly related to childhood maltreatment experiences, such 
that more severe forms of childhood psychological maltreatment were associated with a higher incidence of emotional inhibition and emotional rehearsal. The habitual use of an emotional inhibition or rehearsal strategy may be the result of traumatic experiences during childhood that overwhelmed normal emotion processes. Results of the present study support theory in this area, which stipulates that emotional processing for traumatic events starts with an event that is so traumatic that it overwhelms the individuals psyche and normal coping mechanisms (Eid, Johnsen, \& Saus, 2005; Rachman, 2001). The inability to appropriately label and identify emotions results in the inability to properly make sense of traumatic events (Baker, 2001). As a result, maladaptive emotional control can occur through over-control, in which the individual inhibits all expression of emotion essentially inhibiting and suppressing all difficulty; or under-control, in which the person habitually cannot control actions, words or impulses even when they ought to (Baker, 2001). Researchers have also found that hiding one's emotions requires a high degree of self-monitoring and a suppression of the emotional experience itself (Rachman, 2001). In relation to the present study, young adults that experienced maltreatment in childhood were more likely to habitually inhibit negative emotions and tended to rely on rumination as an emotional processing strategy.

The present finding that a higher level of psychological maltreatment in childhood was associated with a lower level of emotional competence in adulthood also is consistent with research on school-aged children. One study found that suppression may lead to a rumination process in which mulling over problems frequently and 'on one's own' was associated with prolonged symptoms of depression, an increase in negative emotion, anxiety, anger, and thoughts of revenge (Broderick, 2005; Matheson \& Anisman, 2003; 
McCullough, Bono, \& Root, 2007). In terms of development through childhood, securely attached children have stronger emotion regulation capacities than insecurely attached children, identify emotions in others more readily, have a better understanding of negative emotions and 'mixed feelings', express emotions freely, engage in more self-disclosure, and have better overall communication competence (Anders \& Tucker, 2000; Feeney, 1999; Keenan et al., 1998; Thompson, 2008; Thompson \& Meyer, 2007). In addition, through the use of Stress tasks, several studies have found that securely attached children have better coping mechanisms and use more constructive anger management strategies than insecurely attached children (Gilliom et al., 2002; Kerns et al., 2007). Thus, childhood maltreatment sets into motion early dysfunctional emotional processes, such as suppressing or being overwhelmed by distressing emotions that interfere with emotional competence in adulthood, which, in turn, can negatively impact relational capacity.

Indeed, the present study found that high levels of emotional inhibition and rehearsal were related to the avoidance of intimacy in romantic relationships. Participants who reported that they value self-sufficiency over relationships and tend to avoid close emotional relationships, were more likely to report inhibiting their emotions and ruminating about upsetting events. Thus, the present study is consistent with prior research that found that avoidant adults tend to inhibit awareness of their feelings and block access to emotion (Mallinckrodt \& Wei, 2005 ;Mikulincer \& Shaver, 2008). They tend to deny or suppress thoughts and memories related to emotions, and mask expressions of emotions both verbally and nonverbally (Mikulincer \& Shaver, 2003). Since the very definition of adult intimacy is the capacity to relate to another person in an emotionally open and caring manner, young adults who habitually inhibit their emotional 
state and ruminate over upsetting events will likely have a lower capacity to engage in an intimate relationship with their partner, thus finding their relationships less emotionally fulfilling.

Self-concept. Findings of the present study are consistent with theory and research, which define secure attachment in terms of a positive sense of self. The present study showed that higher self-esteem was associated with a secure attachment style in adults. This is consistent with prior research that assessed self-integration using a Stroop task and found that securely attached individuals could easily describe both positive and negative aspects of themselves and integrate them into a self-structure (Mikulincer, 1995). In contrast, avoidant individuals could not access negative self-attributes because of a defensive self-organization and could not integrate their attributes with other aspects of the self (Mikulincer, 1995). Research indicates that secure attachment is not only associated with overall higher levels of self-esteem and self-worth (Bylsma, Cozzarelli, \& Sumer, 1997) but also with the stability of self-esteem (Foster, Kernis, \& Goldman, 2007; Kernis, 2003, 2005). Although stability of self-esteem was not investigated in this study, the present study supports the view that global positive self-esteem is predictive of more adaptive relationship dynamics in couples.

Results of the present study failed to show that identity integration mediated the relationship between psychological maltreatment and adult romantic attachment. However, identify integration did prove to be an important factor in explaining emotional competence. Identity integration fit well into the model when it was positioned as a predictor for emotional competence; thus, individuals who had higher self-esteem, more autonomous self-regard (knowing who you are despite what other people say), and a 
greater sense of contentment, worthiness, and significance, had higher levels of emotional competence and were able to express and process emotions more adaptively. The present study supports the view that self-esteem and a sense of personal worth are important for maintaining emotional balance and sustaining autonomous emotion regulation by providing people with effective self-soothing strategies that alleviate distress (Mikulincer \& Shaver, 2008).

\section{Specific Effects of Abuse and Neglect}

Results of the present study did not find different effects for psychological abuse and neglect, but rather found that both were associated with a lack of contentment, worthiness, and significance, as well as alexithymia (poor emotional awareness) and a fearful attachment style in adulthood.

The present study tested whether emotional abuse is more associated with a fearful attachment style, while emotional neglect is more associated with a dismissing attachment style. Results indicated that both emotional abuse and neglect were associated with fearful attachment in adulthood. A primary reason for this may be that both fearfully attached adults and dismissing adults are characterized by an avoidant style.

The failure to differentiate between abuse and neglect may be partly because the scales used to assess "emotion regulation" (Emotional Inhibition and Emotional Rehearsal) were not sufficiently distinct from the scale used to assess alexithymia (Toronto Alexithymia Scale-20; Bagby, Taylor, Quilty, \& Parker, 2007). Both scales measure a form of emotional suppression. Perhaps if the present study had included a measure of emotional reactivity, results may have showed that emotional inhibition was 
related to alexithymia while emotional reactivity was not. Studies have found that anxiously attached individuals have a tendency to react with intense emotion to threatening events and anxious attachment correlates highly with intense anger, sadness, and anxiety in daily social interactions; while avoidant attachment, on the other hand, is more associated with blocking and inhibiting emotional reactions and lower emotional reactivity (Feeney, 1999; Mikulincer \& Shaver, 2008; Searle \& Meara, 1999). Therefore, in terms of the present study, perhaps results may have differed to show that young adults who experienced childhood emotional abuse become emotionally reactive and develop a fearful attachment style in adulthood, while those who were emotionally neglected become emotionally inhibited leading to a dismissive attachment style in adulthood.

The present study found that, as expected, emotional abuse is associated with low self-esteem; however, contrary to expectations, emotional neglect was not uniquely related to identity confusion. Rather, results of the study showed that both emotional abuse and neglect were associated with low self-esteem in adulthood. One reason for this may be the fact that the scales used to measure identity confusion (Contentment, Worthiness and Significance; and Autonomous Self-Regard) were not sufficiently distinct from the Rosenberg Self-Esteem Inventory (Rosenberg, 1965). Both scales measure forms of global positive or negative self-concept. At the time of the study design, this author believed that the measure for identity confusion was distinct from self-esteem because it seemed to measure how well a person thought of themselves independent of the evaluations of others (e.g. I am not embarrassed to let people know my opinions). Thus, this author reasoned that this would tap into the concept of an integrated and autonomous identity. Perhaps, if the present study had measured identity in terms of ego 
formation, results may have showed that those who experienced emotional abuse were more committed to their opinion in various life domains, such as, politics, occupation, religion, intimate relationships, friendships, and gender roles (Marcia, 1966; Bennion \& Adams, 1986). Individuals who were emotionally abused may have shown more commitment to their beliefs and opinions than those who were emotionally neglected. Research on the concept of ego identity as defined by Marcia (1966) found associations between secure adult attachment style and identity achievement. Research using this measure has also found that an association between preoccupied and fearful attachment with ego diffusion (undecided) and moratorium (vaguely defined commitments) (Kennedy, 1999). The reason for not selecting these measures was that this author was more interested in whether individuals who had experienced psychological abuse had a sense of self related to being 'one's own best friend' and autonomous or separate from their caregiver. This is a different conceptualization of identity than the one described by Marcia (1966), which asks about specifically formed opinions and beliefs on issues that contribute to an individual's identity, such as politics, occupation, and religion.

In addition, the failure to find support for the differential effects of emotional abuse and emotional neglect may have been due to statistical shortcomings. When psychological maltreatment was divided to test separately for emotional abuse and emotional neglect, the measures were also separated to correspond to hypothesized relationships. For example, when testing the emotional abuse model, the Emotional Abuse subscale from the Childhood Trauma questionnaire became the predictor and the Fearful attachment subscale from the Relationship Styles Questionnaire became the outcome variable. The Rosenberg Self-Esteem scale became the only measure of identity, 
and the Emotional Inhibition and Emotional Rehearsal subscales of the Emotion Control Questionnaire became the measures for emotional competence. In testing the emotional neglect model, the Emotional Neglect subscale of the Childhood Trauma questionnaire became the predictor and the Dismissing attachment subscale of the Relationship Styles Questionnaire became the outcome variable. The Contentment, Worthiness and Significance, and Autonomous Self-Regard subscale of the Robson Self-Concept Questionnaire became the measure of identity, and the Alexithymia scale became the measure of emotional competence. Statistically, this is problematic because accurate predictions in path analysis are obtained when each construct has no less than two measures per construct. In testing the differential trajectories for emotional abuse and emotional neglect separately, some of the constructs were only quantified by one measure, which may have led to inaccurate predictions.

\section{Practical Implications}

The present study has real life implications for young adults. It reiterates the fact that early attachment styles are malleable and not all individuals with an abusive history will develop a dysfunctional relational style; the relationship is mediated by self-esteem and emotional competence in adulthood. The negative impact that childhood maltreatment has on relationships in adulthood can be addressed through interventions that focus on improving self-esteem and emotional competence in young adults. In young adulthood, individuals with a history of psychological child maltreatment may be taught self-awareness techniques in which they can observe how their own level of emotional competence and self-concept impact their romantic relationships. In turn, this will 
improve emotional communication and the overall quality of adult romantic relationships. Strengths and Limitations of the study

The present study tested a unique model of causal relations and effects of psychological maltreatment (emotional abuse and neglect) and it's relation to sense of self and emotional competence. This study has real-life implications for young adults with a history of child maltreatment and supports the importance of emotional competence.

The present study was unique in that it illuminated a possible directionality between identity and emotional competence among young adult survivors of childhood maltreatment that can foster future research in this area. Present results suggest that negative self-concept may be predictive of poor emotion management.

Path analysis is a sophisticated form of causal modeling that tests the theorized relationships between variables in a two-step process. The first step tests the relationships between the latent constructs in order to show that the chosen scales are measuring the constructs in the model adequately. The second step actually tests the hypothesized paths of the model and provides the opportunity to improve model fit to the data through modification of the paths. Thus, although causation cannot be proven, path analysis is a much more sophisticated statistical technique than testing simple associations.

Some of the measures in the present study, specifically the measures for identity integration did not seem to capture the intended construct adequately, but instead measured aspects of self-concept. Future researchers could improve on the present study by retesting the model using an alternate measure of identity integration (e.g. Marcia 1965), or by developing a new measure of identity which taps into 'developing a separate self from an abusive caregiver', perhaps an enmeshed identity versus autonomous identity 
scale.

Since statistical modifications were applied to the models, replication is required to ensure results generalize beyond the present sample. Although there is evidence for the validity of retrospective reports of childhood maltreatment (Dube et al., 2004; KendallTackett \& Becker-Clease, 2004; Paivio, 2001; Schumacher, Hinz, \& Brahler, 2002) the present study still may have underestimated or overestimated the extent to which abuse occurred, as participants may be unable to recall accurately. Due to this limitation, caution must be taken in interpreting the results of the present study.

In terms of external and internal validity, the present study should be replicated using a clinical sample or a more culturally diverse community sample in order to increase the range of severity of abuse and enhance the generalizability of the model. In addition, there was an inability to prove causation due to statistical methodology. Path analysis deals with correlation, not causation of variables and so causation among the variables cannot be confirmed.

\section{Conclusion and Directions for Future Research}

In conclusion, findings of this study highlight the importance of emotional competence in understanding the relationship between psychological abuse in childhood and relational styles in adult romantic relationships. Due to the difficulties inherent in retrospective studies, future researchers should aim to retest this model using a longitudinal design. This research is important because it highlights the long-term effects of dysfunctional early attachments and family environments in general, but also provides hope for young adults in highlighting that some of the negative effects of early insecure 
attachments and traumatic experiences can be ameliorated through building emotional competence. In addition, the results of the present study encourage young adults to seek romantic partners who are high in emotional competence, as this construct was shown to be an important predictor for healthy adult attachment styles.

Future research should aim to obtain an ethnically diverse population and control for different cultural interpretations of maladaptive parenting styles and abuse, as this may have an effect on the accuracy of results. Some of the difficulties of this study also involved teasing apart the separate effects of emotional abuse and emotional neglect. Although some of the effects may overlap, future researchers should focus on finding measures of emotional competence which have separate subscales for inhibition and reactivity, and measures of identity which focus more on 'the autonomous self' or 'enmeshment versus autonomy' in an effort to tease apart distinct effects. 


\section{REFERENCES}

Aber, J. L., \& Cicchetti, D. (1984). Socioemotional development in maltreated children: An empirical and theoretical analysis. In H. Fitzgerald, B. Lester, \& M. Yogman (Eds.), Theory and research in behavioral pediatrics (Vol. 2, pp. 147-205). New York: Plenum.

Ainsworth, M. S. (1989). Attachments beyond infancy. American Psychologist, 44(4), 709-716.

Ainsworth, M. S., Blehar, M. C., Waters, E., \& Wall, 5. (1978). Patterns of attachment: A psychological study of the Strange Situation. Hillsdale, NJ: Erlbaum.

Ainsworth, M. S., \& Bowlby, J. (1991). An ethological approach to personality development. American Psychologist, 46, 331-341.

Allen, B. (2008). Adjustment in early adulthood: An analysis of the impact of diverse forms of childhood psychological maltreatment on emotional adjustment in early adulthood. Child Maltreatment, 13 (3), 307-312.

Allen, J. G. (2001). Traumatic relationships and serious mental disorders. Chichster, UK: John Wiley \& Sons.

Anders, S. L. \& Tucker, J. S. (2000). Adult attachment style, interpersonal communication competence, and social support. Personal Relationships, 7(4), 379389.

Anderson, J.C. \& Gerbing, D.W. (1988). Structural equation modeling in practice: A review and recommended two-step approach. Psychological Bulletin, 103(3), 411423.

Arbuckle, J.L. (1997). Amos user's guide version 3.6. Chicago: Smallwaters.

Arndt, J., Schimel, J., Greenberg, J., \& Pyszczynski, T. (2002). The intrinsic self and defensiveness: Evidence that activating the intrinsic self reduces self-handicapping and conformity. Personality and Social Psychology Bulletin, 28(5), 671-683.

Bagby, M., Taylor, G., Quilty, L., \& Parker, J. (2007). Reexamining the factor structure of the 20-item Toronto Alexithymia Scale: Commentary on Gignac, Palmer, and Stough. Journal of Personality Assessment, Special Issue: Personality Assessment in Medical Settings, 89(3), 258-264.

Baker, R. (2001). An emotional processing model for counseling and psychotherapy: A way forward? Counselling in Practice, 7(1), 8-11. 
Bartholomew, K. (1990). Avoidance of intimacy: An attachment perspective. Journal of Social and Personal Relationships, 7(2), 147-178.

Bartholomew, K. \& Horowitz, L. (1991). Attachment Styles among young adults: A test of a four-category model. Journal of Personality and Social Psychology, 61(2), 226-244.

Bell, K.L. (1998). Family expressiveness and attachment. Social Development, 7(1), 3753.

Bennion, L. D. \& Adams, G. R. (1986). A revision of the extended version of the Objective Measure of Ego Identity Status: An identity instrument for use with late adolescents. Journal of Adolescent Research, 1(2), 183-197.

Bentler, P. M. (1990). Fit indexes, Lagrange multipliers, constraint changes and incomplete data in structural models. Multivariate Behavioral Research, 25(2), 163-172.

Bentler, P. M., \& Bonett, D. G. (1980). Significance tests and goodness-of-fit in the analysis of covariance structures. Psychological Bulletin, 88, 588-600.

Berenbaum, H., \& James, T. (1994). Correlates and retrospectively reported antecedents of alexithymia. Psychosomatic Medicine, 56(4), 353-359.

Berlin, L. J., Cassidy, J., \& Appleyard, K. (2008). The influence of early attachments on other relationships. In Cassidy, J. \& Shaver, P. R. (Ed.), Handbook of Attachment: Theory, Research, and Clinical Applications (2 ${ }^{\text {nd }}$ Ed.) (pp.333-348). The Guilford Press: New York.

Bernstein, D.P., \& Fink, L. (1998). Childhood Trauma Questionnaire: A retrospective self-report manual. San Antonio, TX: The Psychological Corporation.

Bifulco, P.M., Moran, C., Ball, C., Jacobs, R., Baines, A., Bunn, J. \& Cavagin, A. (1998). Childhood adversity, parental vulnerability and disorder: examining intergenerational transmission of risk. University of London, UK.

Biringen, Z. \& Robinson, J. (1991). Emotional availability in mother-child interactions: A reconceptualization for research. American Journal of Orthopsychiatry, 61(2), 258-271.

Bowlby, J. (1969). Disruption of affectional bonds and its effects on behavior. Canada's Mental Health Supplement, 59, pp. 12.

Bowlby, J. (1982). Attachment and loss, Vol. 1. New York: Basic Books. 
Bowlby, J. (1988). A secure base: Parent-child attachment and healthy human development. New York: Basic Books.

Brassard, M.R. \& Gelardo, M.S. (1987). Psychological maltreatment: The unifying construct in child abuse and neglect. School Psychology Review, 16(2), 127-136.

Briere, J. (2002). Treating adult survivors of severe child abuse and neglect: Further development of an integrated model. In J. Myers, L. Berliner, J. Briere, T. Hendrix, C. Jenny, \& T. Reid (Eds.), The APSAC Handbook on Child Maltreatment ( $2^{\text {nd }}$ ed., pp. 582). Thousand Oaks, CA, US: Sage Publications, Inc.

Briere, J. \& Rickards, S. (2007). Self-awareness, affect regulation, and relatedness: Differential sequels of childhood versus adult victimization experiences. Journal of Nervous and Mental Disease, 195(6), 497-503.

Briere, J. \& Runtz, M. (1990). Differential adult symptomatology associated with three types of child abuse histories. Child Abuse \& Neglect, 14(3), 357-364.

Briere, J., Scott, C. (2006). Principles of trauma therapy: A guide to symptoms, evaluation, and treatment. Thousand Oaks, CA, US: Sage Publications, Inc. xiii, $295 \mathrm{pp}$.

Broderick, P. C. (2005). Mindfulness and coping with dysphoric mood: Contrasts with rumination and distraction. Cognitive Therapy and Research, 29(5), 501-510.

Brown, J., \& Dunn, J. (1991). "You can cry, Mum": The social and developmental implications of talk about internal states. British Journal of Developmental Psychology, 9, 237-256.

Buchner, A., Erdfelder, E., \& Faul, F. (1997). How to Use G*Power [WWW document]. URL http://www.psycho.uniduesseldorf.de/aap/projects/gpower /how_to_ use_ gpower.html

Burrowes, B.D. \& Halberstadt, A.G. (1987). Self- and family-expressiveness styles in the experience and expression of anger. Journal of Nonverbal Behavior, 11(4), 254268.

Bylsma, W. H., Cozzarelli, C. \& Sumer, N. (1997). Relation between adult attachment styles and global self-esteem. Basic and Applied Social Psychology, 19, 1-16.

Byrne, B.M. (2001). Structural equation modeling with AMOS: Basic concepts, applications, and programming. New Jersey: Lawrence Erlbaum Associates, Publishers.

Carson, J.L. \& Parke, R.D. (1996). Reciprocal negative affect in parent-child interactions and children's peer competency. Child Development, 67(5), 2217-2226. 
Chernus, L.A. (2008). Separation/abandonment/isolation trauma: An application of psychoanalytic developmental theory to understanding its impact on both chimpanzee and human children. Journal of Emotional Abuse, 8(4), 447-468.

Ciarrochi, J. Robb, H. (2005). Letting a little nonverbal air into the room: Insights from acceptance and commitment therapy: Part 2: Applications. Journal of RationalEmotive \& Cognitive Behavior Therapy, 23(2), 107-130.

Collins, N. L., \& Read, S. J. (1990). Adult attachment, working models, and relationship quality in dating couples. Journal of Personality and Social Psychology, 58(4), 644663.

Colman, R.A. \& Widom, C.S. (2004). Childhood abuse and neglect and adult intimate relationships: a prospective study. Child Abuse and Neglect, 28(11), 1133-1151.

Courtois, C.A. \& Ford, J.D., Herman, J. L., \& Van Der Kolk, B. A. (2009). Treating Complex Traumatic Stress Disorders: An Evidence-Based Guide. Guilford Press.

Crittenden, P.M. \& Ainsworth, M.D.S. (1989). Child maltreatment and attachment theory. in Cicchetti, Dante; Carlson, Vicki (1989). Child maltreatment: Theory and research on the causes and consequences of child abuse and neglect. (pp. 432463). New York, NY, US: Cambridge University Press. xx, 794 pp.

Davidson, R.J. (1992). Emotion and affective style: Hemispheric substrates. Psychological Science, 3(1), 39-43.

De Bellis, M.D., Keshavan, M.S., Shifflett, H., Iyengar, S., Beers, S.R., Hall, J., \& Moritz, G. (2002). Brain structures in pediatric maltreatment-related posttraumatic stress disorder: A sociodemographically matched study. Biological Psychiatry, 52(11), 1066-1078.

Denham, S.A. \& Grout, L. (1992). Mothers' emotional expressiveness and coping: Relations with preschoolers' social-emotional competence. Genetic, Social, and General Psychology Monographs, 118(1), 73-101.

Depape, A.R., Hakim-Larson, J., Voelker, S., Page, S., Jackson, D.L. (2006). Self-talk and emotional intelligence in university students. Canadian Journal of Behavioural Science/Revue canadienne des sciences du comportement, 38(3), 250-260.

DiLillo, D., Lewis, T., \& Di Loreto-Colgan, A. (2007). Child maltreatment history and subsequent romantic relationships: Exploring a psychological route to dyadic difficulties. Journal of Aggression, Maltreatment \& Trauma, 15(1), 19-36.

Dong, M., Anda, R. F., Felitti, V. J., Dube, S. R., Williamson, D. F. Thompson, T. J., 
Loo, C. M., \& Giles, W. H. (2004). The interrelatedness of multiple forms of childhood abuse, neglect, and household dysfunction. Child Abuse \& Neglect, 28(7), 771-784.

Dube, S. R., Williamson, D. F., Thompson, T., Felitti, V. J., \& Anda, R. F. (2004). Assessing the reliability of retrospective reports of adverse childhood experiences among adult HMO members attending a primary care clinic. Child Abuse \& Neglect, 28(7), 729-737.

Dunn, J. \& Brown, J. (1991). Relationships, talk about feelings, and the development of affect regulation in early childhood. In J. Garber \& K. A. Dodge. The development of emotion regulation and dysregulation. Cambridge studies in social and emotional development. (pp. 89-108). New York, NY, US: Cambridge University Press. xii, 338 pp.

Egeland, B., Cicchetti, D., \& Toth, S.L. (1997). Mediators of the effects of child maltreatment on developmental adaptation in adolescence. in Developmental perspectives on trauma: Theory, research, and intervention. Rochester symposium on developmental psychology, Vol. 8. (pp. 403-434). Rochester, NY, US: University of Rochester Press. xvii, 613 pp.

Egeland, B. \& Erickson, M. F. (1987). Psychologically unavailable caregiving. In M. Brassard, B. Germain, \& S. Hart (Eds.), Psychological maltreatment of children and youth (pp. 110-120). Elmsford, NY: Pergamon.

Egeland, B. \& Erickson, M. F. (1999). Findings from the Parent-Child Project and implications for early intervention. Zero to Three, 11(2), 29-35. In J. Briere, L. Berliner, J. A. Bulkley, C. Jenny, \& T. Reid. The APSAC handbook on child maltreatment. (pp. 4-20). Thousand Oaks, CA, US: Sage Publications, Inc. xiii, $449 \mathrm{pp}$.

Eid, J., Johnsen, B. H., \& Saus, E. (2005). Trauma narratives and emotional processing. Scandinavian Journal of Psychology, 46(6), 503-510.

Eisenberg, N. \& Fabes, R.A. (1992). Emotion, regulation, and the development of social competence. In M.S. Clark, Emotion and social behavior. Review of personality and social psychology, Vol. 14. (pp. 119-150). Thousand Oaks, CA, US: Sage Publications, Inc. xi, $311 \mathrm{pp}$.

El-Masri, M.M. \& Fox-Wasylyshyn, S.M. (2005). Best practices in research methods missing data: An introductory conceptual overview for the novice researcher. CJNR, 37(4), 156-171.

Erickson, M., Egeland, B., \& Pianta, R. (1989). The effects of maltreatment on the development of young children. In D. Cicchetti \& V. Carlson (Eds.), Child 
maltreatment: theory and research on the causes and consequences of child abuse and neglect (pp. 647-684). Cambridge: Cambridge University Press.

Erickson, M. F., Sroufe, L. A., \& Egeland, B. (1985). The relationship between quality of attachment and behavior problems in preschool in a high-risk sample. Monographs of the Society for Research in Child Development, 50(1-2), 147-166.

Faust, J. \& Stewart, L. M. (2008). Impact of child abuse timing and family environment on psychosis. Journal of Psychological Trauma, 6(2), 65-85.

Feeney, J. A. (1999). Adult attachment, emotional control, and marital satisfaction. Personal Relationships, 6(20), 169-185.

Feeney, J. A. (2008). Adult romantic attachment: Developments in the study of couple relationships. In Cassidy, J. \& Shaver, P. R. (Ed.), Handbook of Attachment: Theory, Research, and Clinical Applications (2 ${ }^{\text {nd }}$ Ed.) (pp.456-482). The Guilford Press: New York.

Feeney, J. A. \& Noller, P. (1990). Attachment style as a predictor of adult romantic relationships. Journal of Personality and Social Psychology, 58, 281-291.

Feeney, J. A., Noller, P., \& Hanrahan, M. (1994). Assessing adult attachment: Developments in the conceptualization of security and insecurity. In M. B. Sperling \& W. H. Berman (Eds.) Attachment in adults: Theory, assessment, and treatment (pp.128-152). New York: Guilford.

Feiring, C. (2005). Emotional development, shame, and adaptation to child maltreatment. Child Maltreatment, 10(4), 307-310.

Fergusson, D. M., Boden, J. M., \& Horwood, J. (2008). Exposure to childhood sexual and physical abuse and adjustment in early adulthood. Child Abuse \& Neglect, 32(6), 607-619.

Ford, J.D. (2005). Treatment Implications of Altered Affect Regulation and Information Processing Following Child Maltreatment. Psychiatric Annals, 35(5), 410-420.

Foster, J. D., Kernis, M. H., Goldman, B. M. (2007). Linking Adult Attachment of SelfEsteem Stability. Self and Identity, 6(1), 64-73.

Gallo, L.C., \& Smith, T.W. (2001). Attachment style in marriage: Adjustment and responses to interaction. Journal of Social and Personal Relationships, 18, 263-290.

Garson, G. David. (2009). "Reliability Analysis", from Statnotes: Topics in Multivariate Analysis. Retrieved 07/14/2009 from http:/faculty.chass.ncsu.edu /garson/pa765/ statnote.htm. 
Gibb, B.E. (2002). Childhood maltreatment and negative cognitive styles: A quantitative and qualitative review. Clinical Psychology Review, 22(2), 223-246.

Gilbert, P. \& Proctor, S. (2006). Compassionate Mind Training for People with High Shame and Self-Criticism: Overview and Pilot Study of a Group Therapy Approach. Clinical Psychology and Psychotherapy, 13(6), 353-379.

Glaser, D. (2002). Emotional abuse and neglect (psychological maltreatment): A conceptual framework. Child Abuse and Neglect, 26(6-7), 697-714.

Greenberg, L.S., \& Johnson, S.M. (1988). Emotionally Focused Therapy for Couples. New York: Guilford Press.

Griffin, D.W. \& Bartholomew, K. (1994). Models of the self and other: Fundamental dimensions underlying measures of adult attachment. Journal of Personality and Social Psychology, 67(3), 430-445.

Gross, J.J. (1998). The emerging field of emotion regulation: An integrative review. Review of General Psychology. Special Issue: New directions in research on emotion, 2(3), 271-299.

Gross, J.J. (2007). Handbook of emotion regulation (pp. 688). The Guilford Press.

Halberstadt, A. G. (1986). Family socialization of emotional expression and nonverbal communication styles and skills. Journal of Personality and Social Psychology, 51(4), 827-836.

Hamilton, C.E. (2000). Continuity and discontinuity of attachment from infancy through adolescence. Child Development, 71(3), 690-694.

Harrocks, A. \& Callahan, J. L (2006). The role of emotion and narrative in the reciprocal construction of identity. Human Resource Development International, 9(1), 69-83.

Harter, S. \& Pike, R. (1984). The pictorial scale of perceived competence and social acceptance for young children. Child Development, 55(6), 1969-1982.

Hazan, C., \& Shaver, P.R. (1987). Romantic love conceptualized as an attachment process. Journal of Personality and Social Psychology, 52, 511-524.

Hazan, C., \& Shaver, P.R. (1990) Love and work: An attachment-theoretical perspective. Journal of Personality and Social Psychology, 59(2), 270-280.

Hazan, C., \& Shaver, P.R. (1994). Attachment as an organizational framework for research on close relationships. Psychological Inquiry, 5, 1-22. 
Hazan, C., Zeifman, D., \& Middleton, K. (1994). Adult romantic attachment, affection, and sex. Paper presented at the 7th International Conference on Personal Relationships, Groningen, The Netherlands.

Heifer, R. \& Kempe, C. (1976). Child abuse and neglect: The family and the community. Cambridge, MA: Ballinger Publishing.

Hendrick C. \& Hendrick S.S. (1986). A theory and method of love. Journal of Personality and Social Psychology, 50(2), 392-402.

Herman, J. (1992). Trauma and recovery. New York: Basic Books.

Herrenkohl, R. C., Herrenkohl, E. C., Egolf, B., \& Wu, P. (1991). The developmental consequences of child abuse: the Lehigh longitudinal study. In R. Starr \& D. Wolfe (Eds.), The effects of child abuse and neglect; issues and research (pp. 5780). New York: Guilford Publications.

Hoffman-Plotkin, D. \& Twentyman, C.T. (1984). A multimodal assessment of behavioral and cognitive deficits in abused and neglected preschoolers. Child Development, 55(3), 794-802.

Holmbeck, G.N. (1997). Toward terminological, conceptual, and statictical clarity in the study of mediators and moderators: Examples from the child-clinical and pediatric psychology literatures. Journal of Consulting and Clinical Psychology, 65(4), 599610.

Hooven, C., Gottman, J., Mordechai, K., \& Lynn, F. (1995). Parental meta-emotion structure predicts family and child outcomes. Cognition \& Emotion, 9(2-3), 229264.

Howes, C., Hamilton, C.E., \& Phillipsen, L.C. (1998). Stability and continuity of childcaregiver and child-peer relationships. Child Development, 69(2), 418-426.

Hu, L., \& Bentler, P. M. (1995). Evaluating model fit. In R. H. Hoyle (Ed.), Structural equation modeling: Concepts, issues, and applications (pp. 76-99). Thousand Oaks, CA: Sage.

Hu, L. \& Bentler, P.M. (1998). Fit indices in covariance structure modeling: Sensitivity to underparameterized model misspecification. Psychological Methods, 3(4), 424453.

Jellis, J. (2001). Attachment style, working models of sexuality, and their relation to safer sex behavior in young adults. Dissertation Abstract, University of Saskatchewan. 
Johnson, S. (2000). Emotionally focused couples therapy. In F. Dattilio, L. Bevilacqua, (2000). Comparative treatments for relationship dysfunction. Springer series on comparative treatments for psychological disorders. (pp. 163-185). New York, NY, US: Springer Publishing Co. xvii, 414pp.

Johnson, S. (2003). The revolution in couple therapy: A practitioner-scientist perspective. Journal of Marital \& Family Therapy, 29(3), 365-384.

Johnson, S. \& Best, M. (2003). A systemic approach to restructuring adult attachment: The EFT model of couples therapy. in Erdman, Phyllis; Caffery, Tom. Attachment and family systems: Conceptual, empirical, and therapeutic relatedness. The family therapy and counseling series. (pp. 165-189). New York, NY, US: Brunner-Routledge. xiv, 273 pp.

Johnson, S. M., Greenman, P.S. (2006). The path to a secure bond: Emotionally focused couple therapy. Journal of Clinical Psychology, 62(5), 597-609.

Johnson, S. \& Williams-Keeler, L. (1998). Creating healing relationships for couples dealing with trauma: The use of emotionally focused marital therapy. Journal of Marital \& Family Therapy, 24(1), 25-40.

Jones, K., Abbey, B., \& Cumberland, A. (1998). The development of display rule knowledge: Linkages with family expressiveness and social competence. Child Development, 69(4), 1209-1222.

Joukamaa, M., Luutonen, S., von Reventlow, H., Patterson, P., Karlsson, H., \& Salokangas, R. (2008). Alexithymia and Childhood Abuse Among Patients Attending Primary and Psychiatric Care: Results of the RADEP Study. Psychosomatics: Journal of Consultation Liaison Psychiatry, 49(4), 317-325.

Kachadourian, L. K., Fincham, F. D., \& Davila, J. (2005). Attitudinal ambivalence, rumination, and forgiveness of partner transgressions in marriage. Personality and Social Psychology Bulletin, 31, 334-342.

Kauhanen, J., Kaplam, G., Julkunen, J., Wilson, T., \& Salonen. (1993). Social factors in alexithymia. Comprehensive psychiatry, 34(5), 330-335.

Keenan, K., Shaw, D., Delliquadri, E., Giovannelli, J., \& Walsh, B. (1998). Evidence for the continuity of early problem behaviors: Application of a developmental model. Journal of Abnormal Child Psychology, 26(6), 441-452.

Kendall-Tackett, K. \& Becker-Clease, K. (2004). The importance of retrospective findings in child maltreatment research. Child Abuse \& Neglect, 28(7), 723-727.

Kennedy, J. H. (1999). Romantic Attachment Style And Ego Identity, Attributional Style, 
And Family Of Origin In First-Year College Students. College Student Journal, 33(2), 171-180.

Kernis, M. H. (2003). Toward a conceptualization of optimal self-esteem. Psychological Inquiry, 14, $1-26$.

Kernis, M. H. (2005). Measuring self-esteem in context: The importance of stability of self- esteem in psychological functioning. Journal of Personality, 73, 1 - 37.

Kerns, K. A., Abraham, M. M. Schlegelmilch, A., Morgan, T. A. (2007). Mother-child attachment in later middle childhood: Assessment approaches and associations with mood and emotion regulation. Attachment \& Human Development, 9(1), 33-53.

Kline, R.B. (2004). Priniciples and practice of structural equation modeling. New York; Guilford Press.

Kopp, C.B. (1982). Antecedents of self-regulation: A developmental perspective. Developmental Psychology, 18(2), 199-214.

Krystal, H. (1978). Trauma and affects. The Psychoanalytic Study of the Child, 33, 81116.

Kurdek, L. (2002). On being insecure about the assessment of attachment styles. Journal of Social and Personal Relationships, 19(6), 811-834.

Landy, S. \& Menna, R. (2006). Early intervention with multi-risk families: An integrative approach. Baltimore, MD, USL Paul H Brookes Publishing. xx, 501 pp.

Lane, R.D., Ahern, G.L., Schwartz, G.E., \& Kaszniak, A.W. (1997). Is alexithymia the emotional equivalent of blindsight? Biological Psychiatry, 42(9), 834-844.

Lee, J.A. (1973). Colours of love: an exploration of the ways of loving. New York: New Press.

Lee, J.A. (1988). Love-styles. In R.J. Sternberg \& M.L. Barnes (Eds.), The psychology of love (pp. 38-67). New Haven, CT: Yale University Press.

Lesnik-Oberstein, M. (1983). Denial of reality: A form of emotional child abuse. Child Abuse \& Neglect, 7(4), 471-472.

Levy, M.B. \& Davis, K.E. (1988). Lovestyles and attachment styles compared: Their relations to each other and to various relationship characteristics. Journal of Social and Personal Relationships, 5(4), 439-471.

Lewis, M., Feiring, C., \& Rosenthal, S. (2000). Attachment over time. Child Development, 71(3), 707-720. 
Lindemann, E. (1944). Symptomatology and management of acute grief. American Journal of Psychiatry, 101, 141-148.

Lupien, S.J., McEwen, B.S., Gunnar, M.R., \& Heim, C. (2009). Effects of stress throughout the lifespan on the brain, behavior and cognition. Nature Reviews Neuroscience, 10, 434-445.

Macklem, G.L. (2007). Practicioner's guide to emotion regulation in school-aged children. New York: Cambridge University Press.

MacLean, P.D.(1990). A reinterpretation of memorative functions of the limbic system. In E. Goldberg. Contemporary neuropsychology and the legacy of Luria. Institute for research in behavioral neuroscience. (pp. 127-154). Hillsdale, NJ, England: Lawrence Erlbaum Associates, Inc. xi, 287 pp.

Main, B. (1985). Minnesota Parent-Child project. In J. Myers, L. Berliner, J. Briere, T. Hendrix, C. Jenny, \& T. Reid (Eds.), The APSAC Handbook on Child Maltreatment ( $2^{\text {nd }}$ ed., pp. 582). Thousand Oaks, CA, US: Sage Publications, Inc.

Main, M. (2000). The organized categories of infant, child, and adult attachment: Flexible vs. inflexible attention under attachment-related stress. Journal of the American Psychoanalytic Association, 48, 1055-1096.

Marcia, J. E. (1966). Development and validation of ego identity status. Journal of Personality and Social Psychology, 3, 551-558.

Masten, C.L., Guyer, A.E., Hodgdon, H.B., McClure, E.B., Charney, D.S., Ernst, M., Kaufman, J., Pine, D.S., \& Monk, C.S. (2008). Recognition of facial emotions among maltreated children with high rates of post-traumatic stress disorder. Child Abuse \& Neglect, 32(1), 139-153.

Matheson, K. \& Anisman, H. (2003). Systems of coping associated with dysphoria, anxiety, and depressive illness: A multivariate profile perspective. The International Journal of the Biology of Stress, 6(3), 223-234.

Mayer, J.D. \& Salovey, P. (1993). The intelligence of emotional intelligence. Intelligence, 17(4), 433-442.

McCann, I. L. \& Pearlman, L. (1990). Psychological trauma and the adult survivor: Theory, therapy, and transformation. In M. Brunner (Ed.) Psychosocial stress Series (No. 21) (pp.360). Philadelphia, US: Brunner \& Mazel Publishing.

McCarthy, G. \& Taylor, A. (1999). Avoidant/ambivalent attachment style as a mediator between abusive childhood experiences and adult relationship difficulties. Journal of Child Psychology and Psychiatry, 40(3), 465-477. 
McCullough, M. E., Bono, G., \& Root, L. M. (2007). Rumination, emotion, and forgiveness: Three longitudinal studies. Journal of Personality and Social Psychology, 92(3), 490-505.

McGee, R., Wolfe, D., \& Wilson, S. (1997). Multiple maltreatment experiences and adolescent behavior problems: adolescents' perspectives. Development \& Psychopathology, 9, 131-149.

Meyers, S.A., \& Landsberger, S.A. (2002). Direct and indirect pathways between adult attachment style and marital satisfaction. Personal Relationships, 9, 159-172.

Mikulincer, M. (1995). Attachment style and the mental representation of the self. Journal of Personality and Social Psychology, 69(6), 1203-1215.

Mikulincer, M. \& Nachshon, O. (1991). Attachment styles and patterns of selfdisclosure. Journal of Personality and Social Psychology, 61(2), 321-331.

Mikulincer, M. \& Shaver, P. R. (2008). Adult attachment and affect regulation. In Cassidy, J. \& Shaver, P. R. (Ed.), Handbook of Attachment: Theory, Research, and Clinical Applications ( $2^{\text {nd }}$ Ed.) (pp.503-532). The Guilford Press: New York.

Mikulincer, M., Shaver, P. R., \& Zanna, M. P. (2003). The Attachment Behavioral System in Adulthood: Activation, Psychodynamics, and Interpersonal Processes. Advances in experimental social psychology, 35, 53-152.

Montebarocci, Codispoti, Baldaro, \& Rossi. (2004). Adult Attachment Style and alexithymia . Personality and Individual Differences, 36, 499-507.

Morris, A.S. Silk, J.S., Steinberg, L., Myers, S. S., \& Robinson, L. (2007). The role of the family context in the development of emotion regulation. Social Development, 16(2), 361-388.

Mullen, P.E., King, N.J., \& Tonge, B.J. (2000). Child sexual abuse: An overview. Special Issue: Sexually abused children, 17(1), 2-14.

Myers, J. (2006). Child protection from 1962 to the present. In J. Myers (Ed.), Child protection in America: Past, present, and future ( $1^{\text {st }} \mathrm{ed}$.). Oxford University Press.

National Child Traumatic Stress Network. (Fall, 2003). What is Child Traumatic Stress? Retrieved November 14, 2008, from www.nctsnet.org/nctsn_assets/pdfs/what_is_ child_traumatic_stress.pdf

Newberger, E. (1973). The Myth of the Battered Child Syndrome. Current Medical Dialog, 4, 327-334. 
O’Hagan, K. P. (1995). Emotional and Pscyhological Abuse: Problems of Definition. Child Abuse and Neglect, 19, 449-461.

Okun, M.A., Huff, B.P., August, K.J., \& Rook, K.S. (2007). Testing hypotheses distilled from four models of the effects of health-related social control. Basic and Applied Social Psychology, 29(2), 185-193.

Paivio, S. (2001). Stability of retrospective self-reports of child abuse and neglect before and after theapy for child abuse issues. Child Abuse \& Neglect, 25(8), 1053-1068.

Paivio, S. \& Cramer, K. (2004). Factor structure and reliability of the Childhood Trauma Questionnaire in a Canadian undergraduate student sample. Child Abuse \& Neglect, 28, 889-904.

Paivio, S. \& McCulloch, C. (2004). Alexithymia as a mediator between childhood trauma and self-injurious behavior. Child Abuse \& Neglect, 28(3), 339-354.

Paivio, S. \& Pascual-Leone, A. (2009). (In press) Emotion focused therapy for trauma: An integrative approach. Washington, DC: American Psychological Association.

Pals, J. L. (2006). Authoring a second chance in life: Emotion and transformational processing within narrative identity. Research in Human Development, 3(2\&3), 101-120.

Parker, G., Tuplong, H., \& Brown, L.B. (1979). Parental bonding instrument. British Journal of Medical Psychology, 52, 1-10.

Pearlman, L.A. \& Courtois, C.A. (2005). Clinical Applications of the Attachment Framework: Relational Treatment of Complex Trauma. Journal of Traumatic Stress, 18(5), 449-459.

Pearlman, L.A. \& Saakvitne, K.W. (1995). Trauma and the therapist: Countertransference and vicarious traumatization in psychotherapy with incest survivors. New York: W.W. Norton \& Company.

Perlman, S.B., Kalish, C.W., \& Pollak, S.D. (2008). The role of maltreatment experience in children's understanding of the antecedents of emotion. Cognition \& Emotion, 22(4), 651-670.

Picardi, A., Toni, A., \& Caroppo, E. (2005). Stability of alexithymia and its relationships with the 'Big Five' factors, temperament, character, and attachment style. Psychotherapy and Psychosomatics, 74(6), 371-378.

Pietromonaco, P. R. \& Carnelley, K. B. (1994). Gender and working models of attachment: Consequences for perceptions of self and romantic relationships. 
Personal Relationships, 1, 63-82.

Rachman, S. (2001). Emotional processing, with special reference to post-traumatic stress disorder. International Review of Psychiatry, 13(3), 164-171.

Rathus, S.A., Nevid, J.S., \& Fichner-Rathus, L. (2007). Human sexuality in a world of diversity $\left(7^{\text {th }}\right.$ ed.). Allyn $\&$ Bacon.

Reckling, A.E. \& Buirski, P. (1996). Child abuse, self-development, and affect regulation. Psychoanalytic Psychology, 13(1), 81-99.

Robson, P. (1989). Development of a new self-report questionnaire to measure self esteem. Psychological Medicine, 19(2), 513-518.

Roger, D., de la Banda, G. G., Lee, H. S., \& Olason, D. T. (2001). A factor-analytic study of cross-cultural differences in emotional rumination and emotional inhibition. Personality and Individual Differences, 31(2), 227-238.

Roger, D. \& Masters, R. (1997) The development and evaluation of an emotion control training programme for sex offenders. Legal \& Criminological Psychology 2, 5164.

Roger, D. \& Najarian, B. (1989). The construction and validation of a new scale for measuring emotion control. Personality and Individual Differences, 10(8), 845853.

Roisman, G. I., Collins, W. A., Sroufe, L. A., \& Egeland, B. (2005). Predictors of young adults' representations of and behavior in their current romantic relationship: Prospective tests of the prototype hypothesis. Attachment and Human Development, 7, 105-121.

Roisman, G. I., Padron, E., Sroufe, L. A., \& Egeland, B. (2002). Earned-secure attachment status in retrospect and prospect. Child Development, 73, 1204-1219.

Rothbard, J.C. \& Shaver, P.R. (1994). Continuity of attachment across the life span. In B.R. Sarason, I.G. Sarason, \& G.R. Pierce. (1990). Social support: An interactional view. Wiley series on personality processes. (pp. 97-128). Oxford, England: John Wiley \& Sons. xvi, 528 pp.

Scher, C. D., Stein, M. B., Asmundson, G. J. G., McCreary, D. R., Forde, D. R. (2001). The childhood trauma questionnaire in a community sample: Psychometric properties and normative data. Journal of Traumatic Stress, 14, 843-857.

Schimel, J., Arndt, J., Pyszczynski, T., \& Greenberg, J. (2001). Being accepted for who we are: Evidence that social validation of the intrinsic self reduces general 
defensiveness. Journal of Personality and Social Psychology, 80(1), 35-52.

Schneider-Rosen, K. \& Cicchetti, D. (1991). Early self-knowledge and emotional development: Visual self-recognition and affective reactions to mirror self-images in maltreated and non-maltreated toddlers. Developmental Psychology, 27(3), 471-478.

Schumacher, J., Hinz, A., \& Brahler, E. (2002). The validity of retrospective reports: A comparison of the parental rearing behavior recalled by young adults and their parents. Journal of Differential and Diagnostic Psychology, 23(4), 459-474.

Searle, B. \& Meara, N. M. (1999). Affective dimensions of attachment styles: Exploring self-reported attachment style, gender, and emotional experience among college students. Journal of Counseling Psychology, 46(2), 147-158.

Shaver, P.R. \& Fraley, R.C. (2000). Attachment theory and caregiving. Psychological Inquiry, 11(2), 109-114.

Shaver, P. \& Hazan, C. (1988). A biased overview of the study of love. Journal of Social and Personal Relationships, 5(4), 473-501.

Shaver, P., Hazan, C., \& Bradshaw, D. (1988). Love as attachment: The integration of three behavioral systems. In R. J. Sternberg \& M. L. Barnes (Eds.), The psychology of love (pp. 68-99).

Shields, A., Ryan, R.M., Cicchetti, D. (2001). Narrative representations of caregivers and emotion dysregulation as predictors of maltreated children's rejection by peers. Developmental Psychology, 37(3), 321-337.

Shrout, P.E. \& Bolger, N. (2002). Mediation in experimental and nonexperimental studies: New procedures and recommendations. Psychological Methods, 7(4), 422-445.

Siegel, D.J. (1999). The developing mind: Toward a neurobiology of interpersonal experience. New York, NY, US: Guilford Press. xv, 394 pp.

Simon, V.A., Kobielski, S.J. \& Martin, S. (2008). Conflict beliefs, goals, and behavior in romantic relationships during late adolescence. Journal of Youth and Adolescence, 37(3), 324-335.

Simpson, J. A. (1990). Influence of attachment styles on romantic relationships. Journal of Personality and Social Psychology, 59, 971-980. 
Simpson, J.A., Collins, W.A., Tran, S., \& Haydon, K.C. (2007). Attachment and the experience and expression of emotions in romantic relationships: A developmental perspective. Journal of Personality and Social Psychology, 92, 355-367.

Simpson, J.A., Rholes, W.S., \& Nelligan, J. (1992). Support seeking and support giving within couples in an anxiety-provoking situation: The role of attachment styles. Journal of Personality and Social Psychology, 62(3), 434-446.

Simpson, J.A., Rholes, W., \& Phillips, D. (1996). Conflict in close relationships: An attachment perspective. Journal of Personality and Social Psychology, 71(5), 899914.

Smith, C.A., Ireland, T., Thornberry, T., Elwyn, L. (2008). Childhood maltreatment and antisocial behavior: Comparison of self-reported and substantiated maltreatment. American Journal of Orthopsychiatry, 78(2), 173-186.

Sneddon, H. (2003). The Effects of Maltreatment on Children's Health and Well-Being. Child Care in Practice, 9(3), 236-250.

Sperling, M.B., Berman, W.H. (1994). Attachment in adults: Clinical and developmental perspectives. New York, NY, US: Guilford Press. xxi, 360 pp.

Spitzer, C., Siebel-Jürges, U., Barnow, S., Grabe, H. \& Freyberger, H.J. (2005). Alexithymia and Interpersonal Problems. Psychotherapy and Psychosomatics, 74(4), 240-246.

Sroufe, L.A. (2005). Attachment and development: A prospective, longitudinal study from birth to adulthood. Attachment and Human Development, 7(4), 349 - 367.

Sroufe, L.A., Egeland, B., Carlson, E.A., \& Collins, W.A. (2005). The development of the person; The Minnesota Study of Risk and Adaptation from birth to Adulthood. New York: Guilford Press.

Sroufe, L. A. \& Jacobvitz, D. (1989). Diverging pathways, developmental transformations, multiple etiologies and the problem of continuity in development. Human Development, 32(3-4), 196-203.

Stage, F.K., Carter, H.C. \& Nora, A. (2004). Path Analysis: An Introduction and Analysis of a Decade of Research. Journal of Educational Research. Special Issue: Methodology, 98(1), 5-12.

Sternberg, R.J. (1986). "A triangular theory of love". Psychological Review, 93(2), 119135. 
Stolorow, R. D. (2007). Trauma and human existence: Autobiographical, psychoanalytic, and philosophical reflections. New York \& London: Routledge.

Sumer, N. \& Cozzarelli, C. (2004). The impact of adult attachment on partner and selfattributions and relationship quality. Personal Relationships, 11(3), 355-371.

Taylor, G.J. \& Bagby, R.M. (2004). New Trends in Alexithymia Research. Psychotherapy and Psychosomatics, 73(2), 68-77.

Thompson, R. A. (2008). Early attachment and later development: Familiar questions, new answers. In Cassidy, J. \& Shaver, P. R. (Ed.), Handbook of Attachment: Theory, Research, and Clinical Applications ( $2^{\text {nd }}$ Ed.) (pp.348-356). The Guilford Press: New York.

Thompson, R. A., Meyer, S., \& Gross, J. J. (2007). Socialization of Emotion Regulation in the Family. Handbook of emotion regulation. (pp. 249-268). New York, NY, US: Guilford Press. xvii, 654 pp.

Tidwell, M.O., Reis, H.T., \& Shaver, P.R. (1996). Attachment, attractiveness, and social interaction: A diary study. Journal of Personality and Social Psychology, 71(4), 729-745.

Turner, A., \& Paivio, S. C., (2002). Alexithymia as a transmission mechanism between childhood trauma, social anxiety, and limited social support. Poster presented at the American Psychological Association convention, Chicago, IL.

Treboux, D., Crowell, J.A., \& Waters, E. (2004). When "new" meets "old": configurations of adult attachment representations and their implications for marital functioning. Developmental Psychology, 40(2), 295-314.

Vanheule, S., Desmet, M., Meganck, R., \& Bogaerts, S. (2007). Alexithymia and interpersonal problems. Journal of Clinical Psychology, 63(1), 109-117.

Vanheule, S., Vandenbergen, J., Desmet, M., Rosseel, Y., \& Insleghers, R. (2007). Alexithymia and core conflictual relationship themes: A study in a chronically fatigued primary care population. International Journal of Psychiatry in Medicine, 37(1), 87-98.

Van Ijzendoorn, M. H. \& Sagi-Schwartz, A. (2008). Cross-cultural patterns of attachment: Universal and contextual dimensions. In Cassidy, J. \& Shaver, P. R. (Ed.), Handbook of Attachment: Theory, Research, and Clinical Applications $\left(2^{\text {nd }}\right.$ Ed.) (pp.880-906). The Guilford Press: New York. 
Waters, E., Merrick, S., Treboux, D., Crowell, J., \& Albersheim, L. (2000). Attachment security in infancy and early adulthood: A twenty-year longitudinal study. Child Development, 71(3), 684-689.

Webb, M., Heisler, D., Call, S., Chickering, S., \& Colburn, T. (2007). Shame, guilt, symptoms of depression, and reported history of psychological maltreatment. Child abuse and Neglect, 31, 1143-1153.

Wolfe, D. A. (1999). Child abuse: Implications for child development and psychopathology $\left(2^{\text {nd }}\right.$ ed.) Thousand Oaks, CA: Sage Publications. 


\section{Family Expressiveness Questionnaire}

\section{Instructions}

This is a questionnaire about family expressiveness. We'd like to know more about the degree of expressiveness shown in different families. Therefore, we'd like you to tell us about the frequency of expression in your family while you were growing up. By frequency we mean, "How often does this situation occur in your family, relative to other families?"

Try to think of the following scenarios in terms of how frequently they occurred in your family, compared to other families, while you were growing up. Use the rating scale below to indicate how frequently that activity occurred. Thus, if a situation rarely occurred, or occurred not at all frequently, circle 1, 2, or 3. If it occurred with some or moderate frequency, circle a 4,5 , or 6 . And if it occurred very frequently, circle a 7,8 , or 9.

Some items may be difficult to judge. However, it is important to answer every item. Try to respond quickly, but not randomly. Thank you very much.

\section{Showing forgiveness to someone who broke a favorite possession.}

$\begin{array}{lllllllllll}\text { Not at all frequently } & 1 & 2 & 3 & 4 & 5 & 6 & 7 & 8 & 9 & \text { Very frequently }\end{array}$

2. Thanking family members for something they have done.

$\begin{array}{lllllllllll}\text { Not at all frequently } & 1 & 2 & 3 & 4 & 5 & 6 & 7 & 8 & 9 & \text { Very frequently }\end{array}$

\section{Exclaiming over a beautiful day.}

$\begin{array}{lllllllllll}\text { Not at all frequently } & 1 & 2 & 3 & 4 & 5 & 6 & 7 & 8 & 9 & \text { Very frequently }\end{array}$

4. Showing contempt for another's actions.

$\begin{array}{lllllllllll}\text { Not at all frequently } & 1 & 2 & 3 & 4 & 5 & 6 & 7 & 8 & 9 & \text { Very frequently }\end{array}$

5. Expressing dissatisfaction with someone else's behavior.

$\begin{array}{lllllllllll}\text { Not at all frequently } & 1 & 2 & 3 & 4 & 5 & 6 & 7 & 8 & 9 & \text { Very frequently }\end{array}$

6. Praising someone for good work.

$\begin{array}{lllllllllll}\text { Not at all frequently } & 1 & 2 & 3 & 4 & 5 & 6 & 7 & 8 & 9 & \text { Very frequently }\end{array}$

7. Expressing anger at someone else's carelessness.

$\begin{array}{lllllllllll}\text { Not at all frequently } & 1 & 2 & 3 & 4 & 5 & 6 & 7 & 8 & 9 & \text { Very frequently }\end{array}$

8. Sulking over unfair treatment by a family member.

$\begin{array}{lllllllllll}\text { Not at all frequently } & 1 & 2 & 3 & 4 & 5 & 6 & 7 & 8 & 9 & \text { Very frequently }\end{array}$ 
9. Blaming one another for family troubles.

$\begin{array}{lllllllllll}\text { Not at all frequently } & 1 & 2 & 3 & 4 & 5 & 6 & 7 & 8 & 9 & \text { Very frequently }\end{array}$

10. Crying after an unpleasant disagreement.

$\begin{array}{lllllllllll}\text { Not at all frequently } & 1 & 2 & 3 & 4 & 5 & 6 & 7 & 8 & 9 & \text { Very frequently }\end{array}$

11. Putting down other people's interests.

$\begin{array}{lllllllllll}\text { Not at all frequently } & 1 & 2 & 3 & 4 & 5 & 6 & 7 & 8 & 9 & \text { Very frequently }\end{array}$

12. Showing dislike for someone.

$\begin{array}{lllllllllll}\text { Not at all frequently } & 1 & 2 & 3 & 4 & 5 & 6 & 7 & 8 & 9 & \text { Very frequently }\end{array}$

13. Seeking approval for an action.

$\begin{array}{lllllllllll}\text { Not at all frequently } & 1 & 2 & 3 & 4 & 5 & 6 & 7 & 8 & 9 & \text { Very frequently }\end{array}$

14. Expressing embarrassment over stupid mistakes.

$\begin{array}{lllllllllll}\text { Not at all frequently } & 1 & 2 & 3 & 4 & 5 & 6 & 7 & 8 & 9 & \text { Very frequently }\end{array}$

15. Going to pieces when tension builds up.

$\begin{array}{lllllllllll}\text { Not at all frequently } & 1 & 2 & 3 & 4 & 5 & 6 & 7 & 8 & 9 & \text { Very frequently }\end{array}$

16. Expressing exhilaration after an unexpected triumph.

$\begin{array}{lllllllllll}\text { Not at all frequently } & 1 & 2 & 3 & 4 & 5 & 6 & 7 & 8 & 9 & \text { Very frequently }\end{array}$

17. Expressing excitement over one's future plans.

$\begin{array}{lllllllllll}\text { Not at all frequently } & 1 & 2 & 3 & 4 & 5 & 6 & 7 & 8 & 9 & \text { Very frequently }\end{array}$

18. Demonstrating admiration.

$\begin{array}{lllllllllll}\text { Not at all frequently } & 1 & 2 & 3 & 4 & 5 & 6 & 7 & 8 & 9 & \text { Very frequently }\end{array}$

19. Expressing sorrow when a pet dies.

$\begin{array}{lllllllllll}\text { Not at all frequently } & 1 & 2 & 3 & 4 & 5 & 6 & 7 & 8 & 9 & \text { Very frequently }\end{array}$

20. Expressing disappointment over something that didn't work out.

$\begin{array}{lllllllllll}\text { Not at all frequently } & 1 & 2 & 3 & 4 & 5 & 6 & 7 & 8 & 9 & \text { Very frequently }\end{array}$

21. Telling someone how nice they look. 
$\begin{array}{lllllllllll}\text { Not at all frequently } & 1 & 2 & 3 & 4 & 5 & 6 & 7 & 8 & 9 & \text { Very frequently }\end{array}$ 22. Expressing sympathy for someone's troubles.

$\begin{array}{lllllllllll}\text { Not at all frequently } & 1 & 2 & 3 & 4 & 5 & 6 & 7 & 8 & 9 & \text { Very frequently }\end{array}$

23. Expressing deep affection or love for someone.

$\begin{array}{lllllllllll}\text { Not at all frequently } & 1 & 2 & 3 & 4 & 5 & 6 & 7 & 8 & 9 & \text { Very frequently }\end{array}$

24. Quarreling with a family member.

$\begin{array}{lllllllllll}\text { Not at all frequently } & 1 & 2 & 3 & 4 & 5 & 6 & 7 & 8 & 9 & \text { Very frequently }\end{array}$

25. Crying when someone leaves.

$\begin{array}{lllllllllll}\text { Not at all frequently } & 1 & 2 & 3 & 4 & 5 & 6 & 7 & 8 & 9 & \text { Very frequently }\end{array}$

26. Spontaneously hugging a family member.

$\begin{array}{lllllllllll}\text { Not at all frequently } & 1 & 2 & 3 & 4 & 5 & 6 & 7 & 8 & 9 & \text { Very frequently }\end{array}$

27. Expressing momentary anger over a trivial irritation.

$\begin{array}{lllllllllll}\text { Not at all frequently } & 1 & 2 & 3 & 4 & 5 & 6 & 7 & 8 & 9 & \text { Very frequently }\end{array}$

28. Expressing concern for the success of other family members.

$\begin{array}{lllllllllll}\text { Not at all frequently } & 1 & 2 & 3 & 4 & 5 & 6 & 7 & 8 & 9 & \text { Very frequently }\end{array}$

29. Apologizing for being late.

$\begin{array}{lllllllllll}\text { Not at all frequently } & 1 & 2 & 3 & 4 & 5 & 6 & 7 & 8 & 9 & \text { Very frequently }\end{array}$

30. Offering to do somebody a favor.

$\begin{array}{lllllllllll}\text { Not at all frequently } & 1 & 2 & 3 & 4 & 5 & 6 & 7 & 8 & 9 & \text { Very frequently }\end{array}$

31. Snuggling up to a family member.

$\begin{array}{lllllllllll}\text { Not at all frequently } & 1 & 2 & 3 & 4 & 5 & 6 & 7 & 8 & 9 & \text { Very frequently }\end{array}$

32. Crying for being punished.

$\begin{array}{lllllllllll}\text { Not at all frequently } & 1 & 2 & 3 & 4 & 5 & 6 & 7 & 8 & 9 & \text { Very frequently }\end{array}$

33. Trying to cheer up someone who is sad.

$\begin{array}{lllllllllll}\text { Not at all frequently } & 1 & 2 & 3 & 4 & 5 & 6 & 7 & 8 & 9 & \text { Very frequently }\end{array}$ 
34. Telling family members how hurt you are.

$\begin{array}{lllllllllll}\text { Not at all frequently } & 1 & 2 & 3 & 4 & 5 & 6 & 7 & 8 & 9 & \text { Very frequently }\end{array}$

35. Telling family members how happy you are.

$\begin{array}{lllllllllll}\text { Not at all frequently } & 1 & 2 & 3 & 4 & 5 & 6 & 7 & 8 & 9 & \text { Very frequently }\end{array}$

36. Threatening someone.

$\begin{array}{lllllllllll}\text { Not at all frequently } & 1 & 2 & 3 & 4 & 5 & 6 & 7 & 8 & 9 & \text { Very frequently }\end{array}$

37. Criticizing someone for being late.

$\begin{array}{lllllllllll}\text { Not at all frequently } & 1 & 2 & 3 & 4 & 5 & 6 & 7 & 8 & 9 & \text { Very frequently }\end{array}$

38. Expressing gratitude for a favor.

$\begin{array}{lllllllllll}\text { Not at all frequently } & 1 & 2 & 3 & 4 & 5 & 6 & 7 & 8 & 9 & \text { Very frequently }\end{array}$

39. Surprising someone with a little gift or favor.

$\begin{array}{lllllllllll}\text { Not at all frequently } & 1 & 2 & 3 & 4 & 5 & 6 & 7 & 8 & 9 & \text { Very frequently }\end{array}$

40. Saying "I'm sorry" when one realizes one was wrong.

$\begin{array}{lllllllllll}\text { Not at all frequently } & 1 & 2 & 3 & 4 & 5 & 6 & 7 & 8 & 9 & \text { Very frequently }\end{array}$ 


\section{Rosenberg Self-Esteem Scale}

\section{Instructions}

Below is a list of statements dealing with your general feelings about yourself. If you strongly agree, circle SA. If you agree with the statement, circle A. If you disagree, circle, D. If you strongly disagree, circle SD.

1. On the whole, I am satisfied with myself.
SA
A
$\mathrm{D}$
SD

2. At times, I think I am no good at all.
SA
A
D
SD

3. I feel that I have a number of good qualities.
SA
A
D
SD

4. I am able to do things as well as most other people.
SA
A
D
SD

5. I feel I do not have much to be proud of.

SA $\quad$ A $\quad$ D $\quad$ SD

6. I certainly feel useless at times.

SA $\quad$ A $\quad$ D $\quad$ SD

7. I feel that I'm a person of worth, at least on an equal plane with others.

$\begin{array}{llll}\text { SA } & \text { A } & \text { D } & \text { SD }\end{array}$

8. I wish I could have more respect for myself.

$\begin{array}{llll}\text { SA } & \text { A } & \text { D } & \text { SD }\end{array}$

9. All in all, I am inclined to feel that I am a failure.

$\begin{array}{llll}\text { SA } & \text { A } & \text { D } & \text { SD }\end{array}$

10. I take a positive attitude toward myself.

$\begin{array}{llll}\text { SA } & \text { A } & \text { D } & \text { SD }\end{array}$ 


\section{$\underline{\text { Relationship Scales Questionnaire }}$}

\section{Instructions}

Please read each of the following statements and rate the extent to which you believe each statement best describes your feelings about close relationships.

\begin{tabular}{|c|c|c|c|c|c|}
\hline & $\begin{array}{l}\text { Not at all } \\
\text { like me }\end{array}$ & & $\begin{array}{l}\text { Somewhat } \\
\text { like me }\end{array}$ & & $\begin{array}{l}\text { Very much } \\
\text { like me }\end{array}$ \\
\hline $\begin{array}{l}\text { 1. I find it difficult to depend } \\
\text { on other people. }\end{array}$ & 1 & 2 & 3 & 4 & 5 \\
\hline $\begin{array}{l}\text { 2. It is very important to me } \\
\text { to feel independent. }\end{array}$ & 1 & 2 & 3 & 4 & 5 \\
\hline $\begin{array}{l}\text { 3. I find it easy to get } \\
\text { emotionally close to others. }\end{array}$ & 1 & 2 & 3 & 4 & 5 \\
\hline $\begin{array}{l}\text { 4. I want to merge completely } \\
\text { with another person. }\end{array}$ & 1 & 2 & 3 & 4 & 5 \\
\hline $\begin{array}{l}\text { 5. I worry that I will be hurt } \\
\text { if I allow myself to become } \\
\text { too close to others. }\end{array}$ & 1 & 2 & 3 & 4 & 5 \\
\hline $\begin{array}{l}\text { 6. I am comfortable without } \\
\text { close emotional relationships }\end{array}$ & 1 & 2 & 3 & 4 & 5 \\
\hline $\begin{array}{l}\text { 7. I am not sure that I can } \\
\text { always depend on others to } \\
\text { be there when I need them. }\end{array}$ & 1 & 2 & 3 & 4 & 5 \\
\hline $\begin{array}{l}\text { 8. I want to be completely } \\
\text { emotionally intimate with } \\
\text { others }\end{array}$ & 1 & 2 & 3 & 4 & 5 \\
\hline 9. I worry about being alone. & 1 & 2 & 3 & 4 & 5 \\
\hline
\end{tabular}




\begin{tabular}{|c|c|c|c|c|c|}
\hline & $\begin{array}{l}\text { Not at all } \\
\text { like me }\end{array}$ & & $\begin{array}{l}\text { Somewhat } \\
\text { like me }\end{array}$ & & $\begin{array}{l}\text { Very much } \\
\text { like me }\end{array}$ \\
\hline 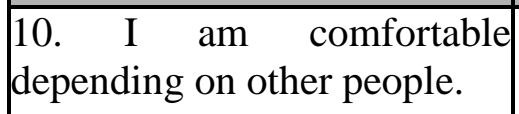 & 1 & 2 & 3 & 4 & 5 \\
\hline $\begin{array}{l}11 . \text { I often worry that } \\
\text { romantic partners don't really } \\
\text { love me. }\end{array}$ & 1 & 2 & 3 & 4 & 5 \\
\hline $\begin{array}{l}\text { 12. I find it difficult to trust } \\
\text { others completely. }\end{array}$ & 1 & 2 & 3 & 4 & 5 \\
\hline $\begin{array}{l}\text { 13. I worry about others } \\
\text { getting too close to me. }\end{array}$ & 1 & 2 & 3 & 4 & 5 \\
\hline $\begin{array}{l}\text { 14. I want emotionally close } \\
\text { relationships }\end{array}$ & 1 & 2 & 3 & 4 & 5 \\
\hline $\begin{array}{l}\text { 15. I am comfortable having } \\
\text { other people depend on me. }\end{array}$ & 1 & 2 & 3 & 4 & 5 \\
\hline $\begin{array}{l}16 . \text { I worry that others don't } \\
\text { value me as much as I value } \\
\text { them. }\end{array}$ & 1 & 2 & 3 & 4 & 5 \\
\hline $\begin{array}{l}\text { 17. People are never there } \\
\text { when you need them. }\end{array}$ & 1 & 2 & 3 & 4 & 5 \\
\hline $\begin{array}{l}18 . \text { My desire to merge } \\
\text { completely sometimes scares } \\
\text { people away. }\end{array}$ & 1 & 2 & 3 & 4 & 5 \\
\hline $\begin{array}{l}\text { 19. It is very important to me } \\
\text { to feel self-sufficient. }\end{array}$ & 1 & 2 & 3 & 4 & 5 \\
\hline \begin{tabular}{|ll}
$20 . \quad$ I am nervous when \\
anyone gets too close to me.
\end{tabular} & 1 & 2 & 3 & 4 & 5 \\
\hline $\begin{array}{l}\text { 21. I often worry that } \\
\text { romantic partners won't want } \\
\text { to stay with me. }\end{array}$ & 1 & 2 & 3 & 4 & 5 \\
\hline
\end{tabular}




\begin{tabular}{|c|c|c|c|c|c|}
\hline & $\begin{array}{l}\text { Not at all } \\
\text { like me }\end{array}$ & & $\begin{array}{l}\text { Somewhat } \\
\text { like me }\end{array}$ & & $\begin{array}{l}\text { Very much } \\
\text { like me }\end{array}$ \\
\hline $\begin{array}{l}\text { 22. I prefer not to have other } \\
\text { people depend on me. }\end{array}$ & 1 & 2 & 3 & 4 & 5 \\
\hline $\begin{array}{l}\text { 23. I worry about being } \\
\text { abandoned. }\end{array}$ & 1 & 2 & 3 & 4 & 5 \\
\hline $\begin{array}{l}24 . \quad \text { I } \quad \text { am } \\
\text { uncomfortable being close to } \\
\text { others. }\end{array}$ & 1 & 2 & 3 & 4 & 5 \\
\hline $\begin{array}{l}25 . \text { I find that others are } \\
\text { reluctant to get as close as I } \\
\text { would like. }\end{array}$ & 1 & 2 & 3 & 4 & 5 \\
\hline $\begin{array}{l}\text { 26. I prefer not to depend on } \\
\text { others. }\end{array}$ & 1 & 2 & 3 & 4 & 5 \\
\hline $\begin{array}{l}\text { 27. I know that others will be } \\
\text { there when I need them. }\end{array}$ & 1 & 2 & 3 & 4 & 5 \\
\hline $\begin{array}{l}\text { 28. I worry about having } \\
\text { others not accept me. }\end{array}$ & 1 & 2 & 3 & 4 & 5 \\
\hline $\begin{array}{l}\text { 29. Romantic partners often } \\
\text { want me to be closer than I } \\
\text { feel comfortable being. }\end{array}$ & 1 & 2 & 3 & 4 & 5 \\
\hline $\begin{array}{l}\text { 30. I find it relatively easy to } \\
\text { get close to others. }\end{array}$ & 1 & 2 & 3 & 4 & 5 \\
\hline
\end{tabular}




\section{$\underline{\text { Relationship Questionnaire }}$}

\section{Instructions: Part 1}

Following are descriptions of four general relationship styles that people often report. Please read each description and CIRCLE the letter corresponding to the style that best describes you or is closest to the way you generally are in your close relationships.

A. It is easy for me to become emotionally close to others. I am comfortable depending on them and having them depend on me. I don't worry about being alone o $r$ having others not accept me.

B. I am uncomfortable getting close to others. I want emotionally close relationships, but I find it difficult to trust others completely, or to depend on them. I worry that I will be hurt if I allow myself to become too close to others.

C. I want to be completely emotionally intimate with others, but I often find that others are reluctant to get as close as I would like. I am uncomfortable being without close relationships, but I sometimes worry that others don't value me as much as I value them.

D. I am comfortable without close emotional relationships. It is very important to me to feel independent and self-sufficient, and I prefer not to depend on others or have others depend on me. 


\section{Instructions: Part 2}

Please rate each of the following relationship styles according to the extent to which you think each description corresponds to your general relationship style.

A. It is easy for me to become emotionally close to others. I am comfortable depending on them and having them depend on me. I don't worry about being alone o $r$ having others not accept me.

B. I am uncomfortable getting close to others. I want emotionally close relationships, but I find it difficult to trust others completely, or to depend on them. I worry that I will be hurt if I allow myself to become too close to others.

C. I want to be completely emotionally intimate with others, but I often find that others are reluctant to get as close as I would like. I am uncomfortable being without close relationships, but I sometimes worry that others don't value me as much as I value them.

D. I am comfortable without close emotional relationships. It is very important to me to feel independent and self-sufficient, and I prefer not to depend on others or have others depend on me.

\begin{tabular}{|l|lllllllll|}
\hline & $\begin{array}{l}\text { Not at all } \\
\text { like me }\end{array}$ & \multicolumn{3}{l}{$\begin{array}{l}\text { Somewhat } \\
\text { like me }\end{array}$} & \multicolumn{2}{l|}{$\begin{array}{l}\text { Very much } \\
\text { like me }\end{array}$} \\
\hline Style A. & 1 & 2 & 3 & 4 & 5 & 6 & 7 \\
\hline Style B. & 1 & 2 & 3 & 4 & 5 & 6 & 7 \\
\hline Style C. & 1 & 2 & 3 & 4 & 5 & 6 & 7 \\
\hline Style D. & 1 & 2 & 3 & 4 & 5 & 6 & 7 \\
\hline
\end{tabular}




\section{VITA AUCTORIS}

Andrea Rose Kapeleris was born in Mississauga, Ontario in 1985. She obtained a B.A. (Specialized Hons.) in Psychology at York University in 2007. She is currently in the $\mathrm{Ph} . \mathrm{D}$. programme in adult clinical psychology at the University of Windsor. 